Portland State University

PDXScholar

5-28-1996

\title{
Wear Due to the Physical and Petrographic Properties of Rocks and their Dynamic Interactions with Mining Equipment
}

Christian Poppeliers

Portland State University

Follow this and additional works at: https://pdxscholar.library.pdx.edu/open_access_etds

Part of the Geology Commons

Let us know how access to this document benefits you.

Recommended Citation

Poppeliers, Christian, "Wear Due to the Physical and Petrographic Properties of Rocks and their Dynamic Interactions with Mining Equipment" (1996). Dissertations and Theses. Paper 5149.

https://doi.org/10.15760/etd.7025

This Thesis is brought to you for free and open access. It has been accepted for inclusion in Dissertations and Theses by an authorized administrator of PDXScholar. Please contact us if we can make this document more accessible: pdxscholar@pdx.edu. 
THESIS APPROVAL

The abstract and thesis of Christian Poppeliers for the Master of Science in Geology were presented May 28, 1996, and accepted by the thesis committee and the department.

COMMITTEE APPROVALS:
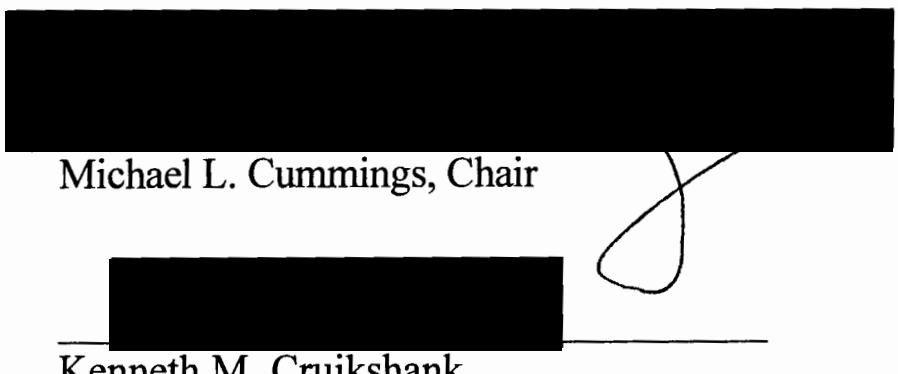

Kenneth M. Cruikshank

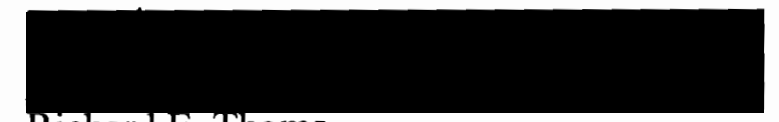

Richard E. Thoms

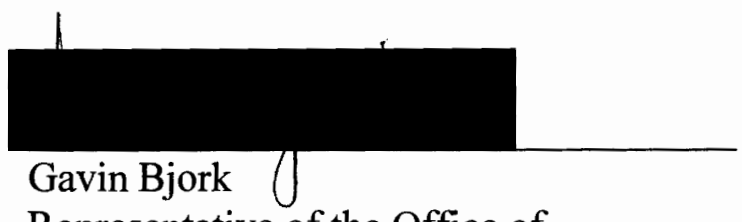

Representative of the Office of

Graduate Studies

DEPARTMENT APPROVAL:

Marvin H. Beeson, Chair

Department of Geology

$* * * * * * * * * * * * * * * * * * * * * * * * * * * * * * * * * * * * * * * * * * * * * * * * * * * * * * * * * * * * * * * * * * * * * * *$

ACCEPTED FOR PORTLAND STATE UNIVERSITY BY THE LIBRARY

by

on Sxlecembex 1996 


\begin{abstract}
An abstract of the thesis of Christian Poppeliers for the Master of Science in Geology presented May 28, 1996

Title: Wear Due to the Physical and Petrographic Properties of Rocks and their Dynamic Interactions with Mining Equipment
\end{abstract}

Wear to mining equipment reduces operational efficiency. If wear rates can be predicted, appropriate matching of alloys to the mine's geologic conditions can aid in improving the operational efficiency. This study addresses rock characteristics which lead to wear. Macroscopic rock tools which lead to wear include sharp edges and corners on rocks. During a rock/equipment interaction, these rock tools cause high point pressures on the surface of the equipment which leads to ductile cutting and gouging of the surface and subsequent removal of metal. Hard mineral grains, or grain tools, produce abrasion as the grains move across equipment surfaces.

Grain and rock tools were analyzed for metamorphic, hydrothermally altered, plutonic, and sedimentary rocks from six mines and quarries. Grain tools were examined by petrographic analysis and Knoop microhardness: rock tools by uniaxial compressive tests, density, and rock size. Fourier analysis of rock and mineral shapes and abrasion tests were used to examine the evolution of tools.

Prediction of wear rates appears most closely related to uniaxial compressive strength, Knoop microhardness, and quartz content. Uniaxial compressive strength relates to rock tool endurance; Knoop microhardness contrast between mineral grains 
and matrix/cement influences evolution of tools during surface interactions; quartz content relates to the abrasive capacity of a rock surface. 


\title{
WEAR DUE TO THE PHYSICAL AND PETROGRAPHIC PROPERTIES OF ROCKS AND THEIR DYNAMIC INTERACTIONS WITH MINING EQUIPMENT
}

$$
\text { by }
$$

Christian Poppeliers

A thesis submitted in partial fulfillment of the requirements for the degree of

\author{
MASTER OF SCIENCE \\ in \\ GEOLOGY
}

Portland State University

1996 


\section{Acknowledgments}

I would like to thank Mike Cummings, Kenneth Cruikshank, and Dan Danks for their contributions to this project. Also ESCO Corporation for providing funding. Lastly, I would like to recognize my grandfather, Dr. Gottfried Rosendal, whose subtle inspiration proved invaluable to the completion of this project. And Jennifer. 


\section{Table of Contents}

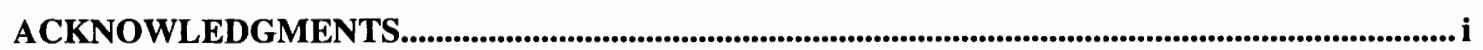

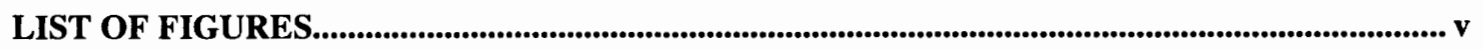

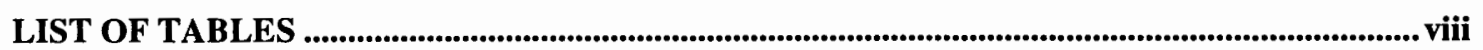

INTRODUCTION

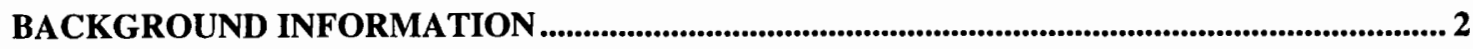

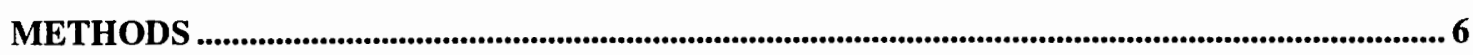

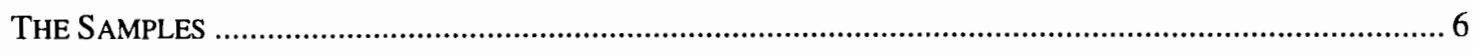

PETROGRAPHIC PROPERTIES: SURFACE QUARTZ PERCENTAGE....................................................... 8

PETROGRAPHIC PROPERTIES: QUARTZ GRAIN SIZE VARIABILITY ................................................... 8

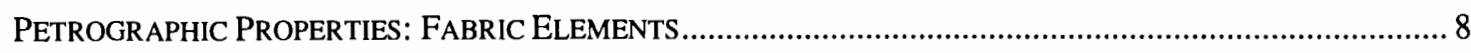

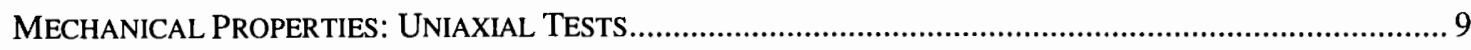

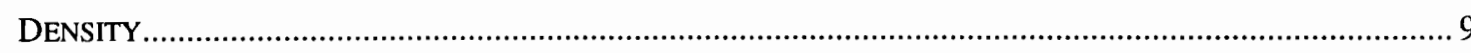

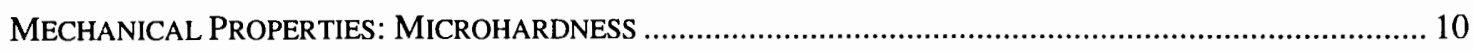

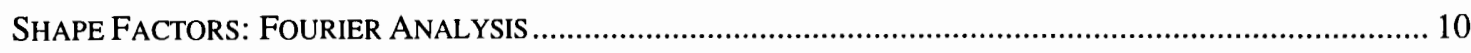

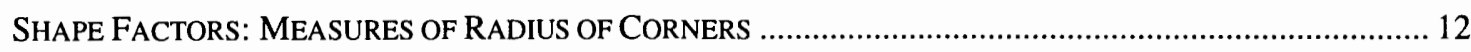

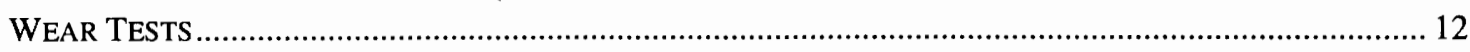

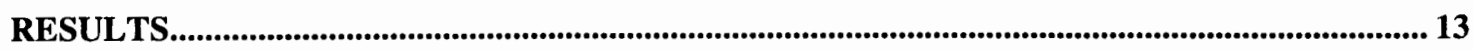

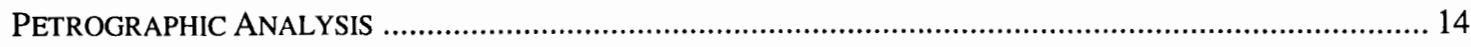

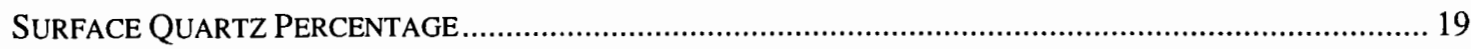

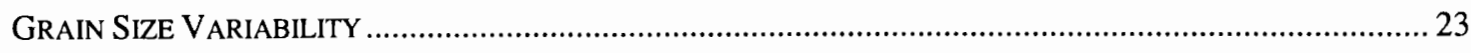

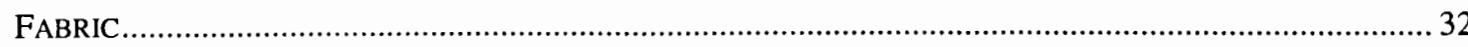




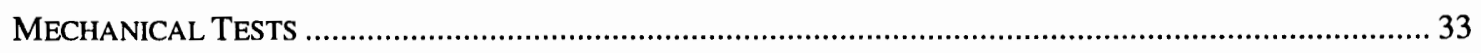

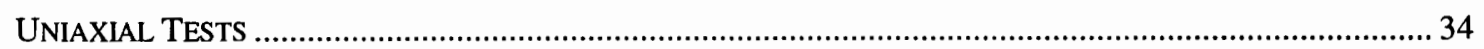

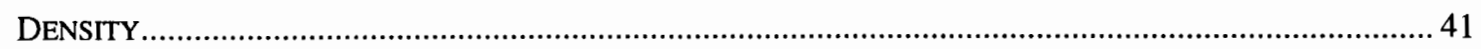

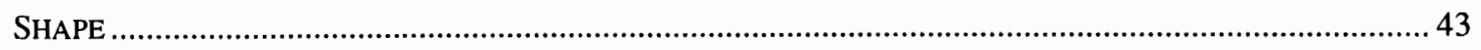

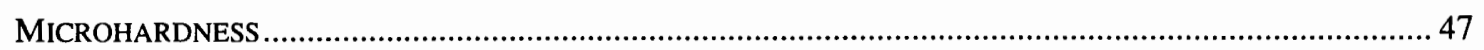

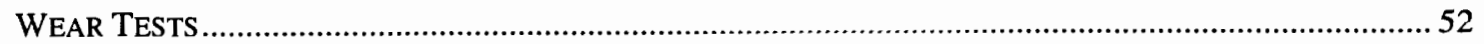

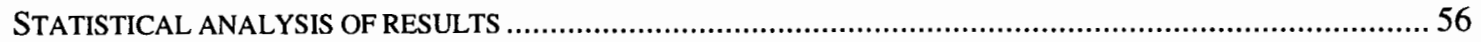

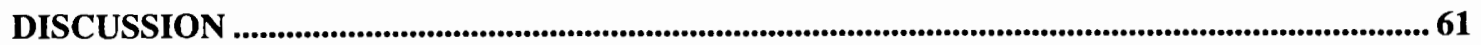

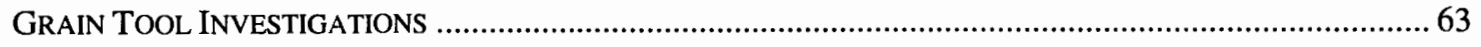

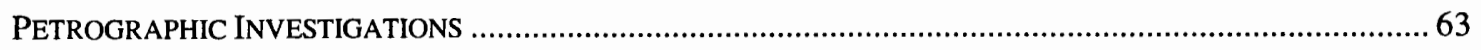

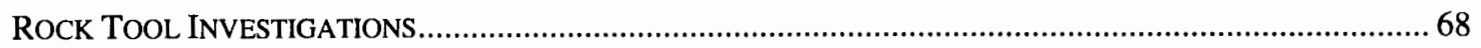

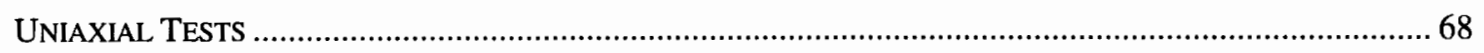

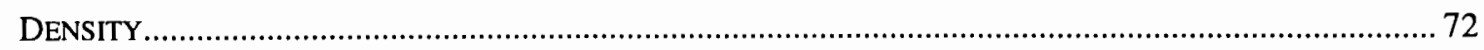

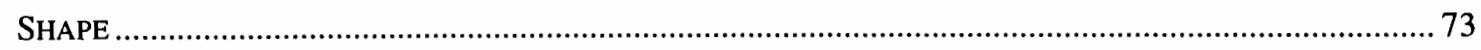

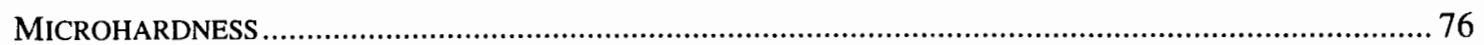

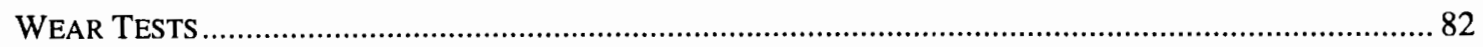

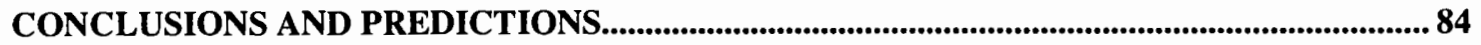

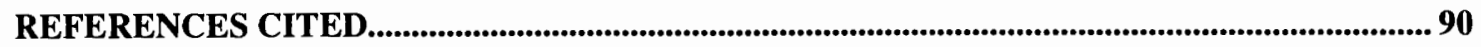

APPENDIX I; THE SAMPLES …........................................................................................................ 94

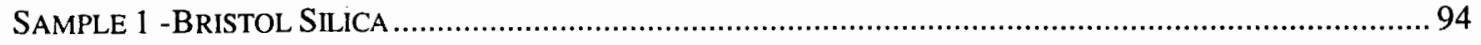

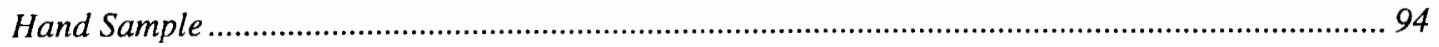

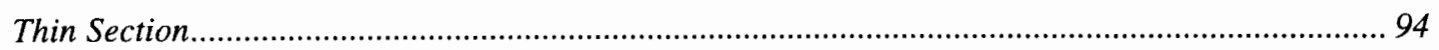

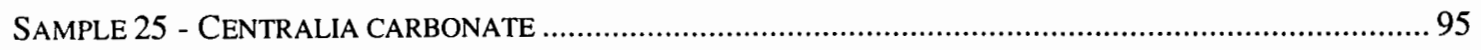




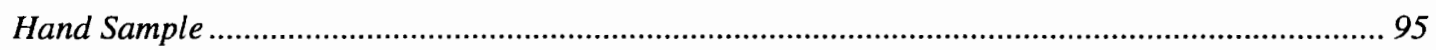

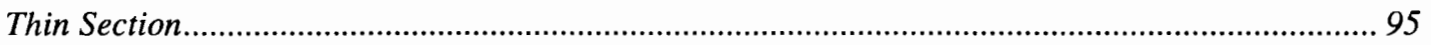

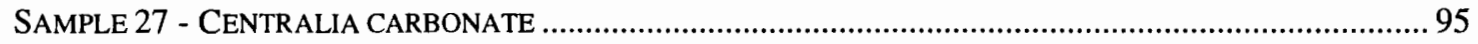

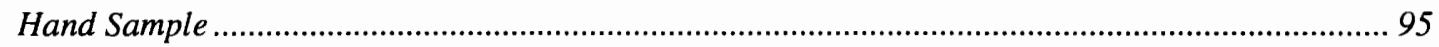

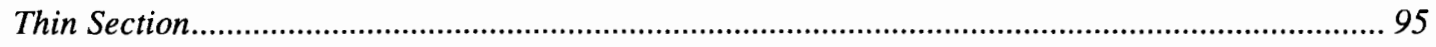

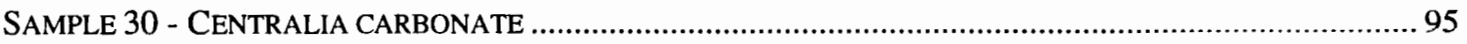

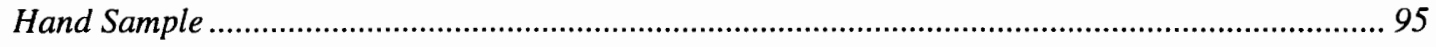

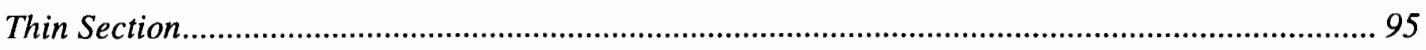

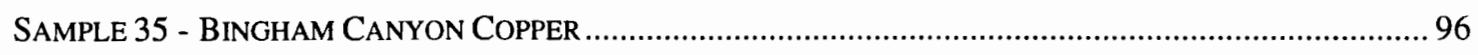

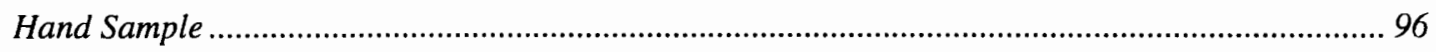

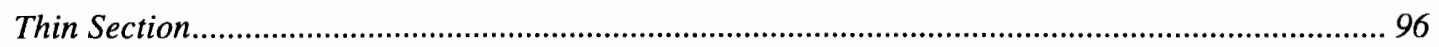

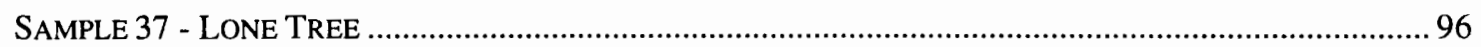

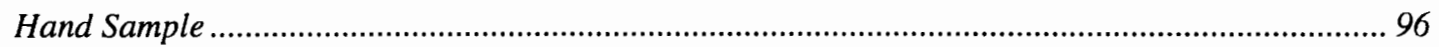

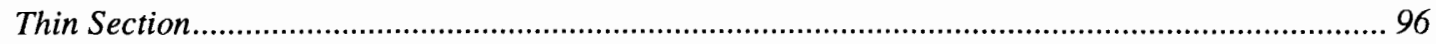

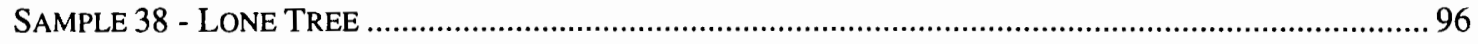

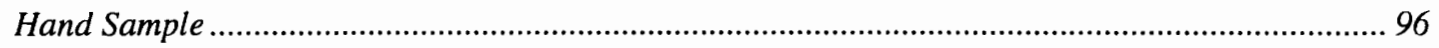

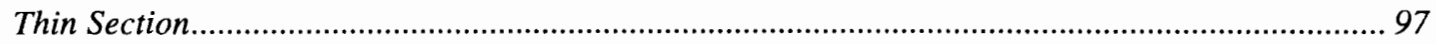

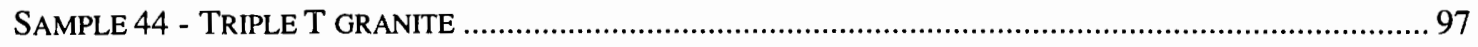

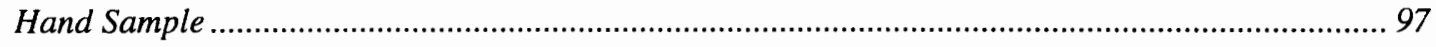

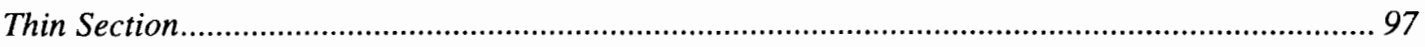

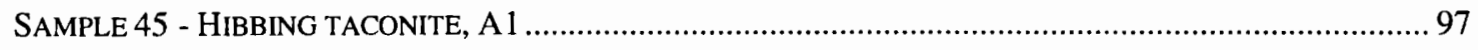

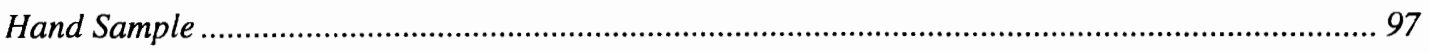

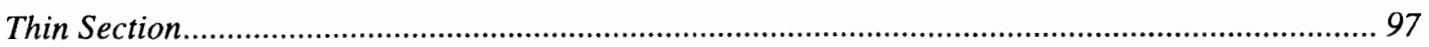

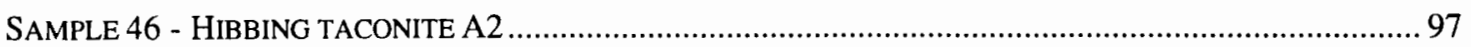

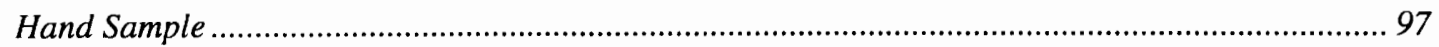




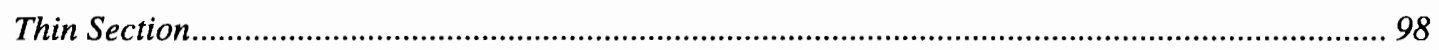

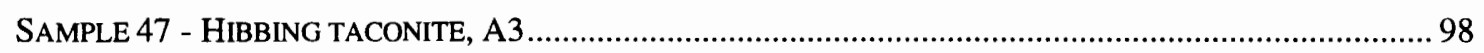

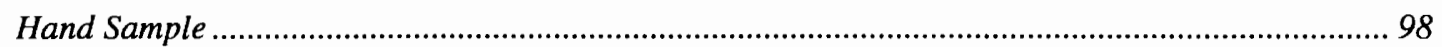

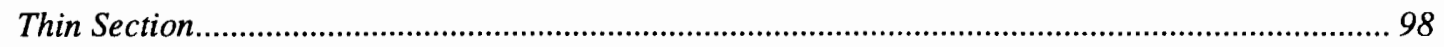

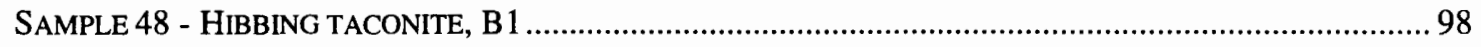

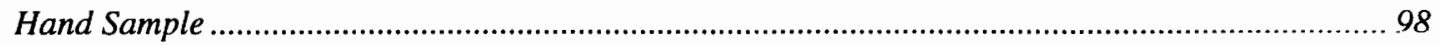

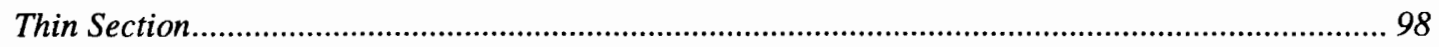

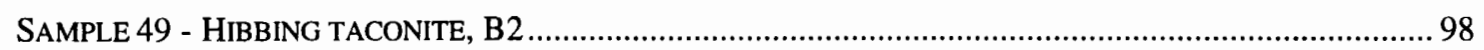

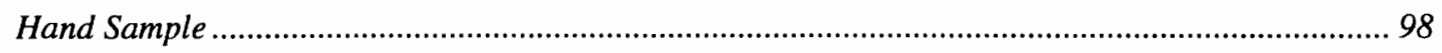

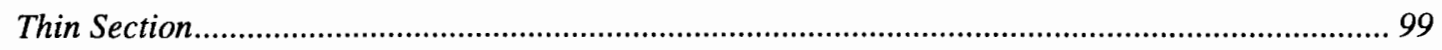

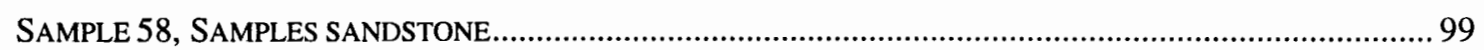

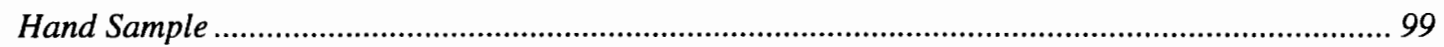

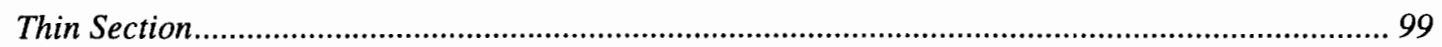

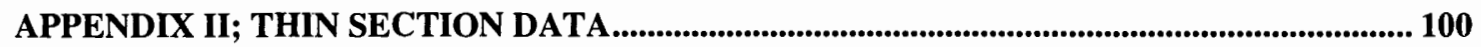

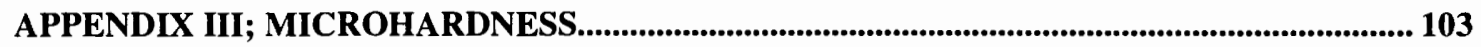

APPENDIX IV; TABULATED RESULTS FROM THE FOURIER ANALYSIS ........................ 105

APPENDIX V; QUARTZ GRAIN SIZE DATA AND STATISTICAL ANALYSIS...................... 108

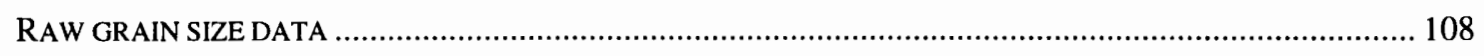

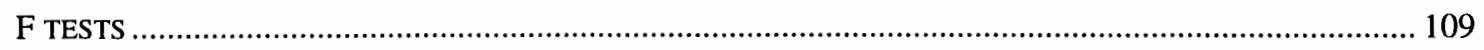

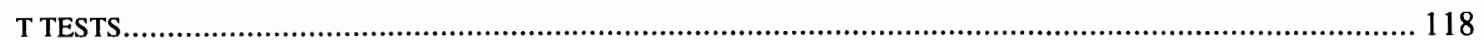

APPENDIX VII; PROGRAM TO PERFORM FOURIER ANALYSIS ....................................... 120 


\section{List of Figures}

Number

Page

Figure 1. Radius versus theta.

Figure 2. Average surface quartz for the samples investigated..

Figure 3. The normal distribution of the quartz grain sizes for Sample \#35

Figure 4. Uniaxial compressive strength for the samples investigated.

Figure 5. An example of a Fourier analysis.

Figure 6. Average measured radii of profile corners of the rocks investigated.

Figure 7. The stress at the tip of a crack

Figure 8. Average Knoop microhardness for the samples at $25 \mathrm{~g}$ indenture load..

Figure 9. The wear resulting from the Dry Sand Rubber Wheel test versus quartz

Figure 10. Wear versus density

Figure 11. Wear versus radius of curvature

Figure 12. Wear versus compressive strength.

Figure 13 Wear versus Poisson's Ratio

Figure 14 Wear Versus Young's Modulus

Figure 15. Results of the discrimanant analysis..

Figure 16. Variation in the percentage of surface quartz in relation to the orientation of the cut of the thin sections..

Figure 17. The uniaxial compressive strength versus the radius of curvature (sharpness) of the corners for the samples investigated. 
Figure 18. The value of microhardness related to the indenture force .77 


\section{List of Tables}

Number

Table 1. The samples and their origin .7

Table 2. Mean quartz grain size and the standard deviations. 30

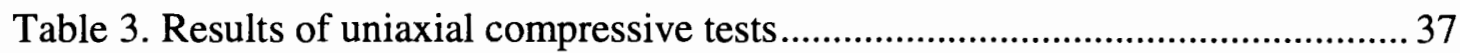

Table 4. Sample densities. The pure quartz is provided as a reference...................... 42

Table 5. Results from the Dry Sand Rubber Wheel tests........................................52

Table 6. Data groups used in the Discriminant Analysis. ..........................................59

Table 7. Average matrix microhardness compared to uniaxial strength.....................81 


\section{Introduction}

Wear of cutting surfaces and teeth in mining equipment reduces operational efficiency and adds to the cost of mining. Appropriate matching of metal alloys used in cutting surfaces and teeth to the physical properties of the mined rocks is known to reduce wear rates (Avery, 1961). Although the physical properties and mechanical behavior of metal alloys are well known (e.g. McLean, 1962; Honeycombe, 1984), a reliable alloy wear-rate scale based on rock properties has yet to be developed. It is vital, therefore, to understand rock properties which lead to wear in order to develop such a scale. Such a scale will allow a selection of an appropriate grade of alloy for an operation leading to an increase in mine efficiency.

The goals of this study are:

1. to investigate mine rocks to ascertain properties which lead to wear;

2. to evaluate the efficacy of the tests used to predict wear;

3. to develop a standardized method of quantifying rock properties which predict wear behavior;

4. to predict relative equipment wear produced by the sample rocks studied in this project.

In order to predict wear to mining equipment, a standardized method of cataloging rock properties is needed. These properties must be shown to influence 
wear and must be quantifiable. No standardized method of observation exists; this project seeks to determine which properties are important and to make suggestions for the standardization of a method by which to catalog and quantify relevant properties which lead to wear.

\section{Background Information}

In order to extend the life of mining equipment, removable teeth are installed onto the front lip of excavating equipment such as dragline buckets and shovel buckets. The teeth are designed to take the majority of the wear, and then be replaced, saving the cost of replacing the entire bucket. This wear to the teeth occurs due to an abrasive interaction between the mine rocks and the teeth as the bucket moves through the mine material. The action of the rocks scraping across the surfaces of the teeth leads to cutting and gouging of the tooth and a consequent removal of the metal comprising the tooth. The removal of metal is by a ductile failure mechanism. Forces are produced as the rocks press against the teeth which causes shear stresses to develop. The shear stresses exceeds the metal's shear strength, and the metal responds by deforming plastically rather than brittly or elastically (Deketh and Verhouf, 1993). This ductile failure and removal of the tooth material will be referred to as abrasive wear for the remainder of this report.

One way of classifying abrasive wear is to differentiate between 1) two-body wear, which consists of an unrestrained abrasive moving across the metal surface, and 
2) three-body wear, which results from an abrasive grain being forced into the metal surface by another surface (e.g. a rock) in close proximity (Lipson, 1967; Bryggman and others, 1985; Huard and others, 1987). A third type of abrasive wear not as commonly seen in metal materials is erosive or impact wear which results from abrasive particles striking a metal surface at a high velocity, causing wear either by ductile failure of the metal or brittle failure (Levy, 1989). The wear to teeth is commonly by two-body and three-body wear mechanisms (Danks, 1995, personal communication).

Previous work on the study of wear has concentrated on the worn object and measurement of wear (e.g. Avery, 1961; Bruce, 1968; Bryggman and others, 1985; Mouritz and Hutchings, 1993). These researchers concentrated on measuring wearrates and comparing them to the properties of the worn part. Little attention was devoted to understanding the wear-inducing objects.

Huard and others (1987) suggested that the size range and shape of the finegrained abrasive particles tested has a strong influence on wear rates to metal specimens produced during the dry sand rubber wheel test. Huard and others (1987) attempt to quantify the shape of the sand particles and relate this to wear rates. Wear tests indicate that wear rates increased as the angularity of particles increased. They concluded that increasing particle size increased wear rates, although no explanation for this phenomenon was offered. 
A theoretical abrasive wear model was developed by Hokkirigawa and Kato (1989) in which the shape factors of the abrasive particle was a key variable. Their model was developed using a diamond point to gouge a metal surface to simulate the action of asperities on abrasive particles and predicted the wear rate to a metal surface relative to 1 ) the shape of the point, 2) the normal load of the point against the metal, and 3) the hardness of the metal.

The aforementioned work indicates that the shape of an abrasive particle can have an affect on wear rates; however, work on the quantification of shape of abrasive particles is limited. This may be due to the difficulty encountered when trying to derive a unique shape descriptor. Lee and Salle (1970) have proven mathematically that unique numerical shape descriptions are impossible. Therefore, most work approaches the problem of shape description by focusing on a particles deviance from sphericity or a particles aspect ratios (e.g. Raadnui and Roylance, 1995; Huard and Masounave, 1987).

In a study in which lithified abrasive mediums are evaluated, Deketh and Verhoef (1993) conducted experiments using chisels were to cut artificial rock. The researchers indicate that grain size and strength of the "rock", as indicated by uniaxial compressive and tensile strength measurements, can be related to wear rates to cutting chisels. The "rock" was created by mixing quartz sand of differing grain size with differing proportions of Portland B cement to fly ash. Chisels then cut a constant length and the wear rates to the chisels were measured. As with the work by Huard and 
Masounave (1987), the wear rates increased with increasing grain size. Wear rates to chisels were also greater for "rocks" of higher values of unconfined compressive strength. It was also determined that for this system wear resulting from two-body wear mechanisms is an order of magnitude higher than wear resulting from three-body wear mechanisms.

Many rock types consist of individual hard grains being supported by a soft matrix. An example of this would be a quartz-bearing carbonate or a carbonatecemented sandstone. Rocks of this type are capable of producing significant wear to teeth, even though the matrix of the rock is softer than the metal of the tooth. Glacial scour is an example of wear of this type (Witkind, 1978; Embleton and King, 1975). Glacial striae, parallel to subparallel grooves in bedrock, are formed as the result of ice flowing over exposed rocks. The ice is significantly softer than the rocks being worn, however, the ice is able to support and move a large number of small rock fragments. These rock fragments act as tools and arm the underside of the glacier concentrating the erosive process. The rock fragments are forced to scrape along exposed bedrock, cutting and crushing the bedrock in the process. The ice is not the actual agent of the erosion, rather, the tools which the ice mobilizes are responsible for the wear process. 


\section{Methods}

\section{The Samples}

In order to investigate the vehicles of wear, rocks from active mines were examined (Table 1). In order to understand rock characteristics which cause wear, samples were chosen from mines known to have highly aggressive rocks (e.g. a taconite from the Hibbing Taconite mine) to mines with relatively unaggressive rocks (e.g. rocks from the Centralia coal mine). Rocks intermediate to these were also used (Appendix I). All samples used in this study were obtained by ESCO Corporation in Portland, Oregon. 
Table 1. The samples and their origin.

\begin{tabular}{|c|c|c|c|}
\hline $\begin{array}{l}\text { Sample } \\
\text { Number }\end{array}$ & Sample Name & Mine and Location & $\begin{array}{l}\text { General Description and } \\
\text { Information }\end{array}$ \\
\hline 1 & Bristol Silica & $\begin{array}{l}\text { Bristol Silica and } \\
\text { Limestone Co. }\end{array}$ & $\begin{array}{l}\text { Silicified carbonate } \\
\text { (Geitgey, 1990). }\end{array}$ \\
\hline $25,27,30$ & Centralia & $\begin{array}{l}\text { Centralia Mining } \\
\text { Company, Centralia, WA }\end{array}$ & $\begin{array}{l}\text { Puget Group, Eocene coal-bearing } \\
\text { fluvio-deltaic locally carbonate } \\
\text { cemented siltstones and } \\
\text { sandstones, weakly indurated } \\
\text { (Burnham, 1990). Samples \#25 and } \\
\# 30 \text { contain fine grained silts and } \\
\text { clays, Sample \#27 is a carbonate } \\
\text { cemented sandstone. }\end{array}$ \\
\hline 35 & Kennecott copper & $\begin{array}{l}\text { Bingham Canyon Copper } \\
\text { Mine, UT }\end{array}$ & $\begin{array}{l}\text { Bingham District copper porphyry } \\
\text { deposit, feldspathic orthoquartzites } \\
\text { and calcareous sandstones and } \\
\text { limestones (Lanier and others, } \\
\text { 1978) }\end{array}$ \\
\hline 37,38 & $\begin{array}{l}\text { Lone Tree } \\
\text { quartzite }\end{array}$ & Lone Tree gold mine, NV & $\begin{array}{l}\text { Hydrothermally altered, silicified } \\
\text { Triassic marine sediments, part of } \\
\text { Jurassic Winnemucca fold and } \\
\text { thrust belt. Area contains } \\
\text { limestones, calcareous shales, and } \\
\text { siltstones grading into sandstone. } \\
\text { Type } 001 \text { ( } \# 37 \text { ) a silica-replaced } \\
\text { sedimentary rock, type } 002 \text { (\#38) is } \\
\text { hydrothermal breccia (Wood, } \\
1988 \text { ). }\end{array}$ \\
\hline 44 & Triple T granite & $\begin{array}{l}\text { Triple T rock quarry, } \\
\text { Lakeside, CA }\end{array}$ & $\begin{array}{l}\text { Granite. Plagioclase, quartz, and } \\
\text { mafic minerals }\end{array}$ \\
\hline $\begin{array}{l}45,46,47 \\
48,49\end{array}$ & Hibbing taconite & $\begin{array}{l}\text { Hibbing Taconite mine, } \\
\text { Hibbing, MN }\end{array}$ & $\begin{array}{l}\text { Banded iron Formation from the } \\
\text { Mesabi Range in northeastern } \\
\text { Minnesota, banded } \\
\text { hematite and chert (Poss, 1982) } \\
\text { Type A1 (\#45) is a slate, types A2, } \\
\text { A3, B1, and B2 (\#46, \#47, \#48, } \\
\text { and \#49, respectively) are banded } \\
\text { chert and iron oxide minerals. }\end{array}$ \\
\hline 58 & $\begin{array}{l}\text { Samples } \\
\text { sandstone }\end{array}$ & $\begin{array}{l}\text { Caternary Coals Samples } \\
\text { Mine, WV }\end{array}$ & \\
\hline
\end{tabular}




\section{Petrographic Properties: Surface Quartz Percentage}

Data on the surface quartz percentage was obtained by point counts of quartz, as seen in thin section, along the surface of the rock. For rock samples $25,27,30,45$, $46,47,48$, and 49 , ten $2.54 \mathrm{~cm}$ by $5.08 \mathrm{~cm}$ thin sections that included the rock surface were examined for each rock. For rock samples $1,35,37,38,44$, and 58 , two $5.08 \mathrm{~cm}$ by $7.62 \mathrm{~cm}$ thin sections, which provided an entire cross section of the rock, were used for each rock. For these larger thin sections, ten areas approximately $2 \mathrm{~cm}$ long along the surface were used for the measure of the surface quartz. Observations were made using a Ziess Universal Cross-Polarizing Binocular microscope. The magnification was $31.25 x$. The thin sections were made by Quality Thin Section, Tucson, Arizona. This method of observation was developed by the author.

\section{Petrographic Properties: Quartz Grain Size Variability}

For each slide, twenty-nine random grains were chosen by moving the slide and measuring the grain in the cross hairs of the scope. Grain size measurements were obtained by visual estimation against a graduated scale in a Ziess Universal CrossPolarizing Binocular microscope. The magnification used was either $31.25 \mathrm{x}$ or $125 \mathrm{x}$.

\section{Petrographic Properties: Fabric Elements}

Fabric elements of the rocks were observed both at the thin section scale and hand sample scale. Ten thin sections for each sample rock were viewed through a Ziess Universal Cross-Polarizing Binocular microscope with magnification of either 
$31.25 \mathrm{x}$ or $125 \mathrm{x}$. Thin sections were obtained from cuts at different orientations in a single rock sample where possible. Hand samples were approximately $20 \pm 10 \mathrm{~cm}$ in diameter. At least two hand samples were evaluated for each mine sample.

\section{Mechanical Properties: Uniaxial Tests}

All uniaxial testing was performed by Rocktech, Salt Lake City, Utah. Cylindrical specimens were cut from hand samples with a diamond tip corer and the ends polished perpendicular to the axis of the cylinders, according to ASTM standard \#D3148. The cylinders had length of $4.54 \mathrm{~cm}$ and a diameter of $2.54 \mathrm{~cm}$. The specimens were loaded axially at a constant strain rate estimated to produce failure within 5 to 15 minutes. The machine used was of Rocktech design. Strain was recorded using strain-gauged transducers and recorded to hard disk files.

\section{Density}

The density of the samples was obtained by comparing the mass to the volume. All samples were weighed and then dipped in wax, to prevent water from entering pore spaces present in the rocks. The volume of wax was estimated by reading the difference in the amount of wax in a graduated cylinder before the rock was coated and then after the rock was coated. The wax coated rock was then submerged in a large graduated cylinder containing a known quantity of water. The volume of the rock was estimated by the water displaced, after the volume of the wax coating was subtracted. The density was calculated by the following equation: 


$$
\rho=\frac{m}{v}
$$

where $\rho$ is the density, $v$ is the volume of the rock sample, and $m$ is the mass of the rock sample.

\section{Mechanical Properties: Microhardness}

All microhardness tests were performed by ESCO Corporation, Portland, Oregon. A Leco Microhardness tester, Model \#M-40061 was used according to ASTM standard E384. A variety of loads were used, but a load of $25 \mathrm{~g}$ was chosen after it was determined that the microhardness is affected by the indentor load (see Figure 18). The indentor point is statically loaded to $25 \mathrm{~g}$ for 30 seconds, and then removed. The width and depth of the resulting dent is then measured with a traveling micrometer and a microhardness assigned. Standard values of Knoop microhardness are based on the width of dents and have been arbitrarily assigned; wider dents indicate lower values of Knoop microhardness and smaller dents indicate higher values of Knoop microhardness according to a standard scale.

Microhardness measures were made over a varied area of a polished rock face. Multiple measurements were made on the matrix material of a rock, which was the material surrounding the grains, and the grains, which were commonly quartz.

\section{Shape Factors: Fourier Analysis}

The Fourier analysis of the samples was conducted both at the thin section scale and the hand sample scale. Surface traces of the thin sections were obtained by 
hand tracing the surface profile of the rock as seen in photo-micrographs taken through Ziess Universal Cross-Polarizing microscope. The total length of each photo trace was $35.5 \mathrm{~cm}$, which corresponded to $7.59 \mathrm{~mm}$ on the thin section. This produced an enlargement factorof 46.8. The trace was then scanned using a Hewlet-Packard ScanJet IIcx and converted to $x-y$ coordinates using Adobe ${ }^{\circledR}$ Streamline software. The Fourier analysis was then performed by software developed by Dr. Kenneth Cruikshank at Portland State University.

To perform the Fourier analysis at the hand sample scale, a different method was required to obtain a surface trace. In performing a Fourier analysis, no two points on the trace may possess a similar $x$ coordinate; for example, a closed line would

\section{sample $37 \mathrm{C}$}

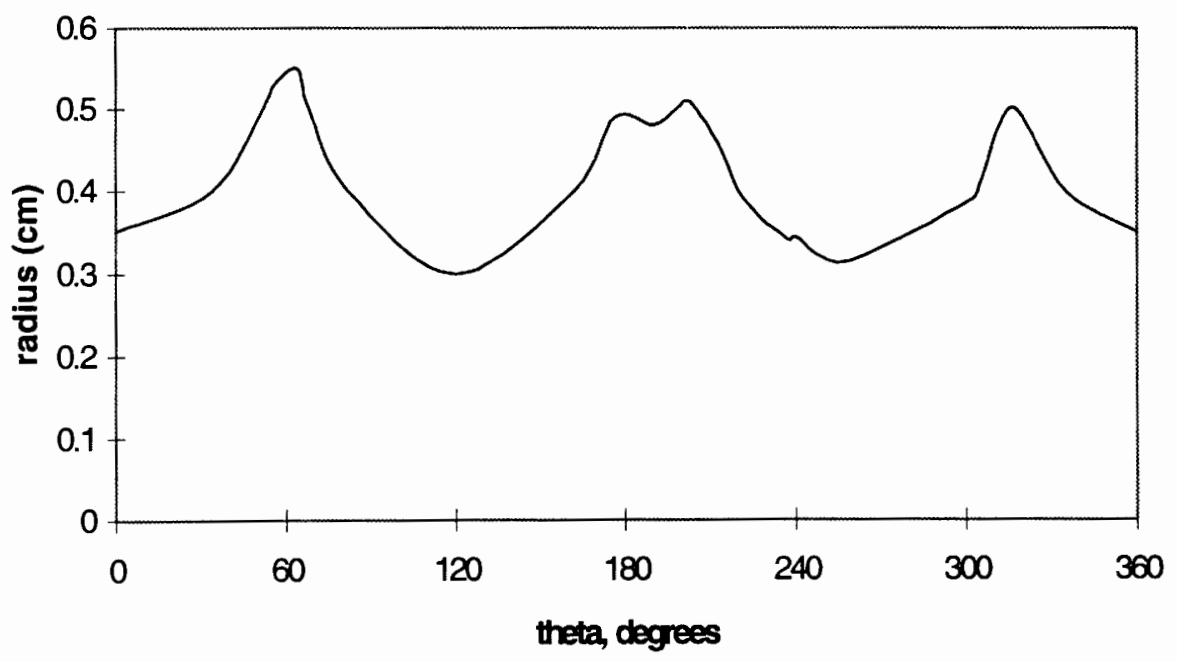

Figure 1. Radius (extended from the centroid to the surface) versus theta for sample 37 . The closed profile was converted to a linear profile by extending a radius from the centroid of the closed profile to the surface of the closed profile and making a plot of the radius versus the angle. This trace was then used for the Fourier analysis. 
violate this condition. A profile trace of a hand sample is a closed line. This problem may be remedied by expressing the outline in polar form, as shown in Figure 1 .

In order to convert the profile of the sample into a polar form as in Figure 1, the centroid of the profile must be located. This was accomplished by tracing the profile of the sample on heavy cardboard, cutting out the resulting shape, and finding the center of gravity. The center of gravity of the shape corresponds to the shape's centroid. The radius was then measured from the centroid to the surface at equal one degree increments to produce a trace similar to that in Figure 1. A Fourier analysis was then performed on the resulting trace (Davis, 1986).

\section{Shape Factors: Measures of Radius of Corners}

Profiles in different directions were cut from eight of the sample rocks. The number of corners on two to three profiles per sample were counted and tabulated. A corner was defined as any curvature which causes a change of direction in the surface of greater than $30^{\circ}$ occurring in an arc length of less than $3 \mathrm{~cm}$.

The value of the radius of the corner is obtained by visually matching a circle of known radius with the corners on the samples. Staedtler-Mars professional circle template number $977-109 \mathrm{C}$ was used for this process.

\section{Wear Tests}

Samples \#1 (Bristol Silica), \#38 (Lone Tree hydrothermal breccia), \#47, \#48 (both Hibbing taconites), and \#58 (Samples sandstone) were crushed, pulverized and 
sieved to a size range of $0.297-0.210 \mathrm{~mm}$ (sieve \#50-70). The resulting sand was then used in a Dry Sand Rubber Wheel test according to ASTM standard \#G65, procedure B.

\section{Results}

In order to predict wear, the properties of the rocks which lead to wear need to be identified and quantified. I believe the most important rock properties to be understood are 1) the identity of the tool, 2) the contact area between the tools and the tooth, 3) the normal load, or pressure, of the tools on the tooth, and 4) the evolution of the tool during its interaction with the tooth. The tools on the rock are important as they are believed to be the mechanisms for gouging the teeth in both two-body and three-body wear. In this thesis, the term 'tool' is given to the feature on the rock which causes wear and the term 'tooth' refers to the equipment being worn.

There are two types of tools; 1) tools related to bulk properties of the rock, and 2) tools related to individual or groups of grains within the rock. The first group relates to polymineral aggregates or rocks. The second group is more related to mineral properties and how the minerals are linked across grain boundaries. The two groups are closely related, but by approaching each group separately, the identification of the two groups of tools and their contribution to the wear process is possible. For the remainder of this report, tools related to the first group are referred to as grain tools, and tools related to the second group are referred to as rock tools. 
The most likely rock tools are sharp corners and edges. The composition and the evolution of these tools will, to a great extent, determine the rate of wear to the mining equipment. The tests were therefore designed in such a way as to address the tool composition and evolution.

Tests gathered information on two main aspects of the rocks: 1) petrographic aspects and 2) mechanical aspects. These tests attempt to address questions regarding the identity and endurance of the rock tools and the grain tools. An understanding of these properties aids in the prediction of wear. Some of the tests were inconclusive. Inconclusive results in this case, however, are important as they indicate which tests or properties are not applicable to this project.

\section{Petrographic Analysis}

The genesis of the rock has an affect on the mechanical behavior of the rock as it interacts with a tooth. As an example, a weakly lithified mudstone will have considerably different wear characteristics than a granite. The petrograhpic analysis addresses the differences in grain tool composition and evolution, which will affect the wear characteristics of the rock.

Rock genesis as portrayed by mineralogy and texture is effectively examined by standard petrographic techniques. These petrographic characteristics are related to primary and secondary mineralogy, crystallization based on diagenetic history, and distribution of microfractures. These properties effect the mechanical behavior of the 
rock, which effects the wear caused by the rock. Properties may differ for rocks within the same petrographic/genetic group, but this variation is far less than rocks from different petrographic/genetic groups (e.g. a metamorphic rock compared to a sedimentary rock). Some fundamental properties of the rock groups investigated in this project are discussed in the following section;

Metamorphic rocks: Metamorphic rocks are formed by recrystallization of an original rock mass into a rock mass which is more stable at the conditions present at the time of metamorphism. Heat, pressure, and strain are the common elements responsible for the creation of new mineral phases, fabrics, and textures. Often, compositional variation within the parent rock produces compositional layering within the final metamorphic rock. The compositional layering may mimic primary variations in the parent material such as interbedded claystone and limestone or it may be metamorphogenic due to metamorphic differentiation. Differential pressure may produce preferential alignment of platy and linear minerals.

Grain size is a function of nucleation rates, growth rates, composition, the presence of fluids (water), temperature, pressure, and length of time of metamorphism. The ultimate size of the crystals, however, depends upon a large number of variables. It is not possible to detect the kinetics of crystallization of a metamorphic rock from a study of grain sizes alone (Spry, 1969).

In the case with the taconite samples studied, metamorphic conditions were those of the lower greenschist facies $\left(\mathrm{P} \cong 1-3 \mathrm{kB}, \mathrm{T} \cong 150-250{ }^{\circ} \mathrm{C}\right.$ ), conditions 
capable of producing a relatively fine grained rock (French, 1973). Compositional layering probably reflects original bedding, but modification due to preferential strain cannot be discounted. A sample from the slatey member of the banded iron formation (Sample \#45) displays well defined compositional layering (bedding) and fine grain size, consistent with relatively low grades of metamorphism. Variations in grain size between different beds in the same rock may reflect response to localized strain, distribution of fluids, presence of organic carbon and chemical variability among neighboring beds subjected to the same metamorphic conditions (Spry, 1964).

Igneous rocks: Plutonic igneous rocks result from the cooling of an unstrained magma in a low to moderate pressure environment. In the absence of strain, minerals crystallize without a preferred orientation, according to the nutrients available and the temperature of the melt. Crystal size is dependent mainly upon cooling history. Generally, larger crystal sizes indicate that the rock cooled more slowly than a rock of similar composition with a smaller grain size (Ehlers and Blatt, 1980). Randomly oriented crystals grow until the invasion of a different crystal boundary, a lack of nutrients, or lowering of temperature prevents the continued growth of the original crystal. Anisotropy can be introduced into an igneous rock by a flowinduced orientation of minerals while the magma is still in a liquid to semi-liquid state. 
Clastic sedimentary rocks: Clastic sedimentary rocks consist of framework grains that may be lithified by the introduction of a cement or by diagenetic recrystallization of a matrix, if present. Framework grains vary widely from rock fragments to quartz, depending upon a number of factors. These factors can include, but are not limited to, the parent rock from which the original sediment was derived, the transport mechanism and history of the sediment, the weathering history of the sediment, and the diagenesis of the sedimentary rock. Quartz is a mineral likely to survive the weathering and transport process better than other minerals. Cementing agents are introduced after sedimentation and by their deposition bind the grains together. The degree to which a sedimentary rock is lithified often depends upon the composition of the cementing agent, the degree to which the cementing agent bonds to the grains, porosity of the rock, and the presence of microfractures in the rock. Clay content can also effect the degree of lithification, as clay minerals can disrupt grain/cement contact, causing the rock to be more friable.

The grain size in a clastic sedimentary rock is mainly a function of the environment of deposition (Ehlers and Blatt, 1980). A fine grained rock indicates a low energy environment, often with silt and clay particles present. Organic matter can accumulate in this type of environment if biological factors are favorable. A progressive increase in grain size is indicative of progressively increasing energy of the depositional environment. The grain size variability in a given rock reflects 
the degree to which the sediment was sorted before lithification, and can also be indicative of the maturity of a sediment.

Sedimentary rocks often display features which result from original sediment deposition (e.g. bedding planes, compositional banding, sorting). A sedimentary rock may be gradational to a metamorphic rock, as a very well indurated sedimentary rock very closely resembles a metamorphic rock. The primary difference is that in a sedimentary rock, the primary weakness is along the grain boundaries. In a metamorphic rock, these boundary weaknesses disappear as recrystallization causes distinct grains to grow into one another.

Hydrothermally altered rocks: Hydrothermally altered rocks are formed as fluids containing cations and anions circulate through a rock mass and cause original minerals to be out of equilibrium with the surrounding environment. This disequilibrium results in the mineral phases adjusting to the new environment, which is dictated by the temperature and composition of the altering fluid, usually water (Henley, 1985).

A high degree of variation of textures, composition, and mechanical properties can exist in a region on the scale of 10 's of centimeters. A rock's chemical and physical properties within a hydrothermal system are dependent on the proximity to the hydrothermal fluid and heat source (Henley, 1985; Fournier, 1985). Dense, strong rocks can be produced by the same hydrothermal system that produces 
friable, clay-containing rocks. Although physical properties may be relatively widespread in some settings, they may also vary greatly over very short distances (cm's) depending upon the dynamics of the hydrothermal system responsible for alteration.

The varied setting over which a rock is altered by hydrothermal fluid is such that a wide variety of grain sizes can coexist in the same rock. The grain size of quartz in a hydrothermally altered rock is a function of silica saturation of the fluid, salinity, solubility of silica, temperature, $\mathrm{pH}$, and fluid composition history. Amorphous silica commonly forms first, and the method of crystallization is dependent on the factors listed above. Generally, the higher the temperature of the amorphous silica during its transformation to crystalline silica, the larger the grain size (Fournier, 1985). However, local temperature gradients and compositional variations can cause significant variation in quartz grain size on a small scale (cm's).

\section{Surface Quartz Percentage}

The most likely grain tool is quartz, a widely occurring, hard, abrasive mineral. The percentage of quartz on the surface of the rock may be related to the wear the rock imparts on mining equipment. If more hard, abrasive grains are present, one might expect higher wear rates on mining equipment due to the fact that more abrasive grains 
would make contact with the tooth per rock interaction. This interaction would involve a scraping of the grain across the surface of the tooth, thus cutting a gouge in the tooth. Data on surface quartz content is also easily quantifiable, making this a potentially valuable test in the prediction of wear.

The percentage of quartz on a surface, grain size, and grain size variability are related to the genesis of the rock (Appendix I). Quartz grain size and size variability are related to the contact area (and thus pressure) of the grain tool on the tooth thus the

\section{Surface Quatz Percentage for the Samples Investigated}

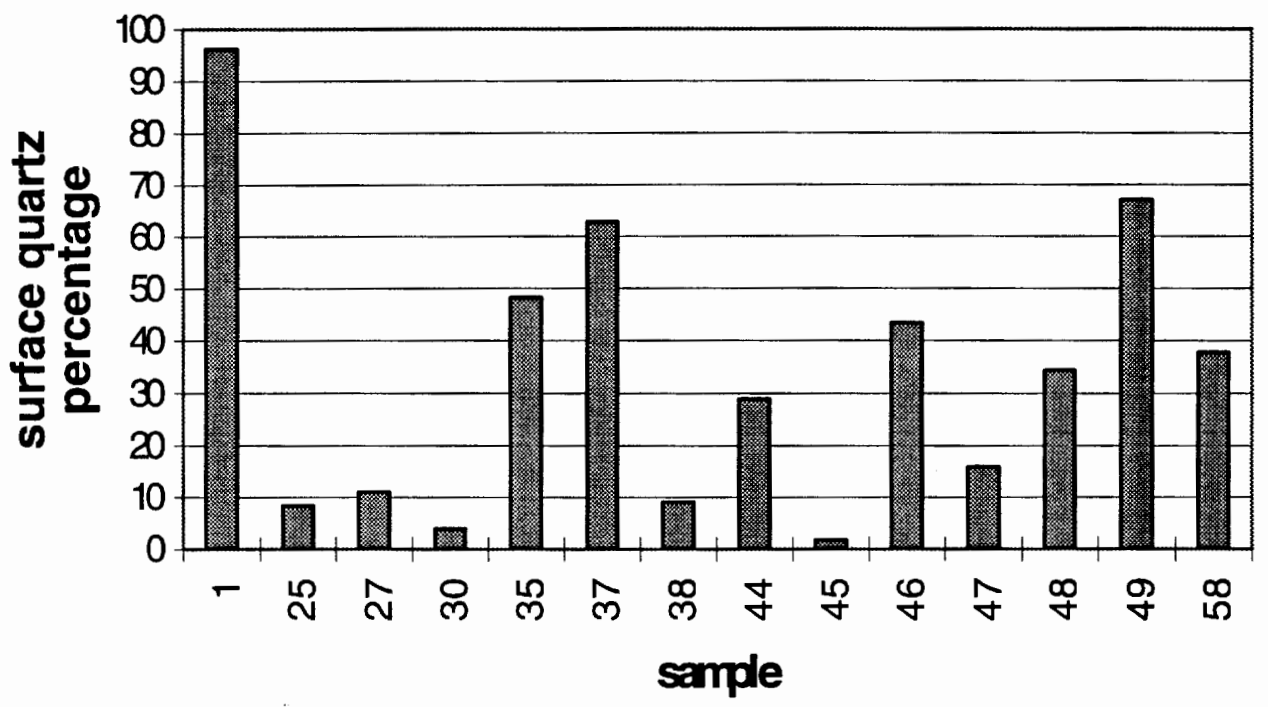

Figure 2. Average surface quartz for the samples investigated. Note the variability in values of quartz for the taconites (samples $44,45,46,47,48$, and 49) which corresponds to differences in initial rock compositions within the same mine. The Lone Tree samples (samples 37 and 38) experienced silica flooding during hydrothermal alteration, which is reflected in the high quartz contents. Sample 1, Bristol Silica; Samples 25, 27, 30, Centralia mine; Samples 37, 38, Lone Tree mine; Sample 44, Triple T granite; Samples 45-49, Hibbing taconite; sample 58, Samples mine. 
size of a gouge produced during an interaction. This will have an effect on the wear rate due to abrasion.

Surface percentage of quartz as seen in point counts are averaged for each sample investigated and shown in Figure 2. A complete table of data collected from thin section is given in Appendix II.

The highest value of surface quartz percentage occurs in Sample \#1, a hydrothermally altered rock from the Bristol Silica mine. This rock is a result of lowtemperature fluid replacement of a carbonate by silica. This process dissolves the carbonate and precipitates microcrystalline quartz (Fournier, 1985; Geitgey, 1990), as is reflected by the high surface quartz percentage in this rock.

The taconite samples (Samples \#44, \#45, \#47, \#48, and \#49) show surface quartz contents which varies between $1.7 \%$ for taconite Sample \#45 to $67 \%$ for taconite Sample \#49. This variation of surface quartz content reflects the wavy layering of chert and iron minerals of these rocks. Taconite Sample \#45 contains well preserved primary clastic textures, however, has undergone complete recystallization. The very fine grain size allows for the preservation of the primary sedimentary texture, with preservation of organic matter between the layers. The carbon content, from the organic matter, may have hindered crystal growth, thus leaving a rock with its primary sedimentary structures still intact, even though the conditions it experienced were similar to the other rocks from this mine. 
Taconite Sample \#49 is a recystallized iron-bearing chert. The high silica content and high degree of recystallization are consistent with the high surface quartz content of this sample.

The Lone Tree rocks (Samples \#37 and \#38) have undergone hydrothermal alteration. In the case of Lone Tree Sample \#37, a high degree of recrystallization of quartz is seen indicating that a high amount of silica was present in the system. The silica may have been present as a dissolved mineral in the hydrothermal fluid or as a silica-bearing mineral in the parent rock. This is reflected by the high surface quartz content. The lower quartz content of Lone Tree Sample \#38 illustrates the degree to which rocks in a hydrothermal system can vary relative to distance. Although the physical distance of these two samples is not exactly known, they did come from the same mine, thus their in-situ location is limited to a distance of no greater than a few hundred meters. This serves as an example of the variability of quartz within a hydrothermal system.

The relatively low values of surface quartz content for the Centralia samples (Samples \#25, \#27, and \#30) are consistent with the sedimentary environment in which these rocks were formed. These rocks are composed predominantly of silt and clay sized particles deposited in a low energy fluvial environment. Also, the low quartz content found in these rocks may be due to the relatively low initial quartz content in many western sands (Boggs, 1969; Hines, 1969). 
The quartz content shown in the Kennecott Sample \#35, a porphyry copper deposit is due to the original quartz content of this rock. This rock is the result of hydrothermal alteration of a sedimentary country rock (Lanier and others, 1978).

Sample \#44, a granite from Triple $\mathrm{T}$ rock quarry shows a value of quartz which most likely reflects the silica content of the magma which formed this rock.

\section{Grain Size Variability}

Deketh and Verhouf (1993) indicated that the size of the abrasive particles in "artificial" rocks (cement bonded quartz sand) affected measured wear rates. The investigation of the size variation of the grain tools in the sample rocks addressed this aspect of wear.

The grain size in a rock is mostly a function of the genesis of the rock. In the study of wear, different rock types must be recognized (plutonic, sedimentary, hydrothermally altered, and metamorphic) before grain size is used to interpret genetic history, thus physical properties.

The variability in the quartz grain size can be an indication of the genesis of the rock, if the history of the rock is not complex (Pirajno, 1992). However, it is often not possible to interpret genesis by an investigation of grain size alone. The investigation of grain size for this project addressed whether the grain size variability could help determine some of the physical properties of the rocks by providing a genetic 
framework. The physical properties important in wear are determined later in this project.

The physical and chemical processes responsible for the formation of a particular rock will determine the range of quartz grain size for that rock (Spry, 1964; Ehlers and Blatt, 1980, Fournier, 1985). These processes may be similar enough for a given rock type, e.g. sedimentary rocks are formed by the low pressure and low temperature lithification of sediments, for a statistical pattern to exist. Thus, it may be possible to recognize rock type by the range of grain size. For the samples investigated, the range and mean of the quartz grain size were statistically analyzed to determine whether a relationship existed between rock type and quartz grain size. In the following section a description of the methods and the results of these methods are described.

In a given sample a range of quartz grain sizes are present. The average value, or mean, is a convenient way to describe such a sample. The mean of a sample is given by the following equation;

$$
\bar{X}=\frac{\sum_{i=1}^{n} X_{i}}{n}
$$

where $X$ is a discrete data point and $n$ is the number of data points within a sample. The mean quartz grain size of a sample, however, says little about the distribution of the quartz grain sizes within the sample. To quantify the distribution of quartz grain 
size about the mean, the standard deviation is calculated for the samples. From Davis (1986), the standard deviation is given by the following equation;

$$
\sigma=\sqrt{\frac{\sum_{i=1}^{n}\left(X_{i}-\mu\right)^{2}}{n}}
$$

where $\mathrm{X}$ is a discrete data point, $\mathrm{n}$ is the number of data points, and $\mu$ is the population mean. Conceptually, the standard deviation describes the shape of a normally distributed sample curve (Figure 3), or the distribution of data points about the sample mean. For two samples having identical mean grain sizes, the variation in grain size would be larger for the sample with a larger standard deviation.

\section{Histogram, Sample \#35}

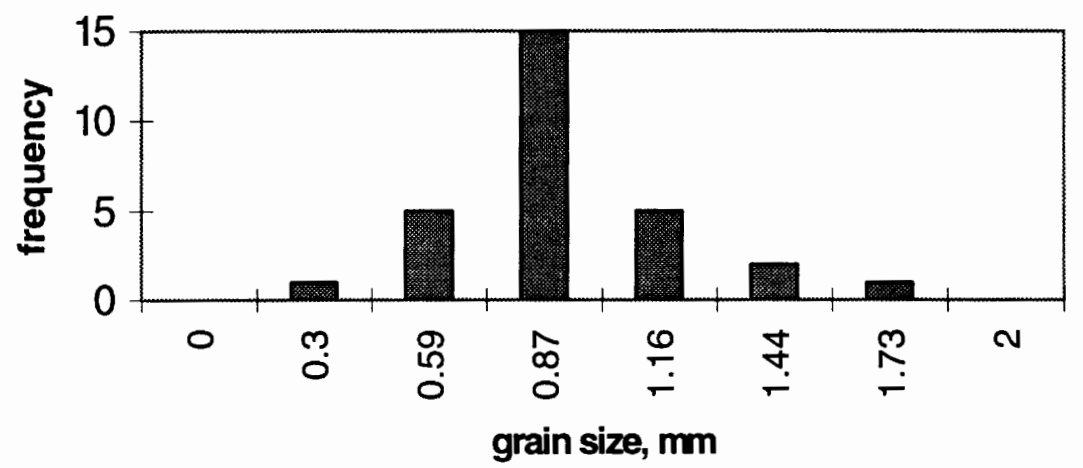

Figure 3. The normal distribution of the quartz grain sizes for Sample \#35, from the Centralia mine. The calculated standard deviation for this sample is $.304 \mathrm{~mm}$. Approximately $68 \%$ of the quartz grains are between 1.064-.456 mm. A sample having an identical mean but more size variability would have a fatter curve, which would be indicated by a larger standard deviation. The process of cutting the thin section does not allow all the grains to be cut in the exact center. Some grains will be cut on the corner, which gives the illusion of a greater number of fine grains than actually exists.

In order to compare grain sizes of the rock types, the grain size variation within one rock type (e.g. a sedimentary rock) had to be from a statistically different 
population than the grain size variation of the other rock type (e.g. a metamorphic rock); the variances of the grain sizes had to be evaluated. This is accomplished by a $F$-test. From Davis (1986) the $F$ statistic is the ratio between the variances of two different samples. This is given by the following equation;

$$
F=\frac{s_{1}^{2}}{s_{2}^{2}}
$$

where $s_{2}^{2}$ is the larger variance of a sample $s_{1}^{2}$ the smaller variance of a different sample. The hypothesis to be tested is

$$
H_{0}: \sigma_{1}^{2}=\sigma_{2}^{2}
$$

against

$$
H_{0}: \sigma_{1}^{2} \neq \sigma_{2}^{2}
$$

The null hypothesis states that the parent populations of the two samples have equal variances; the alternate hypothesis states that they do not.

From before, the variance is the standard deviation squared;

$$
\sigma^{2}=\frac{\sum_{i=1}^{n}\left(X_{i}-\mu\right)^{2}}{n}
$$

where $X$ is a discrete data point, $n$ is the number of data points, and $\mu$ is the population mean. When an $F$-test is performed on two different samples, if the calculated value of $F$ is greater than a critical value of $F$, the conclusion can be made that the variation is not the same for the two groups; i.e. the samples are statistically probably not from the same population. The critical value refers to the area under the 'ends' of a distribution 
curve of data. For this research, the critical value was set at $5 \%$. If $F$ does not exceed the critical value, there is no evidence for concluding that the variances are different.

F-tests were performed on quartz grain size data for the samples. Every sample was tested against all the other samples. The results for these tests are shown in Appendix V and summarized in Table 2. All but four pairs of samples (\#1 and \#49, $\# 27$ and \#37, \#37 and \#46, and \#25 and \#45) failed the F-test, which implies that the grain sizes and the grain size variations of the majority of the samples tested are from statistically different populations (at $5 \%$ confidence). Samples of similar rock type (e.g. the sedimentary rock samples \#58 and \#25) failed this test, which implies that the grain size variation within a specific rock type is non-unique.

Four pairs of samples (\#1 and \#49, \#27 and \#37, \#37 and \#46, and \#25 and \#45) did not fail the F-test. These samples are not necessarily from different populations, as the variances of these samples are equal. Hence very little can be said about their grain size variations relative to one another, as the grain sizes may all be statistically similar. The grain sizes of these samples are not necessarily from different populations despite the different origins of these rock types (Table 1).

Another test, the $t$ test can be utilized for testing the equivalency of the means of two samples. If the grain size variation of similar rock types is similar, a corresponding effect on wear could occur. Thus, the means of the quartz grain sizes of the sample pairs with similar quartz grain size variances was tested. Unlike the $F$ test, the $t$ test assumes equal variances. For comparing two samples sets, the hypothesis 


$$
H o: \mu_{1}=\mu_{2}
$$

which states that the mean of the population from which the first sample is drawn is the same as the mean of the parent population of the second sample. This hypothesis is posed against the alternative

$$
H o: \mu_{1} \neq \mu_{2}
$$

that the two population means are not equal. Again, the level of significance must be specified, in this case, $5 \%$. The $t$ statistic has the form

$$
t=\frac{X_{1}-\bar{X}_{2}}{s_{p} \sqrt{\left(\frac{1}{n_{2}}+\frac{1}{n_{2}}\right)}}
$$

where $X_{1}$ is the mean of the first sample set, $X_{2}$ is the mean of the second sample set, $n$ is the number of observations and $s_{p}$ is the pooled estimate of the population standard deviation, based of both samples. The estimate is found from the pooled estimated variance, given by

$$
s_{p}^{2}=\frac{\left(n_{1}-1\right) s_{1}^{2}+\left(n_{2}-1\right) s_{2}^{2}}{n_{1}+n_{2}-2}
$$

Similar as the $F$ test, if the calculated value of $t$ exceeds a critical value of $t$, the samples are probably from different populations, as the means of the two sample groups are not similar. The results of the $t$ tests are given in Appendix V.

The results of the $t$ tests performed on the pairs of samples \#27 and \#37, \#37 and \#46, and \#25 and \#45 show that the calculated value of $t$ exceeds that of the 
critical value of $t$. This means that the null hypothesis is rejected and the samples are probably from different populations. This is the expected result of these pairs of samples, as these are all different rock types. However, rock types having different quartz grain size means can easily exist. A fine grained sandstone and a coarse grained conglomerate have similar genetic origins and may have similar physical properties, but have vastly different mean grain size.

In the case of the pair of samples \#1 and \#49, the calculated value of $t$ did not exceed the critical value of $t$, therefore the null hypothesis cannot be rejected. Therefore, there is no evidence to suggest that the two samples came from populations having different means. Sample \#1 the Bristol Silica is a replacement quartz and Sample \#49 is a Hibbing taconite. These two samples have similar quartz grain size variances and similar quartz grain size means despite the fact that the genetic origins (and the physical properties) are vastly different.

The perceived variation in the grain size will also be due to a random cut through the grains, which could cut through both the corners of some grains and the middle of other grains, giving the perception of a wider variation in grain size than actually exists. The histogram shown in Figure 3 is skewed to the left, as the corners of grains will be recorded as smaller grains. No distortion will occur to the right side of the histogram, as a random cut will not produce perceived grain sizes larger than what actually exist. If the distortion of the grain size curves (Figure 3) due to the overrepresentation of fine grains could be accounted for, the curves would become 
tighter, or narrower, thus becoming statistically more unique. This would result in the difference between the calculated and critical $F$ values to be greater than those in Appendix V. Hence, the samples would still fail the F-test. However, at this time it is not known how to account for the random cut through the grains.

Quartz grain size variations of samples taken from the metamorphic samples (e.g. samples \#46, \#45 and \#49 are the taconites) were statistically not from the same population. The quartz grain size variations of the sedimentary rocks (Samples \#25, \#27, \#30, from the Centralia mine and \#58 from the Samples mine) displayed a similar phenomenon; statistically the quartz grain sizes were not from the same populations. This is also the case for the hydrothermally altered rocks (Samples \#35, \#37, from the Lone Tree mine and \#38 from the Bingham Canyon mine). Comparing quartz grain size and quartz grain size variation within these rock types is statistically invalid.

Table 2. Mean quartz grain size and the standard deviations.

\begin{tabular}{c|c|c|c}
\hline $\begin{array}{c}\text { Sample } \\
\#\end{array}$ & $\begin{array}{c}\text { Mean quartz grain } \\
\text { size, } \mathrm{mm}\end{array}$ & $\begin{array}{c}\text { standard } \\
\text { deviation, } \mathrm{mm}\end{array}$ & $\begin{array}{c}\text { quartz grain size variation, } \mathrm{mm} \\
( \pm 1 \sigma)\end{array}$ \\
\hline \hline 1 & 3.67 & 2.22 & $5.89-1.45$ \\
25 & .28 & .02 & $.30-.26$ \\
27 & 1.48 & .5 & $1.98-.98$ \\
30 & .42 & .21 & $.63-.21$ \\
35 & .76 & .30 & $1.06-.46$ \\
37 & .83 & .46 & $1.29-.37$ \\
38 & .09 & .05 & $.14-.04$ \\
44 & 4.88 & 3.35 & $7.83-1.13$ \\
45 & .07 & .12 & $.19-.05$ \\
46 & .46 & .35 & $.81-.11$ \\
49 & 1.66 & 1.69 & $3.35--.03$ \\
58 & 2.38 & 1.01 & $3.39-1.07$ \\
\hline
\end{tabular}


The wide variation in quartz grain size seen in the taconite samples (\#45, \#46, \#49) indicates a variation in the original composition of the rock from which the taconite was formed. The variation in quartz grain size in this cherty iron formation is due to compositional variation between different beds within the same rock unit and not due to differing degrees of metamorphism (Morey, 1972). Zones of different composition within a given sample have different quartz grain sizes.

The wide quartz grain size variation seen in the Triple T granite (Sample \#44) is consistent with the igneous crystallization experienced by this rock, as quartz is the last mineral to crystallize, filling the last of the available volume within the crystallizing rock.

The moderate grain size variation $(5.89 \mathrm{~mm}$ to $1.45 \mathrm{~mm})$ in the Bristol Silica (Sample \#1) indicates the varying conditions within the system in which this rock formed. The precipitation of silica and the dissolution of carbonate often produces fine grain size and little grain size variation; however, local variations in the temperature and chemistry of the fluid can have significant effects on the grain size, causing the range of variability seen in this sample (Fournier, 1985). The variability in grain size reported for the other hydrothermally altered rocks, Samples \#37 and \#38 from the Lone Tree gold mine in Nevada, is $1.29 \mathrm{~mm}$ to $0.37 \mathrm{~mm}$ for Sample \#37 and $0.14 \mathrm{~mm}$ to $0.04 \mathrm{~mm}$ for Sample \#38. As in the case with the Bristol Silica, local variations in the chemistry and temperature of the fluid causes a wide to moderate variation in quartz grain size. 
A narrow range of grain size seen the samples from the Centralia mine (Samples \#25,\#27, and \#30) reflects the degree of sorting in the clastic sedimentary rocks associated with the coal seam. This sorting pattern is indicative of the energy regime of the depositional environment, which is low for this system. This low energy system is consistent with the build-up of organic matter which later produced the mineable coal in this mine. Sample \#58, a sedimentary rock from the Samples Mine, also shows this narrow range in quartz grain size. The variability in quartz grain size within the sample type (i.e. sedimentary rocks) is indicative of depositional environment of each rock type. Local variations in the depositional environment will cause a wide variety of grain size within the same rock.

\section{Fabric}

Fabric elements of the rocks relate to inherent structure of the rock mass on the hand sample and thin section scale. Structures such as bedding planes, compositional banding, mineralogical alignment, and internal fracture density can have an effect on the mechanical behavior of a rock mass (Jaegger and Cook, 1979). The mechanical behavior of a rock mass has an effect on the wear characteristics it imparts on a tooth as they will affect the endurance of the rock tools (Deketh and Verhouf, 1993).

In this project, the fabric elements of the rocks were noted (Appendix I). The taconite sample \#45 displayed the most prominent fabric. The pronounced compositional layering is most likely original sedimentary structures that were 
preserved during metamorphism. The taconite Samples \#46, \#47, \#48, and \#49 experienced greater re-crystallization than Sample \#45, and also display a fabric resulting from original sedimentary layering.

The Centralia Samples \#25 and \#30 showed strong evidence of sedimentary structures, as would be expected of this fluvially deposited rock. The lack of fabric in Centralia Sample \#27, the most well indurated of the Centralia samples, is probably due to the fact that the sample's fabric elements are larger than the scale of observation.

Sample \#44, an undeformed granite, lacks preferred orientation of crystals or compositional layering.

\section{Mechanical Tests}

The measure of mechanical properties addresses the nature of the rock tools. In the measurement of a rock body's mechanical properties, the scale to which the properties are measured is a critical factor. The rock body must be large enough to contain a representative sample of the individual constituent rock parts, but small enough to omit large-scale physical and compositional discontinuities. The scale to which a measurement is made must be specified and the interpretation of the measurement must account for the characteristics of the rock body at the scale of measurement. 
The mechanical properties of the rocks on both the macroscopic scale and the microscopic scale have a direct effect on the evolution and endurance of the rock tools and the grain tools. This, in turn, is related to wear rates imparted on the teeth. The mechanical tests gathered information on rock tools and included the following tests; 1) unconfined compressive strength, 2) Young's modulus, 3) Poisson's ratio, 4) density, 5) microhardness, 6) shape, and 7) abrasiveness.

\section{Uniaxial Tests}

It is my hypothesis that the degree to which the rock remains intact during an interaction with a tooth is related to the value of uniaxial compressive strength. Also, I believe that the evolution of the rock tools may be determined in part by the value of this parameter. The question is asked whether a rock with a smaller value of uniaxial compressive strength will more easily lose its rock tools upon interaction with a tooth.

As a rock is subject to uniaxial stress, microcracks begin to grow in the direction parallel to the principle stress (Jaegger and Cook, 1979). The tips of these microcracks are subject to tensile stress in a direction perpendicular to the compressive stress (Lawn and Wilshaw, 1975; Jaegger and Cook, 1979). This results in the extension of the crack. As the crack grows, the ability of a body to resist the load diminishes. This situation is unstable and results in the failure of the body. The magnitude of the tensile strength and the microcrack density can thus have an affect on the magnitude of the compressive strength and shear strength (Jaegger and Cook, 
1979). The tensile strength and shear strength is related to the ability to which a rock will hold its grain tools and rock tools (Deketh and Verhouf, 1993), and thus effects the wear characteristics of a given rock.

Young's Modulus, a value that can also be obtained by uniaxial compression tests, is the relation between the normal stress applied to a rock and the normal strain resulting from the applied stress. Young's modulus is given by the following equation:

$$
E=\frac{\sigma}{\epsilon}
$$

where $\mathbf{E}$ is Young's modulus, $\sigma$ is the uniaxial stress, and $\in$ is the strain parallel to the direction of the principle stress. A rock having a large Young's modulus is more likely to absorb, by deformation, a given stress before failure than a rock with a low magnitude of Young's modulus. Thus, the value of this parameter is related to how brittle the rock is, and may have an affect on wear rates to teeth.

As a rock body is subject to uniaxial stress, the rock exhibits strain in both the directions parallel and perpendicular to the principle stress. The ratio between these two strains is called Poisson's ratio and can be expressed by the following equation:

$$
R=\frac{\epsilon_{1}}{\epsilon_{2}}
$$

where $\mathrm{R}$ is the value for Poisson's ratio, $\epsilon_{1}$ is the strain in the vertical direction and $\epsilon_{2}$ is the strain in the horizontal direction (Davis, 1984). It can be inferred from this equation that a rock which exhibits very small values of Poisson's ratio expands very little in the horizontal direction as it undergoes uniaxial stress. Such a rock absorbs the 
vertical strain $\left(\epsilon_{1}\right)$ rather than accommodating the vertical strain as a lateral bulging. A rock which displays relatively large values of Poisson's ratio will absorb a uniaxial stress by expanding in a horizontal direction $\left(\epsilon_{2}\right)$. The failure of a rock under uniaxial stress with a small value of Poisson's ratio will be far more violent and produce fragments which are much smaller than a rock with a larger value of Poisson's ratio (Davis, 1984).

Huard and Masounave (1987) and Deketh and Verhoef (1993) have shown that particle size is an important factor in wear. A rock having a small value of Poisson's ratio, upon failure, forms small fragments which produce significantly different wear rates than a rock producing large fragments upon failure. However, it is not known how this particle size will contribute to the wear process. Perhaps more important is the size distribution of the rocks in the mine rather than the rock fragment produced upon interaction with the teeth, as many rocks may not fail upon interaction with mining equipment.

The best predictor of whether a rock will fail upon interaction with a tooth is the strength of the rock. This parameter will dictate whether the rock will remain intact during an interaction. An intact rock will scrape a corner across a tooth, resulting in a gouge. A rock which fails upon an interaction will not be able to produce a gouge, thus will produce less wear than the intact rock. 
The value of the uniaxial compressive strength for the taconite Sample \#45 is $2,413,000 \mathrm{kPa}$. This is the highest value seen in the taconite samples, however, this sample is not expected to be as aggressive as the higher quartz percentage taconites.

Table 3. Results of uniaxial compressive tests

\begin{tabular}{c|c|c|c}
\hline sample and mine & $\begin{array}{c}\text { failure strength } \\
(\mathrm{kPa})\end{array}$ & $\begin{array}{c}\text { Young's modulus } \\
(\mathrm{kPa})\end{array}$ & $\begin{array}{c}\text { Poisson's } \\
\text { ratio }\end{array}$ \\
\hline \hline 1, Bristol Silica & $1,151,000$ & $9,376,420,000$ & .04 \\
27, Centralia & 676,000 & $206,832,000$ & .39 \\
30, Centralia & 90,000 & $6,825,000$ & .04 \\
35, Bingham Canyon & 516,000 & $317,143,000$ & .19 \\
37, Lone Tree & 855,000 & $413,665,000$ & .07 \\
38, Lone Tree & 951,000 & $406,770,000$ & .19 \\
44, Triple T & $2,510,000$ & $572,236,000$ & .28 \\
45, Hibbing & $2,413,000$ & $489,503,000$ & .16 \\
46, Hibbing & $1,144,000$ & $875,591,000$ & .10 \\
58, Samples & 827,000 & $172,360,000$ & .36 \\
\hline
\end{tabular}

This sample is a slaty rock with primary sedimentary structures still visible. The load was applied perpendicular to the bedding planes, and this rock is not expected to have this value of uniaxial strength in a direction parallel to the bedding planes. This rock has strong bonding within a given bed, but weak bonding across beds, as suggested by breakage patterns. Thus, this rock is expected to have a relatively low value of shear strength due to these bedding planes and is expected to fail along these planes when handled by mining equipment. A rock such as this might not be as durable as a rock which does not display this anisotropy such as Sample \#44, the Triple T granite. This granite has a uniaxial strength of $2,510,000 \mathrm{kPa}$ and would not have planes of weakness like Sample \#45, thus being less likely to fail during handling. The strength 
of these two rocks is similar despite the difference in the compositional and genetic background. The values of compressive strength for the other taconite, Sample \#46 is $1,144,000 \mathrm{kPa}$, which may be low, as visible fractures exist throughout this rock.

The low strength of the Centralia rocks is consistent with the weakly consolidated character of the siltstones and mudstones from this group. As with the bedded taconite (Sample \#45) these rocks were loaded perpendicular to the prominent bedding planes. The Centralia samples did not experience the metamorphism and subsequent re-crystallization and display a much lower value of uniaxial strength than the bedded taconite. The degree of re-crystallization in the taconite sample is likely the reason for the rock's high uniaxial strength relative to the sedimentary rocks.

The value of compressive strength seen in Sample \#58, the Samples sandstone, is $827,000 \mathrm{kPa}$. This sample is much less friable than the Centralia rocks and posses a much higher magnitude of uniaxial strength. The degree of cementation/consolidation appears to have considerable effect on the value of uniaxial strength.

The intermediate values of unconfined compressive strength shown by the Lone Tree Mine rocks (Samples \#37 and \#38; 855,000 kPa and 951,000 kPa, respectively) and the Bingham Canyon Mine rock (Sample \#35; 516,000) reflect failure along existing micro-fractures in the rock, probably produced during hydrothermal alteration. 


\section{Uniaxial Compressive Strength}

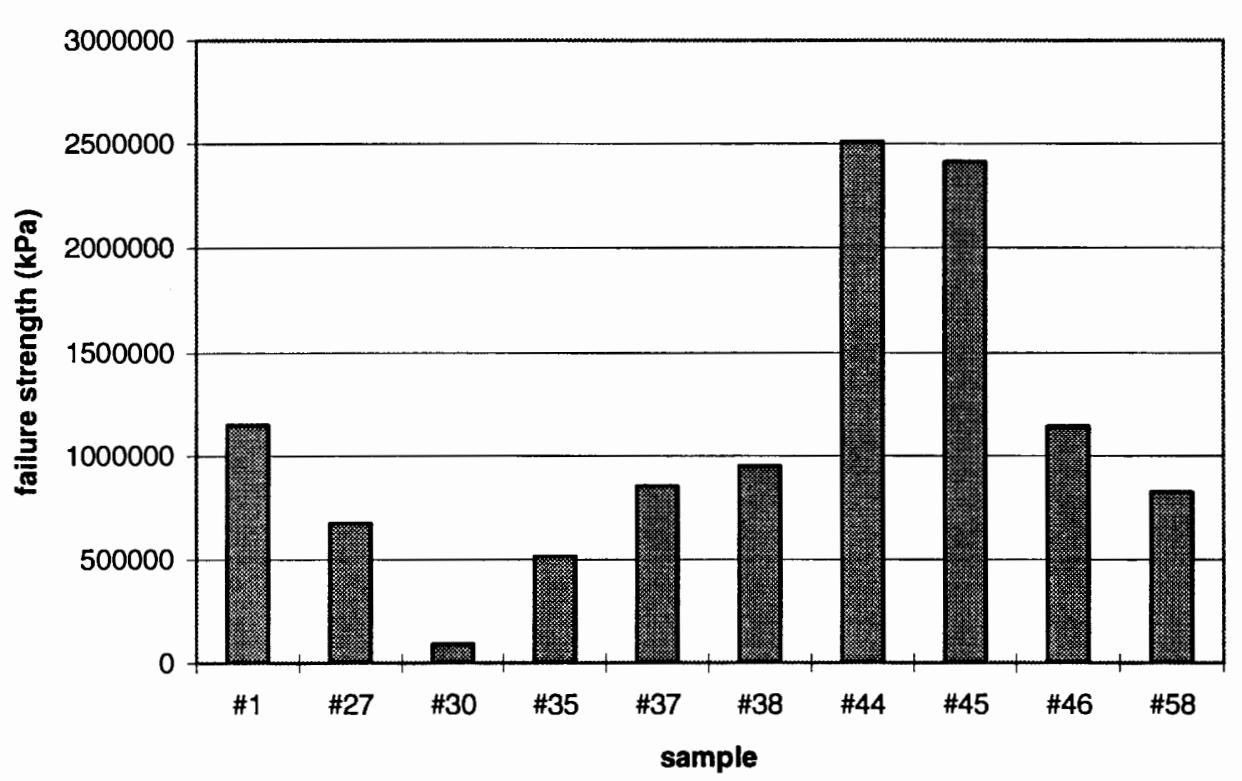

Figure 4. Uniaxial compressive strength for the samples investigated. The strongest samples are the taconite and the granite (Samples \#45 and \#44, respectively), which represent highly crystalline rocks. The low strength of the Centralia rocks is consistent with the weakly consolidated siltstones and mudstones from this group.

The taconite samples display a relatively high value of Young's modulus.

These rocks are expected to be stiff, compared to softer, hydrothermally altered rocks, such as the Lone Tree rocks (Samples \#37 and \#38) and the Bingham Canyon rock (Sample \#35). The collapse of submicroscopic pore space or the opening of microfractures in these hydrothermally altered rocks may cause strain to develop as the rocks are loaded, thus effecting the magnitude of Young's modulus. The value of Young's modulus will be lowered by the strain due to the collapse of pore space and the opening of microfractures. The rocks of the Centralia mine (Samples \# 27 and \#30) also have a relatively low value of Young's modulus, which can be expected for 
weakly indurated sedimentary rocks. The sedimentary rocks contain a high degree of pore space which collapses upon loading. This is also true for the Samples sandstone.

The high value of Young's modulus for Sample \#1 is due to the fact that Sample \#1 is mostly quartz with a small amount of iron. This sample contains interlocking grains of quartz, and is not a mixture of different minerals as are the rest of the samples.

Generally, the magnitude of Young's modulus is the lowest in the sedimentary rocks. The collapse of the relatively abundant pore space in sedimentary rocks would account for this observation. The pore space in hydrothermal rocks may not be as abundant as in the sedimentary rocks, hence the intermediate values of Young's modulus. The metamorphic rocks display the highest values of Young's modulus, as pore space in these rocks was destroyed during re-crystallization.

Poisson's ratio for the samples shows more variability than Young's modulus. The values of Poisson's ratio for the taconite samples range from 0.10 to 0.28 , which are generally lower than the other samples. Exceptions to this are the values of Poisson's ratio for the Lone Tree Sample \#37, with a value of 0.07 and a Centralia Sample \#30, with a value of 0.04 . The low value for the Lone Tree samples is probably due to a collapse of sub-microscopic pore space, which is common in hydrothermally altered rocks (Fournier, 1985). The collapse of pore space would allow a vertical strain to occur without corresponding lateral strain to develop. This phenomenon is likely responsible for the low value of the Centralia sample, Sample 
\#30. The high amount of quartz in Sample \#1 is responsible for the low value of Poisson's ratio seen in this sample (Haas, 1989).

The high value of Poisson's ratio seen in Sample \#58, a sandstone, and Sample \#30, a carbonate cemented sandstone, is likely due to the breaking of cement/grain contacts, allowing a slight re-orientation of the individual grains. The re-orientation of the grains would allow a slight swelling of the sample during uniaxial loading.

The porosity of the hydrothermal rocks causes slightly lower values of Poisson's ratio than in the other rocks. The effects of collapsing pore space in the sedimentary rocks, however, is negated by the strain from the re-orientation of individual grains, thus causing high values of Poisson's ratio.

\section{Density}

Hokkirigawa and Kato (1989) showed that the normal load of a point against metal was directly related to the wear that the point caused to the metal. As the normal load was increased, the wear to the metal was increased. The density of a rock mass will have an effect on the normal loads imparted upon teeth by the rocks. As the normal load increases the pressure on the tooth by the rock increases, thus more metal will be removed by ductile cutting and gouging. The bulk density of the mine rocks will have a direct affect on the normal load, thus pressure, between the rocks and the mining equipment. Density is also an easily obtained rock characteristic. 
The highest densities occur in the taconite samples (Samples \#45, \#47, and \#48), which is due to the iron content of these rocks (Table 4). The Centralia rock (Sample \#25) possesses the lowest density, which probably reflects pore space within the rock. The densities for the Lone Tree rock samples \#37 and \#38 is approximately $2.6 \mathrm{~g} / \mathrm{cm}^{3}$. These rocks are mostly quartz, sot the density is expected to be similar to quartz. The density of the Bristol Silica, which is virtually pure quartz, is slightly higher than the density of pure quartz (Table 4). This is due to a slight iron content, which can be seen as iron oxide in the hand sample.

Table 4. Sample densities. The pure quartz is provided as a reference.

\begin{tabular}{c|c}
\hline Sample & Density \\
\hline \hline Quartz, pure $\mathrm{SiO}_{2}$ & 2.65 (Deer and others, 1969) \\
1, Bristol silica & 2.8 \\
25, Centralia mudstone & 2.2 \\
27, Centralia mudstone & 2.6 \\
35, Bingham Canyon copper porphyry & 2.6 \\
37, Lone Tree & 2.6 \\
38, Lone Tree & 2.6 \\
45, Hibbing taconite & 4.2 \\
47, Hibbing taconite & 3.0 \\
48, Hibbing taconite & 3.4 \\
58, Samples sandstone & 2.7 \\
\hline
\end{tabular}

In the samples investigated, the highest densities are seen in the metamorphic rocks. These unique rocks contain significant amounts of iron, which gives these rocks higher density than typical metamorphic rocks (Judd and Shakoor, 1989). The sedimentary rocks generally have the lowest density due to the presence of abundant pore space. 


\section{Shape}

Modification of a surface by a tool is directly related to the pressure at which the tool acts upon the surface (Huard and others, 1987; Conway and Kirchner, 1980; Hokkirigawa and Kato, 1989). The pressure is proportional to the normal force and inversely proportional to the area of the tool which makes contact with the surface. This can be seen in the following equation:

$$
P=\frac{F}{A}
$$

Where $\mathrm{P}$ is the pressure, $\mathrm{F}$ is the normal load, and $\mathrm{A}$ is the cross sectional area. Thus for a given normal load, a tool with a relatively small cross sectional area (a sharp tool) will impart a much greater pressure upon a tooth than a tool with a relatively large cross sectional area (a dull tool). The removal of tooth material will be considerably greater in the former situation.

If the curvature of the tip of individual tools is measured, sharp tools can be defined as having a smaller tip radius than dull tools. In order to describe a rock face consisting of a number of tools, shape descriptors are commonly used. The shape of a rock possessing a large number of sharp tools will have a different shape then a rock possessing a large number of dull tools. The shape, therefore, of a rock can have an effect on the rate at which the rock can modify the surface of an object.

The surface trace of the samples closely resemble a periodic phenomenon. Thus a harmonic analysis can decompose the trace into its constituent parts. In order 
for this to be done, the trace must be sampled at discreet points which are spaced a distance, $\Delta$, apart (Davies, 1986). If there are $n$ of these points, one of which is $j$, the $\alpha_{k}$ and $\beta_{k}$ coefficients of the Fourier equation can be written as;

$$
Y=\sum_{k=0}^{\infty} \alpha_{k} \cos (k \theta)+\beta_{k} \sin (k \theta)
$$

and its coefficients estimated as

$$
\alpha=\frac{2}{k} \sum_{j=1}^{n} Y_{j} \sin \left(\frac{2 \pi j k}{n}\right)
$$

and

$$
\beta=\frac{2}{k} \sum_{j=1}^{n} Y_{j} \sin \left(\frac{2 \pi j k}{n}\right)
$$

where $k$ is a constant and $\theta$ is the angle (ranging from 0 to 360 degrees for a linear trace, which is converted from linear trace length).

Once the $\alpha$ and $\beta$ coefficients have been determined for a series of harmonics, the interpretation of the Fourier spectrum can be calculated by the following equations;

$$
A_{k}=\sqrt{\left(\alpha_{k}^{2}+\beta_{k}^{2}\right)}
$$

and

$$
\phi_{k}=\tan ^{-1}\left(\frac{\beta_{k}}{\alpha_{k}}\right)
$$

where $A_{k}$ is the amplitude and $\phi_{k}$ is the phase angle.

The quantification of shape using Fourier analysis techniques allows the frequency content of a spectrum to be determined (Davis, 1986), however, the 
frequency content of an unfiltered spectrum (in this case, the surface trace of the sample) is in the spatial domain, so the length of the spectrum being analyzed is important. The length of the spectrum must be consistent throughout the analysis. Therefore, the Fourier analysis was applied to the samples at two different scales. The first analysis was performed on surface traces at the thin section scale and the second analysis was performed at the hand sample scale.

Fourier analysis, slide t4-b, sample 49

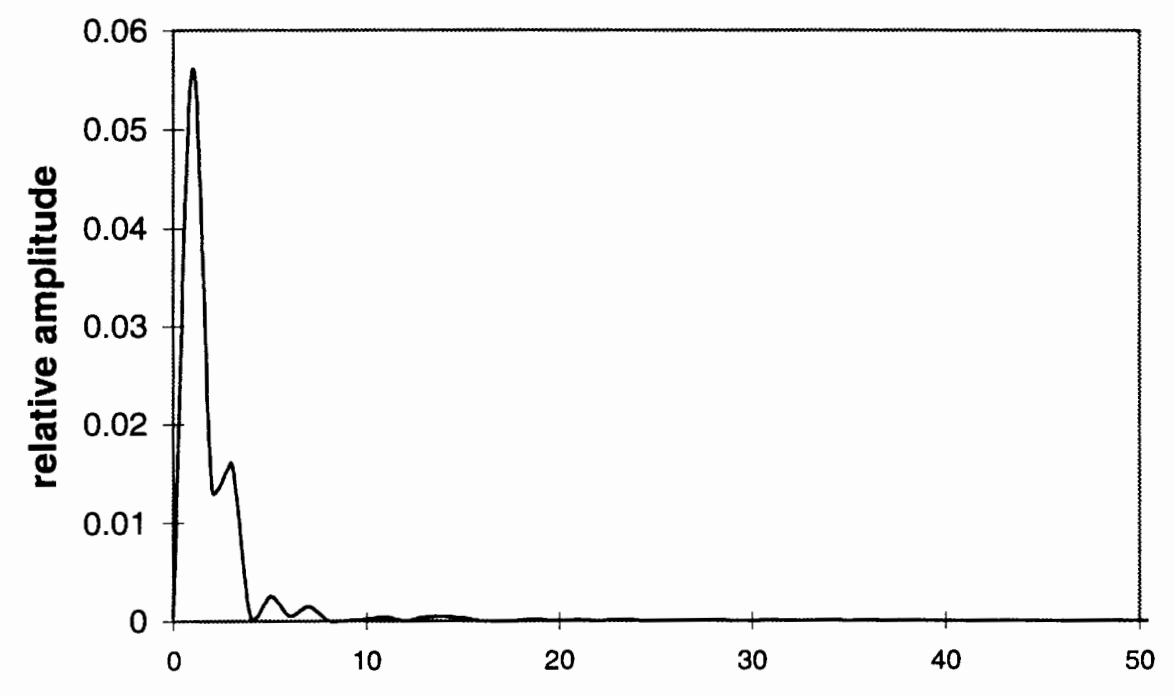

Figure 5. An example of a Fourier analysis completed on slide t4-b, taconite Sample \#49. To obtain the frequency content, divide the surface trace length $(7.59 \mathrm{~mm}$ for the thin sections) by the value corresponding to a peak. For example, the first large peak occurs at 1 , so $7.59 \mathrm{~mm} / 1=7.59 \mathrm{~mm}$ for that wavelength.

Figure 5 gives an example of the results of a Fourier analysis on Sample 49, a taconite. Appendix IV contains the results of the Fourier analysis for additional samples. In order that this be a viable method of shape determination, it must be 
shown that the analysis be repeatable and characteristic for each rock sample. An investigation of the wavelength vs. amplitude for given rock samples (Appendix IV), however, fails to show discernible patterns. Very little consistency was displayed within a given rock sample at both the thin section scale and the hand sample scale. This lack of consistency of wavelength vs. amplitude within a sample group is matched by a lack of clear patterns of wavelength vs. amplitude for multiple samples. Although I believe that shape is a very important property in the contribution to wear, I was unable to obtain usable results from this method of investigation. This prompted the discontinuation of this method of analysis for shape determination.

The sharpness of the corners and the number of corners may be an important factor in the prediction of wear. A rock which has "sharp" corners will be able to produce larger surface pressures, due to smaller contact areas, upon interaction with mining equipment than a rock with "dull" corners. For this reason, the corners were measured in the attempt to quantify the nature of this property on the rock samples.

Figure 6 gives the results of the measure of the radius of curvature for the samples investigated.

Sample \#25, a Centralia Mine rock shows the greatest value for the average radii of curvature. This is to be expected for this weakly indurated siltstone. This weak rock cannot support sharp corners (those corners with a small radius). Sample \#48, a taconite, shows the lowest value of radii of corners, i.e. it's corners are the sharpest. 
This is not unexpected for this quartz-rich, re-crystallized, fine-grained metamorphic rock.

\section{Average Radius of Curvature of Corners, as Measured from Profiles}

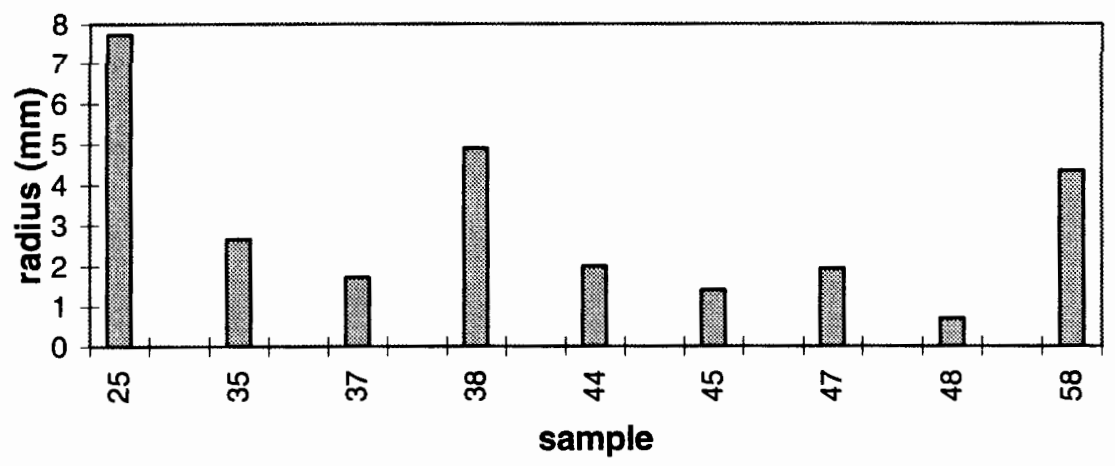

Figure 6. Average measured radii of profile corners of the rocks investigated. Samples 25, Centralia mine; Samples 37, 38, Lone Tree mine, Sample 44, Triple T granite, Samples 45, 47, 48, Hibbing taconite.

\section{Microhardness}

Microhardness is the measure of a material's ability to withstand penetration by a stationary, sharp, indenture which is pressed normally into the surface of the material. A semi-brittle material will first deform plastically under this point; continued pressure will cause the material to deform in a brittle manner (Lawn and Wilshaw, 1975). As the material deforms, tensile stresses accumulate directly beneath the tip of the indenture. If the tensile stress exceeds that of the rock's tensile strength, the rock material will deform in a Mode I crack (Lawn and Wilshaw, 1975) ( Figure 7). 


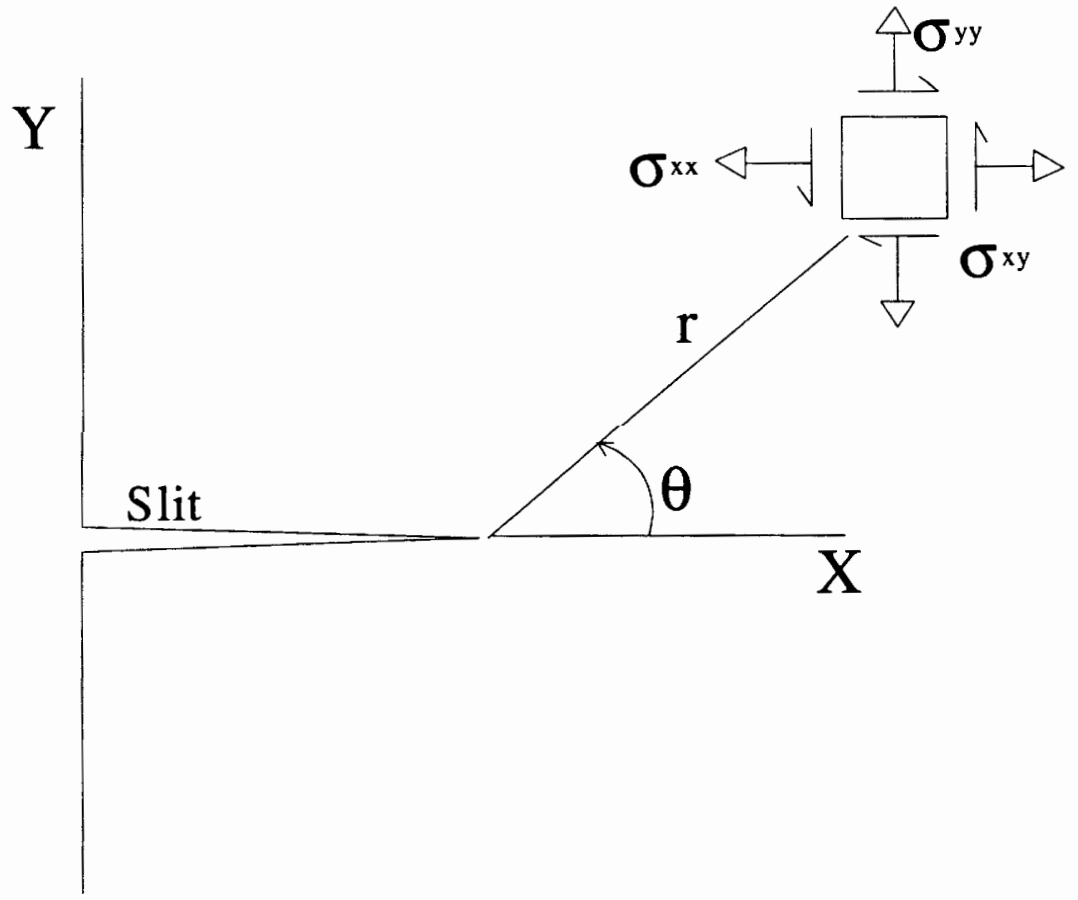

Figure 7. The stress at the tip of a crack as the crack is opening in pure Mode I deformation (after Lawn and Wilshaw, 1975).

The stress at the tip of a Mode I crack can be expressed by the following equations;

$$
\sigma_{x x}=\frac{k_{1}}{(2 \pi r)^{\frac{1}{2}}} \cos \frac{\theta}{2}\left[1-\sin \frac{\theta}{2} \sin \frac{3 \theta}{2}\right]
$$

and

$$
\sigma_{y y}=\frac{k_{1}}{(2 \pi r)^{\frac{1}{2}}} \cos \frac{\theta}{2}\left[1+\sin \frac{\theta}{2} \sin \frac{3 \theta}{2}\right]
$$


where $\sigma_{\mathrm{yy}}$ is the stress at the tip of the crack in the direction perpendicular to the crack, $\sigma_{\mathrm{xx}}$ is the stress parallel to the crack, and $\mathrm{k}_{\mathrm{l}}$ is the stress intensity factor, which is a function of the force separating the crack and the tensile strength of the cracked medium (Lawn and Wilshaw, 1975). The tensile strength of the rock material will therefore relate to the microhardness of the rock material being tested.

The tensile strength of a rock is related to the degree to which a rock will hold a grain tool during its interaction with a tooth (Deketh and Verhouf, 1993). A rock which holds its grain tools will cause the grain to drag across the tooth (two-body wear), cutting a gouge. This degree of gouging may not happen if the rock cannot hold a grain tool during its interaction with the tooth; the grain would be free to mill about between the

Knoop Microhardness for the Samples Tested

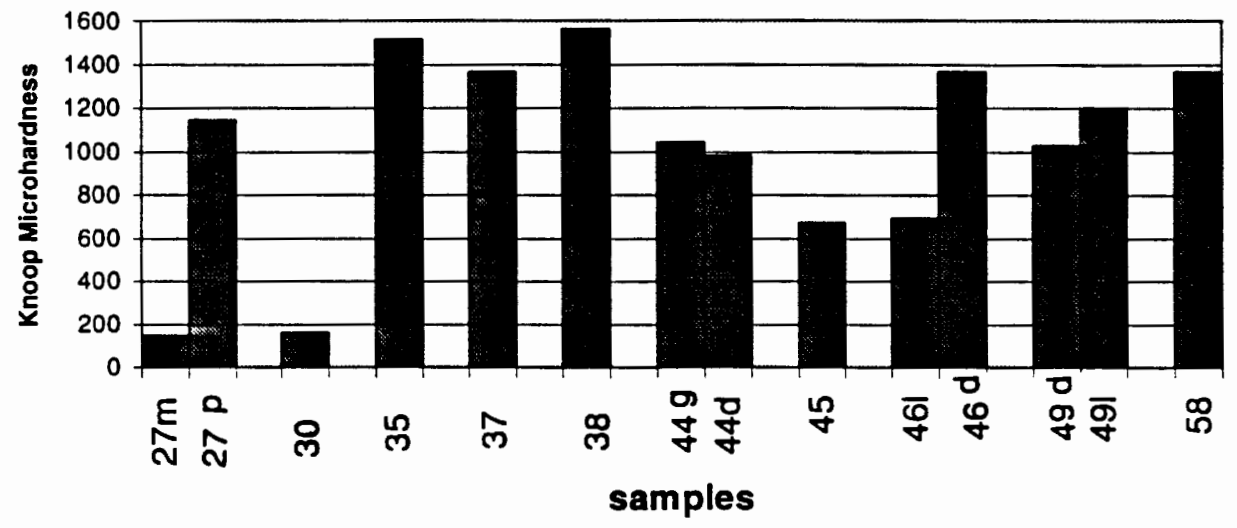

Figure 8. Average Knoop microhardness for the samples at $25 \mathrm{~g}$ indenture load. Samples 27 , 44,45 , and 49 had microhardness tests performed on areas of different composition, as indicated by the letters $(m=$ matrix, $p=$ particle, $g=$ grain, $l=$ light, and $d=$ dark, as assigned by ESCO Corporation). Samples 27, 30, Centralia mine; Sample 35, Bingham Canyon copper; Samples 37, 38, Lone Tree mine; Sample 44, Triple T granite; Samples 45, 46, and 49, Hibbing taconite; Sample 58, Samples mine. 
rock and the tooth (three-body wear). It has been shown that wear resulting from twobody wear is one or two orders of magnitude higher than wear resulting from threebody wear (Deketh and Verhouf, 1993). Although the scale at which the distinction is made between two-body interactions and three-body interactions is not entirely clear.

Figure 8 gives the results for the Knoop Microhardness for the samples tested. Detailed data are recorded in Appendix III. All microhardness data are in units of Knoop Microhardness.

The variation in the microhardness within the same sample (as seen in Samples $\# 27$, \#44, \#46, and \#49) reflect microhardness values for different materials within the same rock. For example, Sample \#27, from the Centralia mine, shows a microhardness of 145 for the matrix material, which is carbonate, and 1142 for the grains, which are mostly quartz and feldspar. The microhardness for Centralia Sample \#30, a poorly indurated siltstone, is 158 . However, due to the size of the individual grains, the indentor point may be too large to test the individual grains. For this sample, this test may actually be testing the degree to which the individual grains are bonded to each other rather than the hardness of the individual grains themselves.

The high values of microhardness for Samples \#35 (Bingham Canyon copper mine), \#37 and \#38 (Lone Tree mine) are due to the high quartz contents of these hydrothermally altered rocks. Samples \#35, the Bingham Canyon copper porphyry, and \#37, the Lone Tree silica-replaced sedimentary rock, experienced a high degree of 
silica flooding during alteration (appendix I). Sample \#38, the Lone Tree hydrothermal breccia, had areas of high quartz content, which was used for the microhardness test.

The Triple T granite (Sample \#44) shows a microhardness of 1041 for the areas labeled as "g", which were quartz grains, and 980 for the areas labeled as "d", which were small, isolated, mafic mineral grains.

The greatest variability in Knoop microhardness exists in the taconite samples. Sample \#45, the taconite with the highest values of unconfined compressive strength shows the lowest values of microhardness (673). Upon examination of the microhardness data for Sample \#45 in appendix III, the highest value of Knoop microhardness is 799 and the lowest value of microhardenss is 539, with an average microhardness of 673 . The variability of the microhardness for this sample only ranged by \pm 130 , which is remarkably consistent. The microhardness of taconite Sample \#46 ranges from a high of 1362 for the dark minerals to a low of 693 for the light minerals, which is likely to be fine-grained quartz. The variation in microhardness for this sample is 570. In Sample \#49, the light mineral has a microhardness of 1201, and the dark mineral has a microhardness of 1030 . The variation in the microhardness is 169 . The composition of the light and dark material is not known in Sample \#46, however, the light material within Sample \#49 is probably quartz. 


\section{Wear Tests}

Wear to teeth is due to direct contact between rock fragments and teeth. The action of the rocks scraping across the tooth are responsible for the wear. The Dry Sand Rubber Wheel test utilizes a rotating rubber wheel which presses against a metal sample at a constant force. The crushed rock is fed between the rubber wheel and the metal sample at a constant rate and the wheel is rotated 2,000 times. The results are then extrapolated to 6,000 revolutions for consistency in comparisons. The wear to the metal sample occurs as the rubber wheel forces the rock fragments to scrape across the metal surface. Table 5 show the results from the Dry Sand Rubber Wheel tests.

Table 5. Results from the Dry Sand Rubber Wheel tests.

\begin{tabular}{c|c}
\hline Sample & wear $\left(\mathrm{mm}^{3} / 6000\right.$ revolutions $)$ \\
\hline \hline ASTM test $\mathrm{SiO}_{2}$ & 245 \\
\#1, Bristol Silica & 1350 \\
\#38, Lone Tree hydrothermal breccia & 264 \\
\#47, Hibbing taconite & 468 \\
\#48, Hibbing taconite & 153 \\
\#58, Samples sandstone & 813 \\
\hline
\end{tabular}

The ASTM test $\mathrm{SiO}_{2}$ is provided as a reference. This sand is very well rounded, as opposed to the other samples which are highly angular due to the crushing process. The difference in wear between the ASTM test $\mathrm{SiO}_{2}$ and the Bristol Silica is quite high, which indicates that this test is shape sensitive. Compositionally, these two samples are very similar. 
The crushed Samples sandstone, which contains $38 \%$ surface quartz, also causes a high relative wear rate. The Hibbing taconite, sample \#47, caused the metal sample to lose $468 \mathrm{~mm}^{3}$ of metal. This sample contains approximately $17 \%$ surface quartz. It is not known why sample \#48, a taconite with approximately $37 \%$ surface quartz was the least aggressive $\left(153 \mathrm{~mm}^{3}\right.$ of metal lost). The Lone Tree hydrothermal breccia, which contains $9 \%$ surface quartz, caused $264 \mathrm{~mm}^{3}$ of metal to be lost.

The wear caused by the crushed samples is likely to be related to the surface quartz percentage of the rocks, as the grain size of the abrasive is similar for the tests. Figure 9 show this relationship between wear and surface quartz percentage. Wear from the Dry Sand Rubber Wheel test is also compared to density (Figure 10), radius of curvature (Figure 11), and compressive strength (Figure 12).

No relationship is seen between the density and the wear, as the abrasive particles are being pressed into the metal surface by an external, constant weight. This external source of the normal force is independent of the density of the abrasive. The radius of curvature is a measure of a hand sample scale property, which is not likely to be related to the shape of the abrasive particle which is a result of crushing the sample. This may be the reason for the lack of a relationship between the wear from the Dry Sand Rubber Wheel test and the radius of curvature. The wear resulting from the Dry Sand Rubber Wheel test is not related to the compressive strength of the rock sample (Figure 12). This method of testing does not call upon the strength of the abrasive to cause wear. 
The Relationship Between Wear and Surface Quartz Percentage

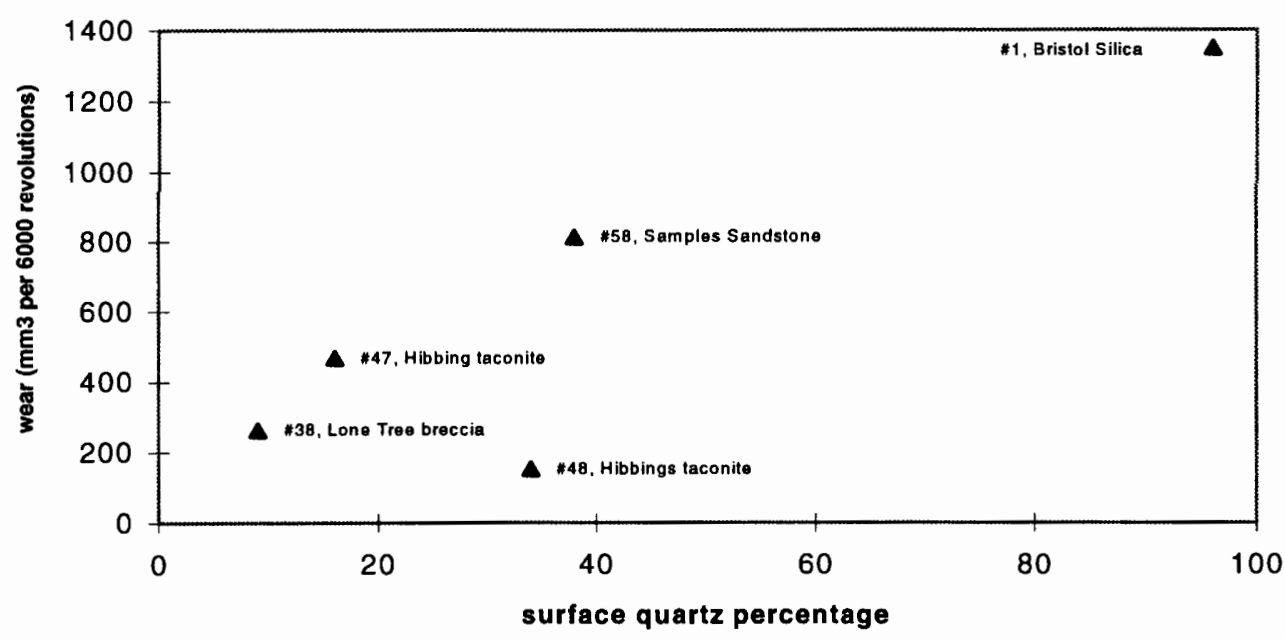

Figure 9. The wear resulting from the Dry Sand Rubber Wheel test is likely related to the surface quartz percentage in the rock samples. More surface quartz results in more aggressive wear.

\section{Wear versus Density}

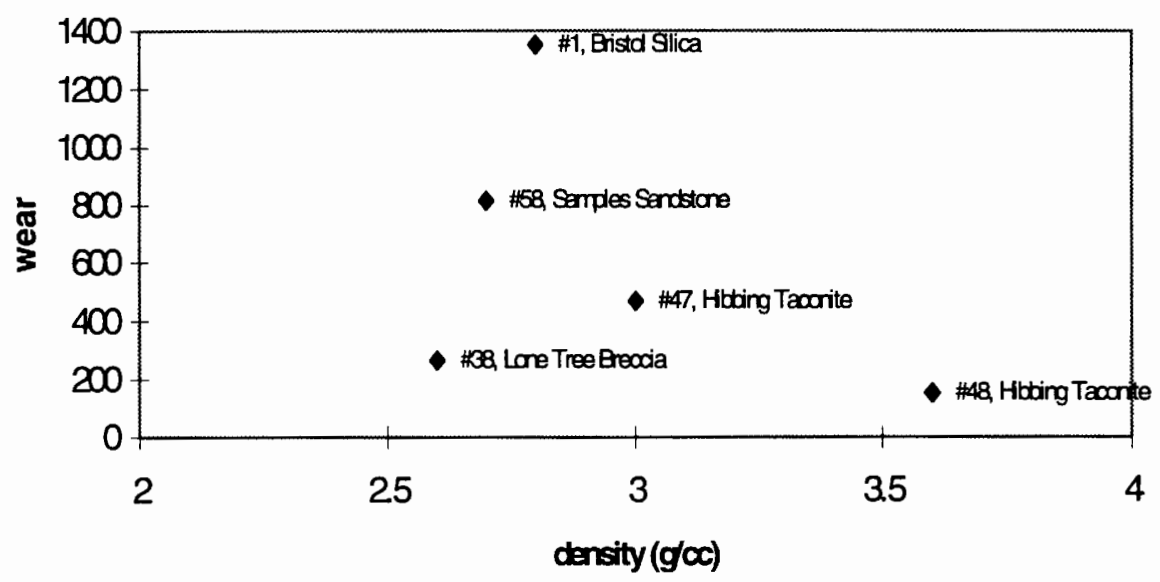

Figure 10. Wear due to the Dry Sand Rubber Wheel test is not likely related to the density of the sample. The normal force used to force the abrasive particles into the worn part is supplied by a suspended mass, and not by the weight of the abrasive particles. 
Wearversus Pedius of anehre

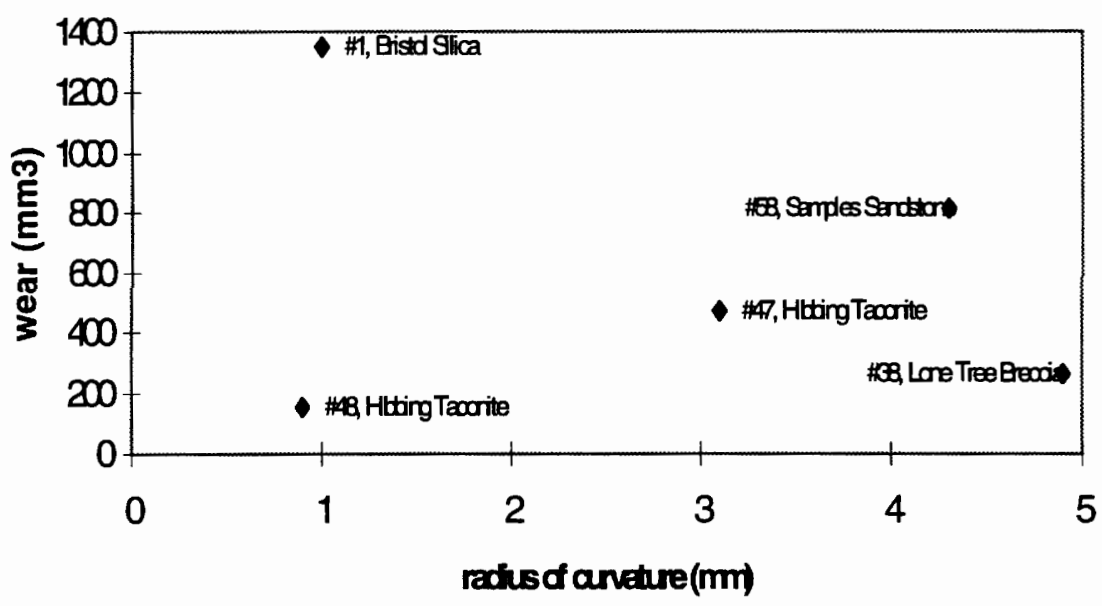

Figure 11. Wear resulting from the Dry Sand Rubber Wheel tests is not likely to be related to the radius of curvature of the rock samples, due to the crushing and sieving of the samples before the test.

\section{Compressive Strength versus Wear}

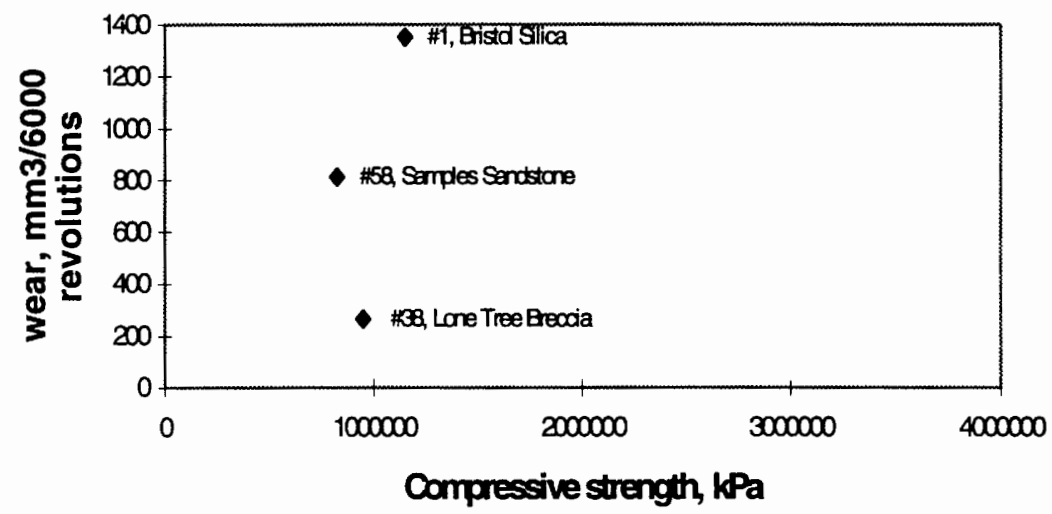

Figure 12. The wear resulting from the Dry Sand Rubber Wheel test is not likely to be related to the compressive strength of the samples. The nature of this wear test doesn't call upon the strength of the abrasive to produce wear. 
Wear fram the Dy Sand Ruber Whed Test versus Poissor's Patio

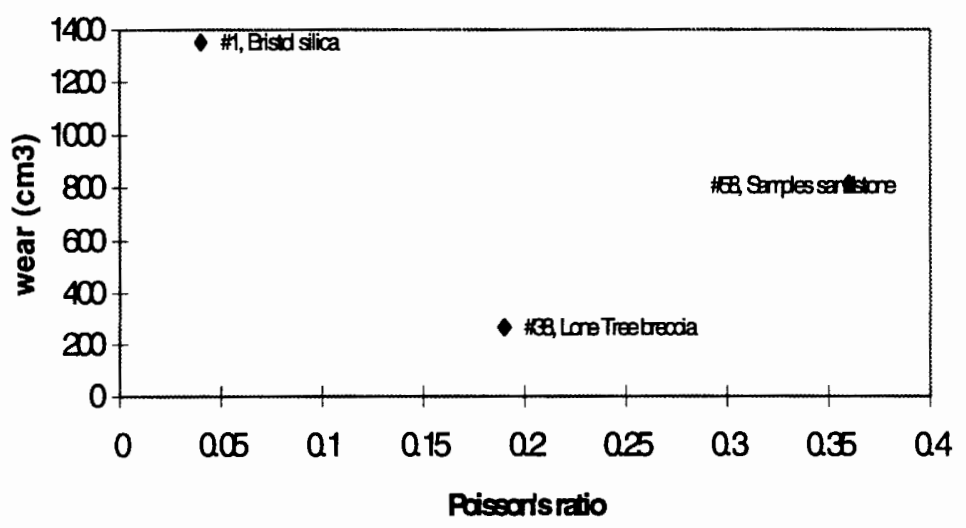

Figure 13. The wear from the Dry Sand Rubber Wheel test is not effected by the Poisson's ratio of the sample rock. The abrasive is not damaged during the test, therefore the breaking characteristics are not a factor in this test.

Wear from the Dry Sand Rubber Wheel Test versus Young's Moctulus

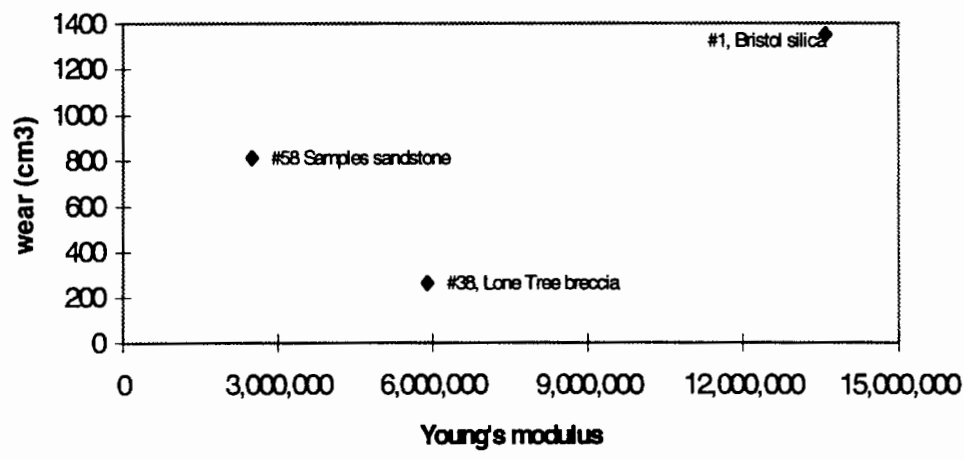

Figure 14. The wear from the Dry Sand Rubber Wheel test is not effected by Youngs modulus of the sample rock. The abrasive is not damaged during the test, therefore the breaking characteristics are not a factor in this test.

\section{Statistical analysis of results}

The analysis of many observations often requires the use of multivariate statistics. Multivariate statistics allows many properties to be considered 
simultaneously. One of the most widely used multivariate procedures is the discriminant function. A simple linear discriminant function transforms an original set of measurements into a single discriminant score, which can then be compared to other sets of measurements.

The method used to find the discriminant function is the regression. In matrix notation, the equation of the form

$$
\left[s_{p}^{2}\right] \cdot[\lambda]=[D]
$$

must be solved, where $\left[s_{p}^{2}\right]$ is a $m \times m$ matrix of pooled variances and covariances of the $m$ variables. The coefficients of the discriminant equation are represented by a column vector of the unknown lambdas.

The right hand side of the equation consists of the column vector of $\mathrm{m}$ differences between the means of the two groups

$$
[\lambda]=\left[s_{p}^{2}\right]^{-1} \cdot[D]
$$

To compute the discriminant function, the various entries of the matrix equation must be determined. This is found by

$$
D_{j}=\bar{A}_{j}-\bar{B}_{j}=\frac{\sum_{i=1}^{n_{a}} A_{i j}}{n_{a}}-\frac{\sum_{i=1}^{n_{b}} B_{i j}}{n_{b}}
$$

where $A_{i j}$ is the $i$ th observation on the variable $j$ in the group $A ; \overline{A_{i j}}$ is the mean of variable $j$ in the group $A$, or the average of $n_{a}$ observations. The same conventions apply to group $B$. The multivariate means of groups $A$ and $B$ can be regarded as 
forming two vectors. The difference between these multivariate means therefore also forms a vector

$$
\left[D_{j}\right]=\left[\overline{A_{j}}\right]-\left[\overline{B_{j}}\right]
$$

The set of $\lambda$ coefficients from the equation

$$
[\lambda]=\left[s_{p}^{2}\right]^{-1} \cdot[D]
$$

are entries in the discriminant function equation of the form

$$
R=\lambda_{1} \psi_{1}+\lambda_{2} \psi_{2}+\cdots+\lambda_{m} \psi_{m}
$$

This is a linear function in which all the terms are added together to yield a single number, the discriminant score. The substitution of the midpoint between the two group means yields the discriminant index, $R_{0}$. That is, for each value of $\psi j$ in

$$
R=\lambda_{1} \psi_{1}+\lambda_{2} \psi_{2}+\cdots+\lambda_{m} \psi_{m}
$$

the term

$$
\psi_{j}=\frac{\bar{A}_{j}+\bar{B}_{j}}{2}
$$

is inserted.

The data used in this project were the results obtained from the uniaxial compressive strength tests, surface quartz percentage, density, matrix microhardness, and the radii of corners. The rocks were divided into groups which are thought to cause high relative wear, low relative wear medium wear, and medium relative wear ( Table 6). 
The data from the high wear group are compared to the data in the low wear group, and discriminant scores are computed for each case (Figure 15). The discriminant scores are also calculated for the data from the medium wear group.

Table 6. Data groups used in the Discriminant Analysis.

\begin{tabular}{|c|c|c|c|c|c|}
\hline sample & $\begin{array}{l}\text { compressive } \\
\text { strength, } \\
\mathrm{kPa}\end{array}$ & $\begin{array}{l}\text { surface } \\
\text { quartz } \\
\text { percentage }\end{array}$ & $\begin{array}{l}\text { matrix } \\
\text { microhardness }\end{array}$ & $\begin{array}{l}\text { density } \\
\text { g/cc }\end{array}$ & $\begin{array}{l}\text { radius of } \\
\text { curvature, } \mathrm{mm}\end{array}$ \\
\hline \multicolumn{6}{|c|}{ High wear rate } \\
\hline $\begin{array}{l}\# 1, \text { Bristol } \\
\text { Silica }\end{array}$ & $1,151,000$ & 96 & NA & 2.8 & 1 \\
\hline $\begin{array}{l}\# 44 \text {, Triple } \mathrm{T} \\
\text { granite }\end{array}$ & $2,510,000$ & 29 & 980 & 3.0 & 2.0 \\
\hline $\begin{array}{l}\text { \# 46, } \\
\text { Hibbing } \\
\text { taconite }\end{array}$ & $1,144,000$ & 43 & 1362 & 3.5 & 1.5 \\
\hline \multicolumn{6}{|c|}{ Low wear rate } \\
\hline $\begin{array}{l}\# 27, \\
\text { Centralia } \\
\text { mine }\end{array}$ & 676,000 & $1 \overline{11}$ & 145 & 2.6 & 3.0 \\
\hline $\begin{array}{l}\# 30, \\
\text { Centralia } \\
\text { mine }\end{array}$ & 90,000 & 4 & 158 & 2.7 & 2.5 \\
\hline $\begin{array}{l}\text { \#35, } \\
\text { Bingham } \\
\text { Canyon } \\
\text { copper }\end{array}$ & 516,000 & 48 & 1514 & 2.7 & 2.7 \\
\hline \multicolumn{6}{|c|}{ Medium wear rate } \\
\hline $\begin{array}{l}\# 45 \text {, Hibbing } \\
\text { taconite }\end{array}$ & $2,413,000$ & 1.8 & 673 & 4.2 & 1.4 \\
\hline $\begin{array}{l}\text { \#58 Samples } \\
\text { sandstone }\end{array}$ & 827,000 & 38 & 1364 & 2.7 & 4.3 \\
\hline$\# 37$, Lone & 854,900 & 63 & 1362 & 2.6 & 1.7 \\
\hline $\begin{array}{l}\text { Tree mine } \\
\# 38, \text { Lone } \\
\text { Tree breccia }\end{array}$ & 951,000 & 9 & 1561 & 2.6 & 4.9 \\
\hline
\end{tabular}


The data from the high wear group are compared to the data in the low wear group, and discriminant scores are computed for each case (Figure 15). The discriminant scores are also calculated for the data from the medium wear group.

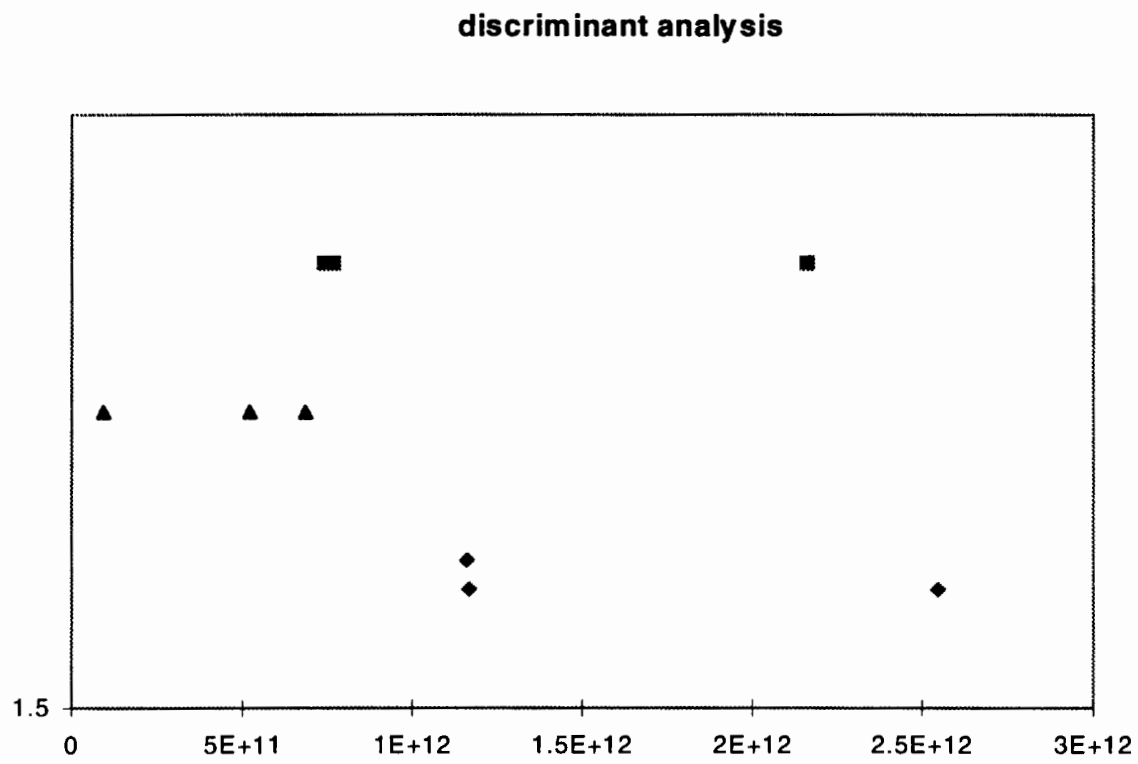

Figure 15. Results of the discrimanant analysis. The triangles represent the results of the rock predicted to have low wear, the diamond represent the rocks predicted to have high wear, and the boxes represent the rocks predicted to have medium wear.

The discriminant analysis shows that the data form the high wear group cluster to the right side of the graph in Figure 15 and the data from the low wear group cluster to the left side of the graph. The data from the medium wear group are spread between the two previous groups. Although the spread of the data in Figure 15 are quite wide, the clustering seen in the graph is the expected result of this analysis, and supports predictions of relative wear rates to teeth. 


\section{Discussion}

The method of the interaction between mining equipment and rocks has an effect on the type of wear experienced. Wear due to a high velocity impact between the teeth and the rocks will impart a different kind of wear than experienced by a low velocity interaction. Wear due to impact is caused by a brittle failure of the metal surface as it absorbs, by mechanical deformation, the kinetic energy of the rock material. The mechanical deformation of the metal in this case exceeds the metal's ability to deform in a plastic manner, thus an elastic fracture mechanism takes place (Levy, 1989).

This research, however, focuses on teeth on dragline buckets and shovel buckets, which are not utilized in such a manner that would cause high velocity interactions. It is assumed that the teeth on these buckets will experience wear due to frictional aspects of tooth/rock interaction. These frictional aspects include, but are not limited to, rolling and scraping of rock across the surface of the tooth causing ductile cutting and gouging of the tooth surface. The wear that teeth experience under these conditions depends not only upon the physical properties of the rocks, but the method in which the equipment is used.

Dragline buckets are commonly used to excavate large amounts of overburden. The volume of these buckets is typically in the range of $70-200 \mathrm{~m}^{3}$. In a soft material, such as in many coal mines, no blasting is required. The bucket is placed on the ground, and manipulated in such a way as to be pulled through the material at a 
constant depth, often parallel to bedding. In this case, the angle of attack between the teeth and the inherent structure of the mine material is relatively low. In a material which is more competent, blasting may be required prior to excavation by dragline.

A smaller shovel bucket is used in blasted material and/or for more precise handling of weakly indurated unblasted material. In a mine where the material is soft enough to not require blasting, a shovel bucket can be used for precise excavation of the ore body. The shovel bucket travels on the end of a pivoting arm. The path traveled by the bucket moves through a vertical circular arc. In such a case, the angle of attack between the teeth and the inherent structure varies and can be very high, with the teeth of the bucket cutting directly across bedding planes of the body being excavated, to very low, with the teeth cutting almost parallel to bedding planes.

Properties of individual rocks within the rock body being handled will also effect the wear experienced by the equipment. The nature of the rock and grain tools will effect the degree to which the tooth surface is modified by the passing of a rock. In the following section, specific properties and their contribution to the wear process are evaluated. In the course of these investigations, the importance of large-scale rock body properties is recognized; however, in this stage of research, hand-sample scale rock properties are investigated in order to constrain the problem. 


\section{Grain Tool Investigations}

\section{Petrographic Investigations}

The petrographic investigations addressed the nature of the grain tools. The contact of the tooth with a rock containing a hard mineral causes gouges and scratches to be formed in the tooth. As fewer abrasive grains make contact with the tooth, fewer gouges and scratches are formed. Therefore, a rock with a small surface quartz percentage is expected to cause less wear to a tooth than a rock with a high surface quartz percentage, all other factors being the same. Work by Deketh and Verhouf (1993) in which the quartz content of artificial rocks was varied supports this hypothesis. These workers found that by increasing the quartz content of artificial rock, wear rates to cutting chisels increased, keeping grain size and strength of the rock consistent. The wear tests performed for this project support this idea.

In this investigation, the character of the quartz is of primary concern. Quartz is often one of the few minerals in mine rocks which is harder than the teeth. Therefore in the standardization of a method of observation, the quantification of this hard, abrasive mineral can aid in the prediction of wear. The percentage of quartz exposed at the surface is a function of the quartz content of the rock and fabric elements in the rock which can preferentially expose or hide quartz-rich regions within a rock.

The percentage of exposed surface quartz is at times less a function of the bulk percentage of quartz in the rock or the grain size of the quartz as it is the fabric 
elements in the rock, e.g. bedding. As an example, sample \#47, a taconite sample, shows very little quartz exposed at the surface (Figure 2). In this sample, iron oxide minerals, the iron-rich bands in iron formations, form the outer surface of the rock and are the layers along which the sample preferentially breaks. Sample \#49, also a taconite sample, indicates the opposite pattern where the rock broke through a quartzrich bed in the iron formation and nearly 70 percent of the surface area contains quartz. This phenomenon was investigated by examining surface quartz percentages relative to the orientation of the cut used to make the thin section (Figure 16).

\section{Surface Quartz Relative to Cut}

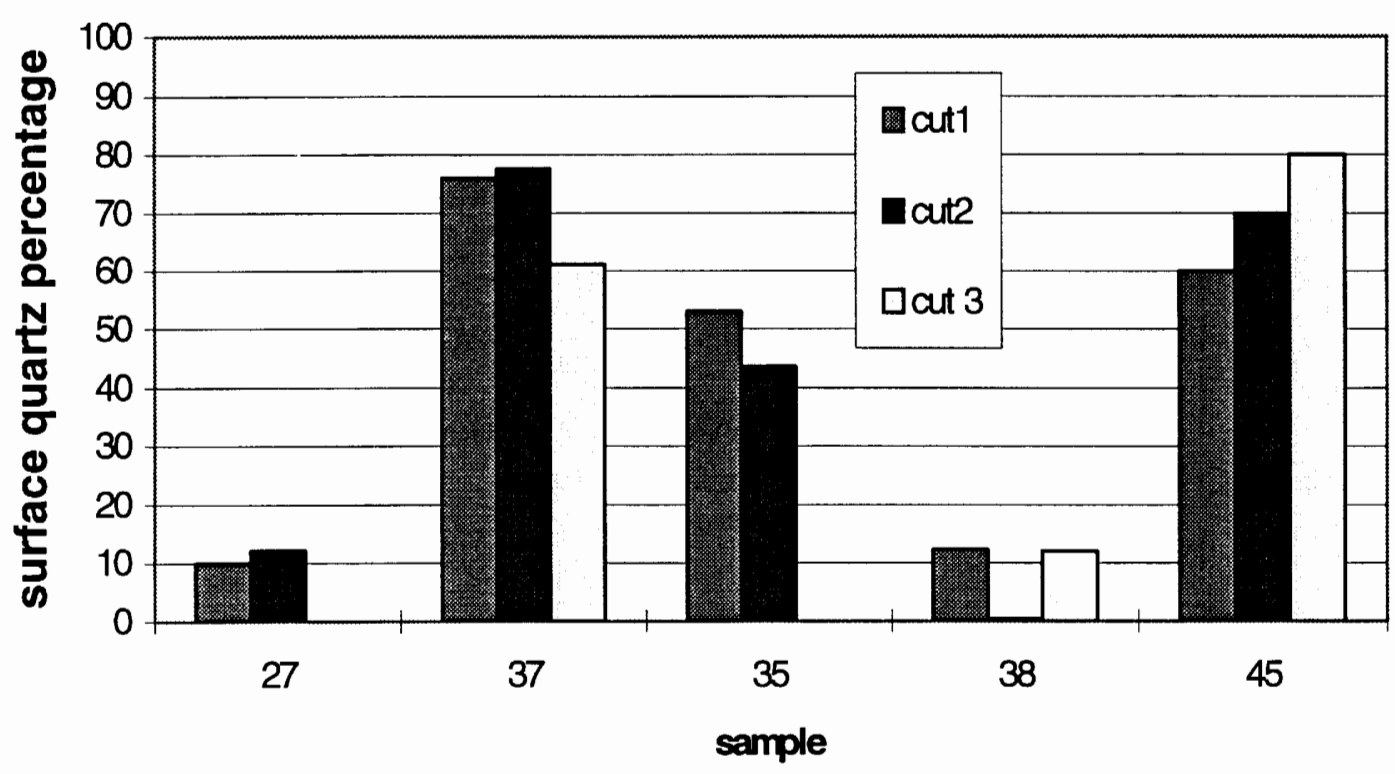

Figure 16. Variation in the percentage of surface quartz in relation to the orientation of the cut of the thin sections. Each cut had a unique orientation on the rock sample, and had several thin sections taken from it. It was thought that fabric elements, e.g. bedding planes, would have an effect on the surface quartz percentage. Sample 27, Centralia mine; Sample 35, Bingham Canyon; Samples 37, 38, Lone Tree mine, Sample 45, Hibbing taconite. 
A close examination of the data presented in Figure 16 reveals a small variation in the exposed surface quartz relative to the cut. Quartz-rich veins will contain areas of higher average surface quartz contents than the other rocks in a mine, and these particular rocks may have a higher corresponding wear rate. However, it is not known how to quantify this aspect of mine rocks, and it may be more fruitful to measure the average surface-quartz content of many rocks from the same mine. The grain size was shown to be related to wear rates by Deketh and Verhouf (1993). This test was performed by placing a chisel onto a cutting stone and measuring wear to the chisel, however, this may not be analogous to a mine situation. In a mine, wear is most likely to occur by the interaction of loose rock fragments and teeth, as opposed to a chisel being pressed firmly against a cutting stone. The degree to which a rock is "loose" will depend upon the rock's position in the rock pile. A rock which is buried deeply may be less able to move about (and thus act more like the chisel model) as a result of the shovel bucket moving through the pile than a rock which is on the top of the pile. The rock fragments are not necessarily related to grain size in the rock. A more important variable in the prediction of wear to teeth in a mine is likely to be the size distribution of the rock fragments rather than the size distribution of the grains in the rocks. The $F$ test performed on the grain size data indicates whether two samples are from similar statistical populations. If two samples fail the $F$ test, the quartz grain size data of the samples are probably from different statistical populations. In order for the quartz grain size to be indicative of genetic origins, rock samples of the same rock 
type would be expected to be from statistically similar populations. Every $F$ test between samples of similar rock types failed this test, which indicates that the quartz grain size and grain size variation are from different statistical populations, despite the similar origins. Four $F$ tests did not fail the test, which means that the grain sizes of these rocks these samples are not necessarily from different populations. These four tests, however, involve rocks of different types, such as Sample \#25, a sedimentary rock from the Centralia mine, and Sample \#45, a metamorphic rock from the Hibbing mine. In these two samples, the grain size and grain size variations are similar despite the different origins of these rocks.

$T$ tests were performed on the samples which did not fail the $F$ test in order to assess whether the mean quartz grain size in these samples was similar. For the pair of samples \#27 and \#37, \#37 and \#46, and \#25 and \#45, the calculated value of $t$ exceeded the critical value of $t$. This indicates that the means of the quartz grain size are probably from different populations. This is to be expected from these pairs of samples, as they have different genetic origins.

In the pair of samples \#1 and \#49, the calculated value of $t$ did not exceed the critical value of $t$, which indicates that these two samples are not necessarily from different statistical populations. This is despite the fact that the origins of these two samples is significantly different. In this example, the mean quartz grain size is not unique relative to genetic origin of the rock. 
However, in order for the $t$ test to be valid, the variances of the samples must be similar. Of the sixty five pairs of samples tested by the $F$ test, this is only the case for four pairs of samples. Due to the small number of pairs of samples with similar variances, the comparison of mean quartz grain size is not usually possible. This leads to the elimination of comparing mean quartz grain size (the $t$ test) as a useful test in predicting wear.

In metamorphic rocks, grain size is due to many factors which make the history of the rock impossible to determine by the investigation of grain size alone. This is also the case with the hydrothermally altered rocks. This situation makes connections between physical properties and grain size variation in metamorphic and hydrothermally altered rocks dubious, as a wide variety of grain size can exist with rock samples taken from the same mine. Supporting evidence comes from the results of the F-tests. F-tests comparing similar rock types failed, indicating that the grain size data from these rock types are not from the same statistical population, rendering statements linking grain size data and origin of these rocks suspect. 
Igneous rocks reflect a grain size which results from the cooling history and the composition of the rock. Davis (1984) has shown that a rock with similar composition but different grain size possesses similar physical properties on the macro scale (e.g. uniaxial compressive strength). Singh (1989) indicates that the opposite is true; rocks having finer grain sizes have more "micro-crack nuclei", thus failing at a lower value of strength than a rock with a courser grain size. The lack of data, however, prevents the relation between strength and grain size in igneous rocks to be completely known.

Quartz grain size variation in sedimentary rocks reflects the energy of the environment of deposition of the rock. The physical properties of the rock are more a function of the degree of lithification and the nature of the cement than the size of the clasts of the rock. Thus, an understanding of the environment of lithification is more important than the understanding of the environment of deposition for the prediction of wear. F-tests comparing sedimentary rocks failed, indicating that grain size data is from different populations. The grain size of sedimentary rocks varies widely and predictions of physical properties effecting wear based on grain size and grain size variation is not appropriate.

\section{Rock Tool Investigations}

\section{Uniaxial Tests}

Tests which measured the physical properties of the rocks addressed the nature of the rock tools. Any measure of a physical property of a rock must recognize the 
scale to which the measurement is made. The specimen must be large enough to contain a representative quantity of constituent minerals and defects, but small enough to avoid large-scale compositional and physical discontinuities. The test specimens are on the order of tens of centimeters for this project. Therefore, large-scale discontinuities, such as joints, are avoided. Discontinuities on the microscale, however, will have an effect on the value of the parameters measured by uniaxial tests (i.e. compressive strength, Young's modulus, and Poisson's ratio) (Jaegger and Cook, 1979; Lawn and Wilshaw, 1975).

The measure of uniaxial compressive strength in this project was performed to estimate the competence of a rock. It was hoped that the effects of microcrack and microflaw density of the specimens could be detected using this test. Microcracks within the rock specimen have been shown to have a significant effect on the uniaxial strength of a rock (Davis, 1984; Jaegger and Cook, 1979; Lawn and Wilshaw, 1975). Failure under uniaxial load begins by the widening of pre-existing microcracks, so as the microcrack density increases, the uniaxial strength decreases, if all other conditions are equal. As an example of this phenomenon, the uniaxial strengths of the hydrothermally altered Lone Tree rocks are in the intermediate range $(854,900 \mathrm{kPa}$ for Sample \#37 and $951,400 \mathrm{kPa}$ for Sample \#38). The process of hydrothermal alteration produces an abundance of microfractures and micropores, which leads to a decrease in the strength of the rock. 
The value of uniaxial compressive strength is expected to have a large affect on the wear rates produced by mine rocks. As a rock interacts with a tooth, the rock experiences compressive, tensile and shear stresses at the point of contact. If these stresses exceed the rock's capacity, the rock will fail, producing smaller fragements and probably lowering the contact pressure between the rock and the tooth surface, as the load will be distributed over more points. A rock which displays a low value of uniaxial compressive strength is more likely to loose its rock tools upon an interaction with a tooth.

The effect of Young's modulus may not be as significant as the effect of uniaxial compressive strength in the production of wear. Young's modulus is the ratio between the stress and the strain in a rock under uniaxial load. A rock displaying a high value of Young's modulus is expected to be stiffer than a rock which displays a low value of Young's modulus. This stiffness may influence the reaction of a rock during its interaction with a tooth. For example, all other variables remaining constant, a rock which has a high value of Young's modulus may break during an interaction with a tooth, causing smaller, less destructive rock fragments. This breakage would result from the rock's inability to absorb stress-induced strain produced by the interaction. A rock having a low value of Young's modulus may not break during a similar interaction with a tooth due to the rock's ability to absorb the strain produced by the interaction; the rock flexes. In the larger fragments this would cause greater wear. Therefore, rocks with low values of Young's modulus are expected to cause 
higher wear rates than rocks with high values of Young's modulus, if all other variables are constant.

Poisson's ratio is the ratio between the vertical strain to the lateral strain. Low values of this variable indicate that the sample is able to absorb vertical strain within the crystal lattice with little lateral expansion. High values of Poisson's ratio indicate that the sample responds to a vertical load by a lateral expansion. Davis (1984) has indicated that a rock which displays a low value of Poisson's ratio will fail more "destructively" (in such a manner as to produce much smaller fragments), than a rock displaying a high value of Poisson's ratio. Fragment size is important in the prediction of wear. Deketh and Verhouf (1993) showed that wear rates increase as particle size increases in two body wear experiments. Therefore, rocks having high values of Poisson's ratio are expected to cause greater wear rates, due to the larger fragment size, than rocks with low values of Poisson's ratio, if all other variables are constant.

Huard and others (1987) indicate that wear resulting from a two-body interaction, in which a tool is supported and dragged across the surface, is one or two orders of magnitude higher than wear rates due to three-body interactions, in which the tools freely mill about between the tooth and a third body which forces the tool into the tooth. In the case of mine rocks, the scale to which this two-body or three-body interaction occurs is not known. The point at which a rock fragment makes the transition between a two-body wear mode to a three-body wear mode is unclear, and may even be transitional. Indeed, it may be argued that all wear is essentially two 
body, as the tools are the only objects making contact with the tooth. Conversely, the wear may be solely three-body, as the rock fragments are being pressed into the teeth by the overburden of the rock pile. The question of scale dependence of two-body and three-body interactions is raised, however, it is known that an increase in the rock fragment size causes an increase in the wear rate to teeth in a mine (Danks, 1994, personal communication).

Young's modulus and Poisson's ratio can be related to the size of rock fragments in a mine if the rocks break in response to compressive stress. However, since the scale of two-body and three-body interactions and resulting contact pressures are not known, the use of these values may not be warranted in the prediction of wear. The uniaxial compressive strength is directly related to the competence of the rock and will be the most important value obtained from uniaxial tests.

\section{Density}

The density of a rock can be effected by a number of different factors. For example, a rock can have a low density due to a large pore volume, or the rock may be composed of low density mineral phases. The measure of density alone cannot distinguish between these two situations and the mechanical behavior is expected to be quite different for both of these situations.

If all other variables are kept constant, however, rocks which impart greater point loads on teeth cause deeper gouges to be cut into the teeth. Point loads produced 
will be directly proportional to the density of the individual rocks of the rock body, assuming that the density of the rocks remains constant throughout the rock body. The depth of these cuts has a direct relationship to the wear rate. Therefore, a rock body containing rocks with a greater average density causes higher wear rates than a rock body containing rocks with a lower average density, if the volume of overburden is constant.

\section{Shape}

When the results of the Fourier analysis are analyzed, the frequency content of the surface traces become known. This information is plotted and shown in Appendix IV. Upon examination of amplitude versus wavelength in Appendix IV, it is clear that no evident pattern exists between graphs for the same sample. It was originally hoped that a pattern existed between the frequency content of the rocks and the frequency content of the worn teeth. The lack of evident patterns on the rocks, however, prompted the discontinuation of this method of analysis. Although shape is important in the wear process, this method of shape quantification is inappropriate. Therefore, the use of Fourier analysis techniques for the quantification of shape is not continued in this project.

The average radius of curvature produces varying results for all of the samples. It is believed to be an important factor in the prediction of wear, as the radius of 
curvature of the corners may be an indicator of the pressure a rock sample would exert on a tooth during its interaction with mining equipment.

\section{Strength versus Radius of Curvature for the samples Investigated}

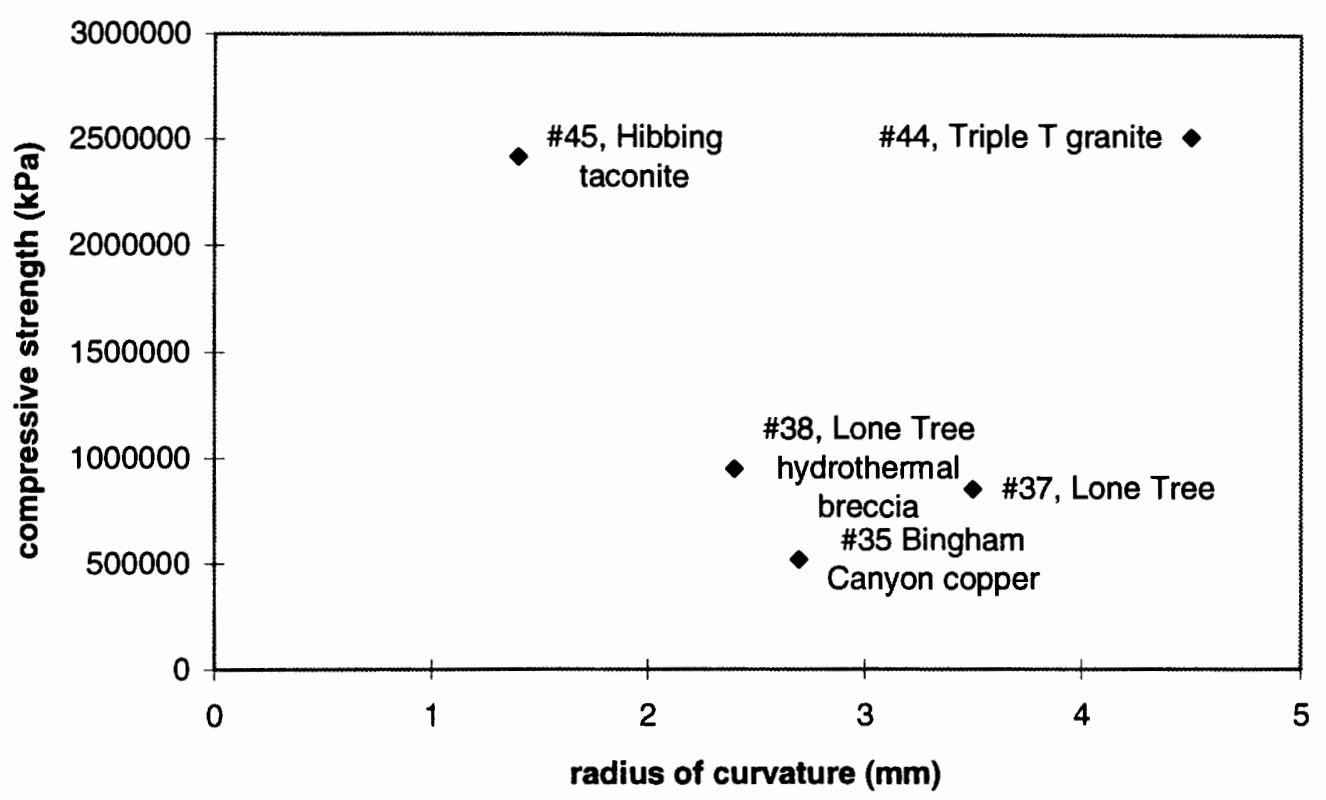

Figure 17. The uniaxial compressive strength versus the radius of curvature (sharpness) of the corners for the samples investigated. It is believed that the sharpness would increase as the strength of the sample increase. In order to compare data such as this, a distinction needs to be made as to the type of rock. Rock types are; metamorphic (\#45), crystalline (\#44), and hydrothermally altered rocks (\#35, \#37, and \#38).

The sharpness of the corners of the rocks was thought to be related to the uniaxial compressive strength. In order to investigate this hypothesis, uniaxial compressive strength was plotted against radius of curvature in Figure 17. The thoroughly crystalline rocks, the taconite, has the highest value of strength and the smsallest value of average corner radius. This rock is expected to cause high relative 
wear to teeth, all other variables being equal. The Triple $\mathrm{T}$ granite has the largest value of average corner radius. This is due to the relatively large grain size of this rock; the radius of curavature os actually the radius of individual, large grains. The hydrothermal rocks have a much lower value of uniaxial strength, but Samples \#37 and \#35 have relatively small average corner radii. The high degree of silicification may account for the sharp corners. Sample \#38 may have a clay content which prevents the corners from becoming sharp.

There seems to be a relationship between the genetic origins and the radius of the corners. Highly crystalline metamorphic rocks tend to have sharper corners, followed by the hydrothermal rocks. Data on the radii of the corners for sedimentary rocks were not available due to the destruction of the samples by previous tests. The sharpness of the corners will be directly related to the surface pressures induced by the rock on the tooth. Wear to teeth is directly related to these surface pressures. The endurance of the corners may be related to the uniaxial compressive strength or the hardness of the rock material.

The results shown in Figure 17 indicate that a relationship may exist between the rock type and the radius of the corners. This is the most promising work performed on the quantification of shape in this project. However, before clear relationships between these two variables are understood, more data are required. Specifically, data for the sedimentary rocks and the metamorphic rocks which were destroyed by the other tests performed in this project. The corner data for these samples were not 
available for this test due to destruction during previous tests. This relationship needs to be more fully understood before it is used in the prediction of wear.

\section{Microhardness}

Uniaxial compressive strength was performed on such a scale as to include a representative constituent mineral content and a representative number of rock defects, such as microfractures. Conversely, the measure of microhardness attempts to isolate and measure indentation resistance on very specific mineral grains or areas of rock matrix.

The value of Knoop microhardness varies with the force on the indentor. This force must be known, however, to calculate the value of microhardness. Figure 18 shows how the values of microhardness for the same material decreased with increasing indentation force. This may be due to heavy fracturing and bursting of the 
Microhardness as a Function of Indentor Force

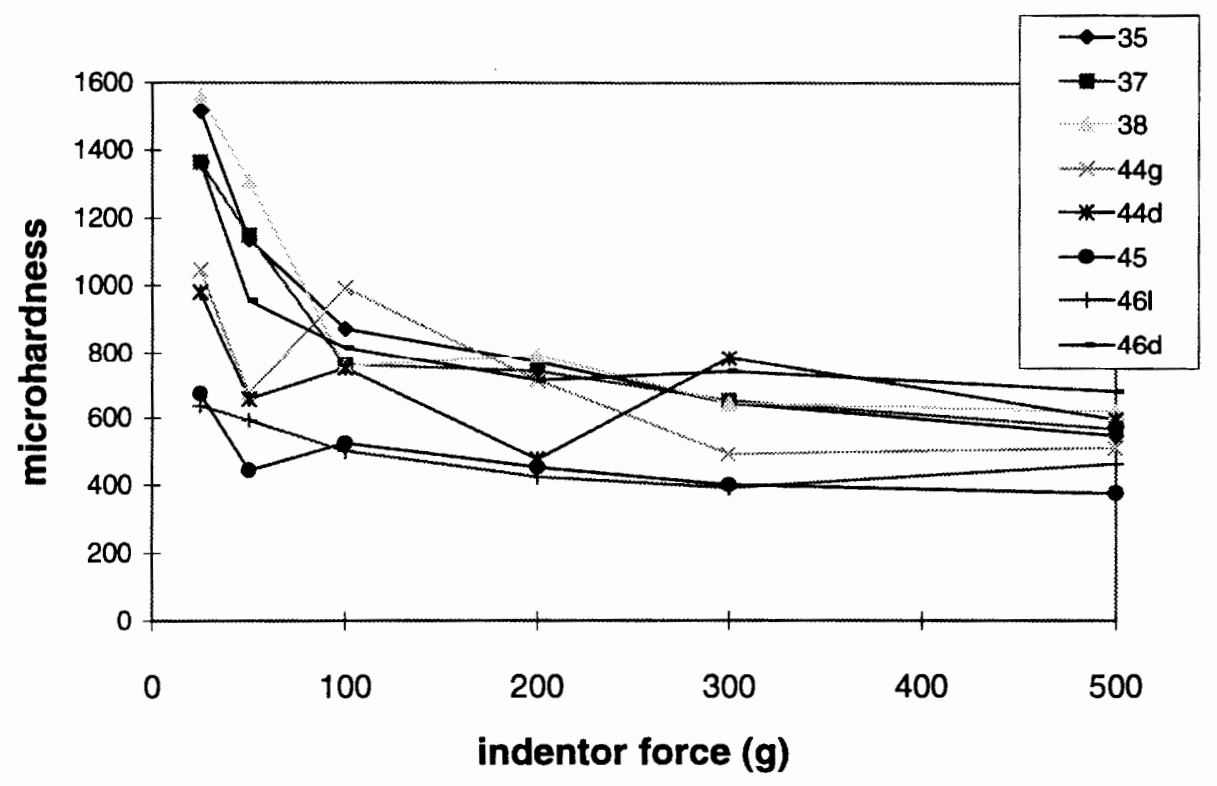

Figure 18. The value of microhardness changed as the indenture force changed. For consistency, the value of microhardness given at $25 \mathrm{~g}$ was use in this project.

rock material resulting from the use of higher values of indentation force. The value of the microhardness at $25 \mathrm{~g}$ force was used in this project.

The resistance to penetration of a specific rock material has been shown in previous sections of this report to be related to the tensile strength of the specific rock material being measured. Therefore, a relationship can exist between the microhardness of the matrix of a rock and the rock's tensile strength, if the matrix material is what is holding the rock together, as is the case for many sedimentary rocks. The tensile strength can also be related to the uniaxial compressive strength, therefore the degree to which a rock will hold it's grain tools and rock tools during an interaction with a tooth. A rock having a higher value of microhardness for its matrix 
material will be expected to hold it's grain tools and rock tools, causing higher wear rates than a rock with a lower value of microhardness.

In the case of a sedimentary rock, the cement holds the grains together in the rock. Thus, the strength of the cement will dictate, in part, how well the grain tools will remain intact during an interaction with a tooth. Values of microhardness are expected to show the variation in hardness between grain material and matrix material in a sedimentary rock. For example, Sample \#27, a carbonate-cemented sandstone from the Centralia Mine, illustrates this pattern quite well. The average hardness of the cement material is 145 (unitless) while the average hardness of the grain material, quartz and feldspar, is 1142 . This may be interpreted to mean that the grains are much harder than the cement material, thus the cement holding the grains would be more likely to fail than the grains themselves. In this situation, grains would be released upon interaction with a tooth. Using this as an example, it is argued that a rock sample which displays a large spread in microhardness values between different materials will be more likely to loose individual grains during an interaction. In this case, contact pressures are likely to be relatively low.

A metamorphic texture is such that the grains often interlock. During the process of metamorphism, the mineral grains grow into one another, creating fused crystal boundaries (Spry, 1969). This structure, in the case of the taconite samples, was composed mainly of chert and iron-bearing minerals (mainly hematite and magnetite). The strength of this structure would be more dependent upon the nature of the fused 
quartz grain boundaries and the degree to which the crystals interlock, rather than the strength of a bonding matrix material.

The results of the microhardness tests for the taconites does not show a distinct difference in the grain and matrix material. The hardness of the grain material is 1200 which is close to the hardness of the matrix material (1050). This difference is rather small and may be due to the spread in the data rather than truly different microhardness values. The results of the taconite Sample \#46 display an opposite pattern, in which the grain material is softer (640) than the matrix material (1380). The microhardness values for the different materials in these rocks does not show as wide a spread as in the sedimentary rocks. These rocks are, however, much stronger than the sedimentary rocks. These data suggest that the variability in the microhardness is more important than the actual values of microhardness. In a rock sample with a small range of microhardness values, individual grains are likely to remain intact during an interaction. In this case, rock tools are the primary cause of wear, resulting in twobody wear.

The question of what the indentor actually measures must be addressed. In a fine grained rock such as the taconite Sample \#45, the individual grains may be too small to be isolated by the indentor point. In this case, the indentor will be placed upon several grains, and will be measuring the average hardness of these several grains. This test would be measuring the degree to which these several fine grains are bonded to one another, rather than the hardness of an isolated, individual grain. 
This test may be inappropriate for hydrothermally altered rocks. The process of crystal growth in hydrothermal rocks usually results from the crystallization of amorphous silica or direct crystal growth of silica on original surfaces (seeds) (Fournier, 1985). This results in fused crystal boundaries with possible contamination of inclusions, ore material, or fluid. This contamination might weaken individual grains and the grain to grain boundary. A microhardness test would not recognize the nature of the crystal boundary in this case, thus be unable to predict the degree to which the grains would remain intact during an interaction with a tooth. Clay content in a hydrothermally altered rock will also effect the degree to which the rock will remain locally intact (e.g. Figure 17).

In the case of igneous rocks, the measure of microhardness will not recognize the nature of grain boundaries. In the prediction of wear, the hardness of individual mineral grains is not as important as the degree to which the individual minerals are bound together. Breakage of an igneous rock depends upon the strength between grain boundaries between minerals, a property which microhardness test does not measure.

For sedimentary rocks having similar cement microhardness, one may infer that the rocks would have a similar compressive strength. However, Sample \#27 with a cement microhardness of 145 , has a compressive strength of 9810 psi whereas Sample \#30, with a microhardness of 158 , has a compressive strength of 1310 psi. This is likely due to a high clay content in Sample \#30. This clay may interfere with the cement/grain contact, 
Table 7. Average matrix microhardness compared to uniaxial strength. The lack of clear patterns between microhardness and compressive strength supports the idea that microhardness tests are inappropriate for the measure of rock tool competence.

\begin{tabular}{|c|c|c|c|} 
rock type & sample & $\begin{array}{c}\text { matrix } \\
\text { microhardness } \\
\text { (knoop } \\
\text { microhardness) }\end{array}$ & $\begin{array}{c}\text { uniaxial } \\
\text { strength } \\
\text { (psi) }\end{array}$ \\
\hline \hline sedimentary & $\# 27$, Centralia mudstone & 145 & 9810 \\
\hline sedimentary & $\# 30$, Centralia mudstone & 158 & 1310 \\
\hline hydrothermal & $\# 35$, Bingham copper porphyry & 1514 & 7480 \\
\hline hydrothermal & $\# 37$, Lone Tree & 1362 & 12400 \\
\hline hydrothermal & $\# 38$, Lone Tree & 1561 & 13800 \\
\hline igneous & $\# 44$, Triple T granite & 980 & 36400 \\
\hline metamorphic & $\# 45$, Hibbing taconite & 673 & 35000 \\
\hline metamorphic & $\# 46$, Hibbing taconite & 1362 & 16600 \\
\hline sedimentary & $\# 58$, Samples sandstone & 1364 & 12000 \\
\hline
\end{tabular}

weakening this rock. Sample \#27, a coarser grained rock, contains very little clay, as it was deposited in a higher energy environment.

An examination of Table 7 does not show a close correlation between the matrix microhardness and the uniaxial compressive strength. This discrepancy between the microhardness and the uniaxial compressive strength is suspected to be a result of the nature of the mineral-to-mineral boundaries. In metamorphic, igneous, and hydrothermal rocks, grains can interlock, a characteristic that microhardness does not necessarily recognize. This interlocking of grains can have an effect on the strength of rock (Singh, 1989). Additionally, internal fractures and compositional variation can 
decrease the value of uniaxial compressive strength for rocks. A test such as microhardness may not recognize these characteristics.

When using microhardness values to predict wear, the variability within a rock may be more important than the absolute values. A rock which displays a wide range of microhardness, such as a carbonate-cemented sandstone, would be more likely to loose its grains during interactions with mining equipment. In this rock, the grain tools are more important than the rock tools, as wear occurs more from three-body interaction than from two-body interactions. A rock which displays a small variability in microhardness, such as the fine-grained taconite Sample \#45, will not loose its grain tools upon interaction with mining equipment. In this case, the rock tools would be

more important than the grain tools. Such a rock would cause wear by a two-body mechanism rather than a three-body mechanism. To predict the endurance of the rock tools, however, the uniaxial compressive strength is more helpful than microhardness.

\section{Wear Tests}

Dry Sand Rubber Wheel tests were performed on crushed and sieved samples. The action of sieving the samples to the same size for every test allows variables other than size distribution of the particles to be investigated. Figure 9 shows that surface quartz correlates well with the measured wear rate. As a sample contains more of this hard, abrasive mineral, more wear results to the metal sample. 
It is important not to oversimplify the relation between the surface quartz content and wear in the Dry Sand Rubber Wheel test. The shape of the crushed rock fragments will have a significant effect on the wear rate in this test. Sample \#1, the Bristol Silica has an average grain size of $3.6 \mathrm{~mm}$, which means the fragments used in the wear test are broken from the original grains. This produces very angular, nonspherical fragments, capable of producing high relative wear rates. This is compared to the standard ASTM test quartz sand. This sand is of the same size as the crushed sample rocks, but observations of this material show that it is very rounded and highly spherical. The wear caused by the ASTM test sand is significantly lower than the wear caused by the Bristol Silica (Table 5).

The relationship between the uniaxial compressive strength and the wear rate in the Dry Sand Rubber Wheel test is not understood as well. The uniaxial strength is thought to be a significant variable in the wear to teeth in a mine situation, but the relationship to wear in the Dry Sand Rubber Wheel test is not certain (Figure 12). More data are required before the relationship between the strength of the abrasive and the wear caused in the Dry Sand Rubber Wheel test are known. In Figure 12, the Hibbing taconite samples \#47 and \#48 are not included as the strength of these samples are not known.

A possible problem in using the Dry Sand Rubber Wheel test to predict wear is that this test does not call upon the strength of the abrasive material to produce wear. During the test, the crushed rock is fed in between the rubber wheel and the metal 
sample. The normal load between the sample is not sufficient to cause the crushed rock to fracture or break. In a mine situation, the normal loads experienced by the teeth and the rock would be much higher, which would cause the rocks to fracture and break. In the latter case, the strength of the rocks would be a significant variable. A stronger rock would be allowed to cut a deeper gouge, as the rock would be more resistant to breakage as the load is increased.

The Dry Sand Rubber Wheel test shows the importance of quartz content in predicting wear, but the relationship to wear caused in a mine situation is not completely understood. The strength of the rock in a mine has been argued to be a significant variable in the prediction of wear in a mine, however, the strength of the abrasive in the Dry Sand Rubber Wheel test is not. The fact that the strength variable is not important in the wear caused by the Dry Sand Rubber Wheel test indicates that this test may not be a good proxy to wear in a mine situation.

\section{Conclusions and Predictions}

The tests performed in this project were not equally effective for the prediction of wear for the range of samples. This difference is due to the different petrographic and structural properties. For example, the test of microhardness was shown to be valid for sedimentary and metamorphic rocks but not equally valid for igneous or hydrothermally altered rocks. 
Of the tests performed in this project the rank of relative importance for predicting wear, from greatest to least, of the tests is as follows; 1) uniaxial compressive tests, 2) surface quartz percentage, 3) density, and 4) microhardness.

The magnitude of the uniaxial compressive strength determines the endurance of the rock tools and the grain tools and is valid for all the rock types tested. An understanding of the endurance of rock tools is the single most important predictor of wear. Rock characteristics such as bedding, and fracture (micro and macro scale) density are expressed as a decrease in the uniaxial compressive strength, thus a corresponding decrease in wear rates to teeth. It must be noted, however, that in a mine situation, the angle of attack between the tooth and an inherent structural aspect of the rock unit (e.g. bedding planes, joints) will have an effect on the wear rates, however, this project is concerned with properties measured on a hand sample scale.

The values of Young's modulus and Poisson's ratio can predict the stress/strain relationship of a rock. This property may have an effect on wear rates due to the particle sizes produced during the breakage of rocks. Young's modulus and Poisson's ratio can be used to predict the relative size of these particles. Relative particle size is closely related to the wear rate. Additionally, particle size will dictate whether twobody wear or three-body wear occurs, with wear rates being significantly different for each mechanism. However, the size of the rock fragments are much more important than the aforementioned wear mechanisms for predicting wear. 
It is suspected that the relative importance of Young's modulus and Poisson's ratio are one or two orders of magnitude less than compressive strength. The exact importance cannot be known until these values are compared to measured wear rates in a mine situation. Wear measured in the Dry Sand Rubber Wheel test is not likely to be related to uniaxial compressive strength, Young's modulus and Poisson's ratio.

The surface quartz percentage of the rocks being handled has a direct effect on wear rates to teeth. It has been shown that as the quantity of this hard, abrasive mineral increases, wear rates increase. This increase in wear rate is due to an increase in quartz/tooth contact. Quartz is harder than the tooth material, thus the tooth material will yield to the quartz upon interaction. This test is valid for all the rock types tested.

The density of the rock body has a direct effect on the surface pressures exerted on the teeth by the rocks, assuming that the height of the overburden remains constant in a dragline bucket situation. This will have a direct effect on the depth of the gouge cut by the rock, thus the wear rate. The values of density of the hand samples in this project are extrapolated to the bulk density of the rock material being handled by the mine. A rock body with a higher density will exert greater surface pressures on the tooth, thus cut deeper gouges than a rock body with a low density, if the height of the overburden and all other variables remain constant. This assumes that a major change in composition does not take place within the mine. The measure of density is a valid test regardless of the rock type. However, the range in density may not vary enough to be important for the prediction of wear. 
The shape of the rocks being handled in a mine will have an effect on the relative wear rates experienced in a mine. This is supported by the results in the Dry Sand Rubber Wheel test. It is not known, however, how to measure and quantify this variable for the prediction of wear. The methods of shape quantification attempted in this project were Fourier analysis, number of corners, and sharpness of corners. Fourier analysis and number of corners were methods of shape quantification that were not effective in this project. For the prediction of wear, the two tests are not used due to the lack of consistent or meaningful results. The sharpness of corners showed some degree of relation to the genetic background of the rock, however, it was not possible to gather enough data to gain a complete understanding of this variable. This method of shape investigation provided the best results and needs to be investigated further at some later time. Due to the lack of data on all the samples, this property is not used in this project for the prediction of relative wear rates.

In developing a standardized method of testing a rock for the prediction of wear, the rock type must be recognized. The following tests and the rock type for which the test is valid are recommended and listed in the order of their relative importance;

1) Uniaxial compressive tests, with special emphasis on compressive strength, for all rock types,

2) Determination of surface quartz percentage, for all rock types,

3) A determination of rock density, for all rock types, 
4) Measure of average radius of curvature of the corners for all rock types, and

5) Knoop microhardness, for sedimentary rocks only.

The relative importance of these tests are estimated based on available data and the quality of the results obtained from these tests. These predictions need to be verified by comparing the obtained variables with measured wear rates. The importance of these tests are supported by the discriminant analysis performed on the rock samples.

In the prediction of wear by the samples used in this project, three categories of wear rate are advanced. These categories are 1) high, 2) medium, and 3) low wear rates. The following predictions are made:

High wear rate:

Triple T granite Sample \#44, due to its high value of compressive strength, intermediate surface quartz content, and intermediate density.

Hibbing taconite Samples \#46, \#48, and \#49, due to the high to intermediate values of compressive strength, high values of surface quartz, and high density. Only Sample \#46 was tested for compressive strength, it is predicted that the other samples of taconite in this section possess similar strength.

Bristol Silica Sample \#1, due to the intermediate value of compressive strength, very high quartz content, and intermediate density.

\section{Medium wear rate:}

Taconite Sample \#45, due to its high value of compressive strength, but very low value for surface quartz percentage, and high density. 
Lone Tree Sample \#37, due to its intermediate compressive strength, intermediate to high value of surface quartz percentage, and intermediate density.

Lone Tree Sample \#38, due to its intermediate compressive strength, low value of surface quartz percentage, and intermediate density.

Samples sandstone \#58, due to its intermediate value of compressive strength, high quartz content, and intermediate density.

\section{Low wear rate:}

Bingham Canyon Copper Sample \#35, due to its low compressive strength, intermediate value of surface quartz percentage, and intermediate density. Centralia Sample \#30, due to its very low compressive strength and very low value of surface quartz percentage.

Centralia Sample \#27 and \#25, due to their low compressive strength, low value of surface quartz percentage, and low density. Only Sample \#27 was tested for compressive strength, but the similarity of Sample \#25 to Sample \#27 suggests that the compressive strengths of the two samples are similar. 


\section{References Cited}

Avery, H. S., 1961, The Measurement of Wear Resistance: Wear, v. 4, p. 427-449

Boggs, S. J., 1969, Distribution of Heavy Minerals in the Sixes River, Curry County, Oregon: Ore Bin, v. 31, p. 133

Bruce, W. E., 1968, Bureau of Mines Conducts Diamond Drilling Experiments: The Mines Magazine, p. 17-21

Bryggman, U., S. Hogmark, O. Vingsbo, 1985, Mechanisms of Gouging Abrasive Wear of Steel Investigated with the Aid of Pendulum Single Pass Grooving in Ludema, K. C., eds., The International Conference on Wear of Materials, Vancouver, B. C. Canada, p. 324-331

Burnham, R. J., 1990, Some Late Eocene Depositional Environments of the Coal Bearing Puget Group of Western Washington State: International Journal of Coal Geology, v. 82, p. 27-51.

Conway, J. C., H. P. Kirchner, 1980, The Mechanics of Crack Initiation and Propagation Beneath a Moving Sharp Indentor: Journal of Materials Science, v. 15, pp. 2879- 2883

Davis, J. C., 1986, Statistics and Data Analysis in Geology; 2nd Edition: New York, John Wiley and Sons, 646 pp.

Davis, J. C. 1984, Structural Geology of Rocks and Regions: New York, John Wiley and Sons, $492 \mathrm{pp}$.

Deer, W. A., R. A. Howie, and J. Zussman, 1969, An Introduction to Rock Forming Minerals: New York, John Wiley and Sons, 528 pp.

Deketh, H. J. R., Verhouf, P. N. W., 1993, Fundamental Aspects of Abrasive Wear of Cutting Tools by Rock, Applied to Rock Dredging in J. B. Herbich, P. E. W. H. B., eds., Proceedings of the Twenty-Sixth Annual Dredging Seminar and WEDA XIV Annual Meeting, May 25-28, 1993, Atlantic City, NJ

Ehlers, E. G., H. Blatt, 1980, Petrology: Igneous, Sedimentary, and Metamorphic: San Francisco, W. H. Freeman and Company, 732 pp. 
Embleton, C., C. A. M. King, 1975, Glacial Geomorphology: New York, John Wiley and Sons, $573 \mathrm{p}$.

Fournier, R. O., 1985, The Behavior of Silica in Hydrothermal Solutions in B. R. Berger and P. M. Bethke eds, Geology and Geochemistry of Epithermal Systems, Volume 2, Society of Economic Geologists, p. 45-61

French, B. M., 1973, Mineral Assemblages in Diagenetic and Low-Grade Metamorphic Iron-Formation: Economic Geology, v. 68, p. 1063-1074

Geitgey, R. P., 1990, Silica in Oregon: Oregon Department of Geology and Mineral Industries Special Paper No. 22, 18 pp.

Haas, C. J., 1989, Static Stress-Strain Relationships in Ho, C. Y., ed., Physical Properties of Rocks and Minerals: New York, Hemisphere Publishing Corporation, II-2, p. 123-176.

Henley, R. W., 1985, The Geothermal Framework of Epithermal Deposits: Solutions in B. R. Berger and P. M. Bethke eds, Geology and Geochemistry of Epithermal Systems, Volume 2, Society of Economic Geologists, p. 1-24

Hines, R. R., 1969, Notes on the History of the Sand and Gravel Industry in Oregon: Ore Bin, v. 31, p. 225

Hokkirigawa, K., K. Kato, 1989, Theoretical Estimation of Abrasive Wear Resistance Based on Microscopic Wear Mechanism in Ludema, K. C., eds., The International Conference on Wear of Materials, Denver, CO, p. 1-8

Honeycombe, R. W. K., 1984, The Plastic Deformation of Metals, 2nd ed. Baltimore, E. Arnold, $438 \mathrm{pp}$.

Huard, G., J. Masounave, M. Fiset, Y. Cote', D. Noel, 1987, The Effects of Size and Shape of Abrasive Particles on the Measurement of Wear Rate Using a Dry Sand Rubber Wheel in Ludema, K. C., eds., Proceedings International Conference on the Wear of Materials, Houston, TX, p. 689-699

Jaeger, J. C., N.G.W. Cook, 1979, Fundamentals of Rock Mechanics, Third Edition: New York, Chapman and Hall Ltd., 593p

Judd, W. R., A. Shakoor, 1989, Density in Ho, C. Y., ed., Physical Properties of Rocks and Minerals: New York, Hemisphere Publishing Corporation, II-2, p. 29-39 
Lanier, G., R. B. Folsom, S. Cone, 1978, Mineral Compositions and Quantitative Minerology of Unaltered and Altered Equigranular Rocks in Bingham Mining District, Utah: Economic Geology, v. 70, p. 1154

Lawn, B. R., T.R. Wilshaw, 1975, Fracture of Brittle Solids: New York, Cambridge University Press

Lee, D. R., G. T. Salle, 1970, A Method of Measuring Shape: Geographical Review, v. 60 , p. p. 555

Levy, A. V., 1989, The Abrasion/Erosion and Erosion/Corrosion Characteristics of Steels in Ludema, K. C., eds., The International Conference on Wear of Materials, Denver, CO, p. 115-120

Lipson, C., 1967, Wear Considerations in Design: Englewood Cliffs, NJ, PrenticeHall, Inc., $145 \mathrm{p}$

McLean, D., 1962, Mechanical Properties of Metals: New York, Wiley, 403 p

Morey, G. B., 1972, Mesabi Range in G. M. Schwartz, P. K. Simms, G. B. Morey, eds., Geology of Minnesota: A Centennial Volume: St. Paul, Minnesota Geological Society, p. 204-214

Mouritz, A. P., I. M. Hutchings, 1993, Abrasive Wear of Steels Against Silica-filled Epoxy Resins Under Combined Rolling and Sliding Motion: Tribology International, v. 26, p. 41

Pirajno, F., 1992, Hydrothermal Mineral Deposits: New York, Springer-Verlag, 709 pp.

Poss, J. R., 1982, Lake Superior Iron and Copper Ranges: World Mining, v. 35, p. 6870

Raadnui, S., B. J. Roylance, 1995, The Classification of Wear Particle Shape: Lubrication Engineering, v. 51, p432

Singh, M. M., 1989, Strength of Rock in Ho, C. Y., ed., Physical Properties of Rocks and Minerals: New York, Hemisphere Publishing Company, II-2, p. 83-121

Spry, A., 1969, Metamorphic Textures: New York, Pergamon Press, 350 pp. 
Witkind, I. J., 1978, Giant Glacial Groves at the North End of the Mission Range, Northwest Montana: Journal of Research of the U.S. Geological Survey, v. 6, p. $423-433$

Wood, J. D., 1988, Geology of the Sleeper Gold Deposit, Humbolt County, Nevada in R. Buffa, B. C., E. Seedorff, ed., Hot-Spring Related Gold Deposits of Northwestern Nevada and Southeastern Oregon: Geological Society of Nevada 


\section{Appendix I; The Samples}

Rocks were obtained from mines known to have different geologic conditions. These mines handle rocks ranging from extremely hard (Hibbing taconite) to relatively weakly lithified (Centralia coal mine).

Table 1. The samples and their origin

\begin{tabular}{|c|c|}
\hline Sample Name Number & Mine and Location \\
\hline \hline 1, Bristol Silica & Bristol Silica and Limestone, OR \\
\hline 25, Centralia carbonate & Centralia Mining Co., WA \\
\hline 27, Centralia carbonate & Centralia Mining Co., WA \\
\hline 30, Centralia sandstone & Centralia Mining Co., WA \\
\hline 35, Bingham Canyon copper & Bingham Canyon Copper Mine, UT \\
\hline 37, Lone Tree rock, 001 & Lone Tree gold mine, NV \\
\hline 38, Lone Tree breccia, 002 & Lone Tree gold mine, NV \\
\hline 44, Triple T granite & Triple T rock quarry, Lakeside, CA \\
\hline 45, Hibbing taconite, A1 & Hibbings Taconite mine, MN \\
\hline 46, Hibbing taconite, A2 & Hibbings Taconite mine, MN \\
\hline 47, Hibbing taconite, A3 & Hibbings Taconite mine, MN \\
\hline 48, Hibbing taconite, B1 & Hibbings Taconite mine, MN \\
\hline 49 Hibbing taconite, B2 & Hibbings Taconite mine, MN \\
\hline
\end{tabular}

\section{Sample 1 -Bristol Silica}

\section{Hand Sample}

White, crystalline, rock composed almost entirely of white quartz. Some fractures which contain red staining are visible. The rock is intact, and about 4 to $6 \mathrm{~cm}$ average diameter.

\section{Thin Section}

Virtually pure quartz. Grains interlock tightly. Grains are not deformed or fractured, and make complete contact with one another. A very "clean" sample. Average grain size is approximately three to four $\mathrm{mm}$. The fractures seen in the hand sample scale go through the quartz grains. 


\section{Sample 25 - Centralia carbonate}

\section{Hand Sample}

Very fine grained, soft, carbonate-bearing mudstone. Sample exhibits distinct bedding planes, with bands of darker material forming thin interbeds. This dark material may be organic in nature. Sample is soft enough to crush in hands and will slake when submerged in water.

\section{Thin Section}

Very-fine to fine-grained mudstone. Possible carbonate cement. Grains of quartz are visible. Distinct bedding planes. Bedding planes are of organic material.

\section{Sample 27 - Centralia carbonate}

\section{Hand Sample}

A light colored quartz-bearing carbonate. Sample has visible pores at the surface, but very few. The rock is strong and tends to break in large angular pieces. It will hold a sharp edge, but this edge is easily broken with the fingers. Fine to very fine grained.

\section{Thin Section}

Carbonate cements quartz grains, rock is hard and competent. Quartz grains not in contact with each other. Quartz grains are very angular and non-fractured. At the surface, most grains appear plucked. This subjective observation is made by locating "holes" on the surface.

\section{Sample 30 - Centralia carbonate}

\section{Hand Sample}

Very fine grained, soft, carbonate bearing mudstone. This sample exhibits distinct bedding planes, with bands of darker material forming thin interbeds. This dark material is probably organic material. Sample is soft enough to crush with bare hands and will slake when submerged in water. All samples received were broken and had diameters less then $4 \mathrm{~cm}$.

\section{Thin Section}

Very fine grained, many calcite crystals and a few quartz grains. Strongly bedded, with organics in dark colored bedding planes. 


\section{Sample 35 - Bingham Canyon Copper}

\section{Hand Sample}

A finely crystalline, hard, competent rock. Visible pyrite exists along poorly defined joint surfaces. Evidence of extensive hydrothermal alteration. Sample forms angular pieces and sharp edges where broken. Sample is highly weathered/altered.

\section{Thin Section}

Fine grained, quartz-rich granular rock. Grain size fairly consistant throughout the slide. Chlorite exists between the quartz grains. Internally fractured, fractures are filled with chlorite and carbonates. Appears as though carbonate veins were emplaced before chlorite. Veins are probably fractures later filled with these materials. Rock tends to break along these fractures.

\section{Sample 37 - Lone Tree}

\section{Hand Sample}

A massive and light colored rock. Fine grained, appears to be micro crystalline quartz. Sample is very hard and strong and tends to break in large, angular chunks with sharp edges. No apparent bedding planes or other planes of weakness exist. Healed fractures exist on surface of sample. These healed fractures appear to be onceopen fractures filled with secondary quartz.

\section{Thin Section}

Predominately interlocking quartz grains, fine grained. Many primary sedimentary textures. May have originaly been a feldspathic sandstone or arkose before hydrothermal alteration. Very little evidence of strain in the quartz grains, grains are sub-angular to sub-rounded. During hydrothermal alteration, primary porosity was eliminated, by deposition of muscovite and biotite. Some clay alteration exists. Majority of grains are very fine grained. The very fine grains tend to be in locations between the fine grains (a matrix of very fine quartz grains supporting fine quartz grains). At the surface, it appears as though the fine grains are plucked. Fractures in the rock are filled with coarser secondary quartz.

\section{Sample 38 - Lone Tree}

\section{Hand Sample}

A massive medium gray highly crystalline rock. Sample forms sharp, angular pieces where broken. No apparent bedding planes. Sample is highly re-crystallized. 


\section{Thin Section}

Very fine-grained matrix supporting individual quartz grains. Very fine grained matrix may be cerrussite. This sample is likely a hydrothermal breccia. During formation, quartz was not in equilibrium as evidenced by zonation around visible quartz grains. Quartz grains generally not in contact with each other and evidence of strain exists. At surface, quartz grains are held, as fractures go through the grains. Slide shows clasts, or lumps, of material of a differing composition within a very finegrained matrix. Typically clasts have more quartz, whereas the matrix has very little to no visible quartz. Generally, a greater amount of matrix material is present than quartz.

\section{Sample 44 - Triple T granite}

\section{Hand Sample}

Light colored, fine- to medium-grained granite to granodiorite. Highly crystalline, with visible quartz, feldspars and biotite. Rock breaks into very sharp, angular pieces.

\section{Thin Section}

Medium- to course-grained granite to granodiorite. Crystalline, crystals lock tightly. Contains plagioclase, potassium feldspar, quartz, biotite and a small amount of cerrussite. Some grains are internally fractured.

\section{Sample 45 - Hibbing taconite, A1}

\section{Hand Sample}

Very distinct bedding planes, very fine grained, slatey. Light gray in color with lighter colored layers. Bedding planes may represent planes of weakness. This rock is very hard, and produces sharp edges as it breaks along the bedding planes. Breakage often occurs perpendicular to the bedding, however.

\section{Thin Section}

Distinct bedding planes, very fine grained, but has quartz grains which parallel bedding. Fracture occurs primarily along bedding, but face is generally oblique to bedding. May contain small amounts of ciderite, organics, chlorite, and iron silicate (cerussite). Bedding planes exhibit folding.

\section{Sample 46 - Hibbing taconite A2}

\section{Hand Sample}

Massive, dark colored crystalline rock. A slight fabric exists in this rock, but that appears to be compositional banding. Very fine grained. 


\section{Thin Section}

Ample interlocking quartz. Iron-bearing cherty rock. Significant lateral compositional variability, going from zones of abundant opaques (and low quartz) to zones of few opaques (and high quartz). Often very fine-grained quartz matrix supports other larger quartz and non-quartz grains.

\section{Sample 47 - Hibbing taconite, A3}

\section{Hand Sample}

Greenish, massive rock. Aphanitic, firmly indurated rock that appears to have undergone only slight recrystallization, very hard. Very fine-grained, however, rock does possess compositional banding. Banding is wavy and inconsistent and does not seem to influence breakage.

\section{Thin Section}

Very fine homogenous material supporting individual quartz grains. Slide varies compositionally throughout between area of almost pure quartz to area of almost pure homogenous material. Fractures near surface are randomly oriented and cut through grains.

\section{Sample 48 - Hibbing taconite, B1}

\section{Hand Sample}

Dark, massive, fine grained, cherty, rock. Has veins of darker more homogenous material which may be a plane of weakness. In hand sample investigation, grains of light colored material are evenly distributed within the darker matrix. Rock breaks in very sharp, angular chunks. It forms very sharp edges.

\section{Thin Section}

Contains ferroginous re-crystallized quartz and iron minerals. Significant lateral compositional variability, going from zones of abundant iron containing minerals (and low quartz) to zones of few iron containing minerals (and high quartz). Often very fine grained quartz matrix supports other larger quartz and non-quartz grains.

\section{Sample 49 - Hibbing taconite, B2}

\section{Hand Sample}

Very cherty, hard, competent rock. Finely crystalline, dark colored with reddish veins. Rock exhibits weak compositional banding. It is not known, however, 
whether the rock preferentially breaks along this bedding, as a large sample is not available.

\section{Thin Section}

Iron minerals larger than quartz grains. Mostly re-crystallized fine grained quartz and opaque minerals. Quartz grains interlock with very few fractures. The few fractures that exist cut across grain boundries.

\section{Sample 58, Samples sandstone}

\section{Hand Sample}

Light colored, very well indurated, course grained, quartz sandstone. Sample breaks into sharp angular pieces. A small amount of semi-metallic minerals are visible, and may be muscovite grains.

\section{Thin Section}

Well sorted, angular grains in contact with one another. Calcite cement predominates with some clays. No zoning on any of the grains. Grains are composed of mainly quartz and feldspar and are tightly packed. 


\section{Appendix II; Thin Section Data}

\begin{tabular}{|c|c|c|c|c|c|c|}
\hline Sample & & Slide & $\begin{array}{c}\text { percentage } \\
\text { surface } \\
\text { quartz }\end{array}$ & $\begin{array}{l}\text { Fabric } \\
\qquad\left(^{*}\right)\end{array}$ & $\begin{array}{c}\text { Cementing } \\
\text { agent }\end{array}$ & $\begin{array}{c}\text { Grain } \\
\text { contact } \\
\left({ }^{\star \star}\right)\end{array}$ \\
\hline Centralia & $\# 30$ & & 1.8 & 1 & calcite & -1 \\
\hline Centralia & $\# 30$ & & 6.2 & 1 & calcite & -1 \\
\hline Centralia & $\# 25$ & C-19 & 10 & 1 & calcite & 0 \\
\hline Centralia & $\# 25$ & C-18 & 9.4 & 1 & calcite & 0 \\
\hline Centralia & $\# 25$ & C-17 & 5.6 & 1 & calcite & 0 \\
\hline Centralia & $\# 27$ & $C-1$ & 12.5 & 0 & clcite & -1 \\
\hline Centralia & $\# 27$ & $C-2$ & 6.1 & 0 & calcite & -1 \\
\hline Centralia & \#27 & $C-3$ & 11 & 0 & calcite & -1 \\
\hline Centralia & $\# 27$ & C-4 & 9.1 & 0 & calcite & -1 \\
\hline Centralia & $\# 27$ & $C-5$ & 11 & 0 & calcite & -1 \\
\hline Centralia & $\# 27$ & $C-6$ & 4 & 0 & calcite & -1 \\
\hline Centralia & $\# 27$ & C-7 & 13 & 0 & calcite & -1 \\
\hline Centralia & \#27 & $C-8$ & 10.6 & 0 & calcite & -1 \\
\hline Centralia & $\# 27$ & C-9 & 10.6 & 0 & calcite & -1 \\
\hline hibtacA2 & $\# 46$ & $t-29$ & 47.6 & 1 & & 1 \\
\hline hibtacA2 & $\# 46$ & $t-30$ & 34.4 & 1 & & 1 \\
\hline hibtacA2 & $\# 46$ & $t-28$ & 48 & 1 & & 1 \\
\hline hibtacB1 & $\# 48$ & $t-31$ & 5.8 & vaquely & & 1 \\
\hline hibtacB1 & $\# 48$ & $t-32$ & 63 & vaquely & & 1 \\
\hline hibtac B2 & $\# 49$ & $t-1$ & 52.89 & 0 & qtz, interlk & 1 \\
\hline hibtac B2 & $\# 49$ & $t-2$ & 51.1 & 1 & qtz, interlk & 1 \\
\hline hibtac B2 & \#49 & $t-3$ & 87.2 & 0 & qtz, interlk & 1 \\
\hline hibtac B2 & $\# 49$ & $t-4$ & 45.5 & 1 & qtz, interlk & 1 \\
\hline hibtac B2 & $\# 49$ & $t-5$ & 75.2 & 1 & qtz, interlk & 1 \\
\hline hibtac B2 & $\# 49$ & $t-6$ & 46.3 & 1 & qtz, interlk & 1 \\
\hline hibtac B2 & \#49 & $t-7$ & 86.4 & 1 & qtz, interlk & 1 \\
\hline hibtac B2 & $\# 49$ & $t-8$ & 92 & 0 & qtz, interlk & 1 \\
\hline hibtacA1 & $\# 45$ & $t-21$ & 0 & 1 & cly,calcite? & \\
\hline hibtacA1 & $\# 45$ & $t-22$ & 3.7 & 1 & & 1 \\
\hline hibtacA1 & \#45 & $t-23$ & 0 & 1 & cly,calcite? & \\
\hline hibtacA1 & \#45 & $t-24$ & 0 & 1 & cly,calcite? & \\
\hline hibtacA1 & $\# 45$ & $t-25$ & 8.8 & 1 & cly,calcite? & 1 \\
\hline hibtacA3 & $\# 47$ & $t-13$ & 4.1 & 1 & $?$ & -1 \\
\hline
\end{tabular}




\author{
Sample
}

hibtacA3

hibtacA3

lone tr 001

lone tr 001

lone tr 001

lone tr 001

lone tr 001

lone tr 001

lone tr 001

lone tr 001

lone tr 001

lone tr 001

lone tr 001

lone tr 001

lone tr 001

lone tr 001

lone tr 002

lone tr 002

lone tr 002

lone tr 002

lone tr 002

lone tr 002

lone tr 002

lone tr 002

lone tr 002

lone tr 002

lone tr 002

lone tr 002

Triple T granite

Triple T granite

Triple $T$ granite

Triple T granite

Triple T granite

Triple $T$ granite

Triple T granite

Triple $T$ granite

Triple $T$ granite

Triple T granite
Slide

\author{
Cement

(1)

Grain

surface

quartz contact
Fabric
18.7

22.9

70.6

81.6

74

78.4

80.6

73.2

59.1

50.9

50.4

41.1

48.4

74.4

57.4

40.3

\#37 LT-26

\#38

\#38

\#38

\#38

\#38

\#38

\#38

\#38

\#38

\#38

\#38

\#38

\#44

\#44

\#44

\#44

\#44

$\# 44$

\#44

$\# 44$

\#44

\#44
LT-11

LT-14

LT-13

LT-12

LT-18

LT-19

LT-20

LT-21

LT-22

LT-23

LT-24

$44 A$

44B

$44 \mathrm{C}$

44D

44E

$44 \mathrm{~F}$

44G

$44 \mathrm{H}$

441

44J
LT -15

\section{7}

9.4

21.8

3.4

9.8

0

0.89

11

6

12.6

8.6

9.8

34

33.6

19.4

35.2

20.2

29.6

29.6

33.4

23.8

30.8 


\section{Sample}

Bignham Canyon

Bignham Canyon

Bignham Canyon

Bignham Canyon

Bignham Canyon

Bignham Canyon

Bignham Canyon

Bristol Silica

Bristol Silica

Bristol Silica

Bristol Silica

Bristol Silica

Bristol Silica

Bristol Silica

Bristol Silica

Bristol Silica

Bristol Silica

Samples SS

Samples SS

Samples SS

Samples SS

Samples SS
Slide

$\begin{array}{ll}\# 35 & 35 \mathrm{~A} \\ \# 35 & 35 \mathrm{~B} \\ \# 35 & 35 \mathrm{C} \\ \# 35 & 35 \mathrm{D} \\ \# 35 & 35 \mathrm{E} \\ \# 35 & 35 \mathrm{~F} \\ \# 35 & 35 \mathrm{G}\end{array}$

$1 a$

$1 \mathrm{a}$

$1 a$

$1 \mathrm{a}$

$1 a$

$1 \mathrm{a}$

$1 a$

$1 a$

$1 a$

1a

$\begin{array}{ll}58 & 58 a \\ 58 & 58 b \\ 58 & 58 c \\ 58 & 58 d \\ 58 & 58 e\end{array}$

percentage
surface
quartz

33.2

63.6

58.2

46.7

65.2

54.4

41

98.4

96

93.6

98.4

96

98.4

93

96

96.4

96

$\begin{array}{ll}38 & 0 \\ 35 & 0 \\ 44 & 0 \\ 41 & 0 \\ 36 & 0\end{array}$

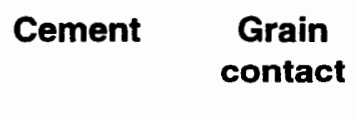

contact

$\begin{array}{ll}0 & 0 \\ 0 & 0 \\ 0 & 0 \\ 0 & 0 \\ 0 & 0 \\ 0 & 0 \\ 0 & 0\end{array}$

* For fabric, a value of 1 indicates a fabric exists, and a value of 0 indicates that no fabric exists.

** For grain contact, a value of 1 indicates that $>60 \%$ of grains are in contact with one another, a value of 0 indincates thatt about half the grains are in contact with one another, and a value of -1 indicates that $<40 \%$ of the grains are in contact with one another. 


\section{Appendix III; Microhardness}

The following table gives microhardness data for the samples tested.

\begin{tabular}{|c|c|c|c|c|c|c|c|c|c|c|c|c|c|}
\hline & & $\begin{array}{l}\text { knoop h } \\
\text { indicate }\end{array}$ & $\begin{array}{l}\text { hardne } \\
\text { d load }\end{array}$ & ss at & & & & $\begin{array}{l}\text { rock } f \\
\text { respo }\end{array}$ & $\begin{array}{l}\text { fractu } \\
\text { onse }\end{array}$ & & & & \\
\hline samp & $\begin{array}{l}\text { grain } \\
\text { type }\end{array}$ & $25 \mathrm{~g} \quad 5$ & $50 \mathrm{~g}$ & $100 \mathrm{~g} 2$ & $200 \mathrm{~g}$ & $300 \mathrm{~g}$ & $500 \mathrm{~g} 2$ & $25 \mathrm{~g}$ & & $100 \mathrm{~g}$ & $200 \mathrm{~g}$ & $\mathrm{~g} 300 \mathrm{~g}$ & $500 \mathrm{~g}$ \\
\hline & & 1248 & 1079 & 771 & 589 & 563 & & $c$ & $f$ & $f$ & $f$ & $f$ & \\
\hline & lgt & 656 & 1032 & 1033 & 940 & 865 & & & c c & $c$ & $f$ & & \\
\hline & $\mathrm{mtx}$ & 438 & 935 & 943 & 371 & 301 & & $c$ & c c & $c$ & $b$ & b & \\
\hline & $\mathrm{mtx}$ & 1414 & 1136 & 855 & 696 & 663 & & & $c \quad b$ & b & c & $f$ & \\
\hline & lgt & 768 & & & & & & $c$ & & & & & \\
\hline & $m t x$ & 1231 & 1114 & 924 & 696 & 677 & $641 \mathrm{c}$ & & b $\quad c$ & $c$ & b & c & $b$ \\
\hline & lgt & 742 & 735 & 541 & 558 & 558 & $537 \mathrm{c}$ & & b $\quad c$ & c & c & c & $b$ \\
\hline & dark & 1241 & 1085 & 793 & 730 & 729 & $687 \mathrm{~b}$ & & & $c$ & b & c & \\
\hline & lgt & 763 & 490 & 526 & 640 & 695 & & & c c & c & c & c & \\
\hline & $\mathrm{mtx}$ & 1475 & 1083 & 881 & 785 & 713 & $624 \mathrm{c}$ & & c c & $c$ & c & $f$ & $f$ \\
\hline & lgt & 1076 & 958 & 644 & & & & $c$ & c c & $c$ & & & \\
\hline & $m t x$ & 1447 & 1143 & 830 & 733 & 641 & $610 \mathrm{~b}$ & & $f$ & f & & $b$ & $b$ \\
\hline & lgt & 668 & 641 & 562 & 349 & & & & c c & $c$ & $f$ & & \\
\hline & red & 1290 & 944 & 825 & 717 & 713 & $686 \mathrm{c}$ & & $c \quad b$ & b & c & & $b$ \\
\hline & drk & 596 & & & & & & & & & & & \\
\hline & drk & 1686 & 1067 & 811 & 759 & 677 & $660 \mathrm{c}$ & & b $\quad c$ & $c$ & $b$ & c & $f$ \\
\hline & drk & 575 & 529 & 478 & 488 & 483 & & & & c & c & & \\
\hline & drk & 1392 & 1129 & 770 & 744 & 698 & & c & $f$ & $f$ & & $f$ & \\
\hline & drk & 690 & 595 & 587 & 478 & 490 & & $c$ & $c \quad b$ & b & & $f$ & \\
\hline & grymt & 1087 & 1047 & 812 & 766 & 655 & $611 \mathrm{~b}$ & & b $\quad c$ & c & c & & \\
\hline & $\mathrm{mtx}$ & 167 & 211 & 153 & 71 & & & b & b b & b & b & & \\
\hline & part & 1237 & 1111 & 958 & 728 & 681 & 687 & & c & & c & & \\
\hline & $m t x$ & 138 & 120 & 147 & 149 & & & b & b $\quad b$ & b & $b$ & & \\
\hline & part & 962 & 1087 & 807 & 561 & 735 & & $c$ & & & $f$ & & \\
\hline & $m t x$ & 161 & 225 & 182 & 110 & & & $b$ & b b & b & $b$ & & \\
\hline & part & 840 & 1341 & 819 & 878 & 609 & 559 & & c & b & c & $c$ & $f$ \\
\hline & $\mathrm{mtx}$ & 122 & 346 & 161 & 151 & & & b & b & b & b & & \\
\hline & part & 1174 & 1176 & 792 & 717 & 447 & & & & b & c & & \\
\hline & $m t x$ & 111 & 158 & 125 & 97 & & & b & b $\quad b$ & b & b & & \\
\hline & part & 1173 & 975 & 955 & 928 & 634 & & c & $c \quad b$ & b & b & $f$ & \\
\hline & $\mathrm{mtx}$ & 186 & 187 & 96 & 70 & & & b & b $\quad b$ & b & $b$ & & \\
\hline & part & 1633 & 1214 & 818 & 551 & 650 & & & c & f & c & $c$ & \\
\hline & $\mathrm{mtx}$ & 130 & 121 & 108 & 110 & 105 & & b & $b \quad b$ & b & b & b & \\
\hline & part & 975 & 883 & 718 & 587 & 396 & $564 \mathrm{~b}$ & & b b & b & c & c & $f$ \\
\hline $44 \mathrm{~A}$ & gray & 1041 & 672 & 991 & 714 & 494 & $512 b$ & & b & b & $b$ & $b$ & \\
\hline & dark & 985 & 657 & 749 & 478 & 782 & $599 \mathrm{~b}$ & & $b \quad b$ & b & b & $b$ & 0 \\
\hline
\end{tabular}




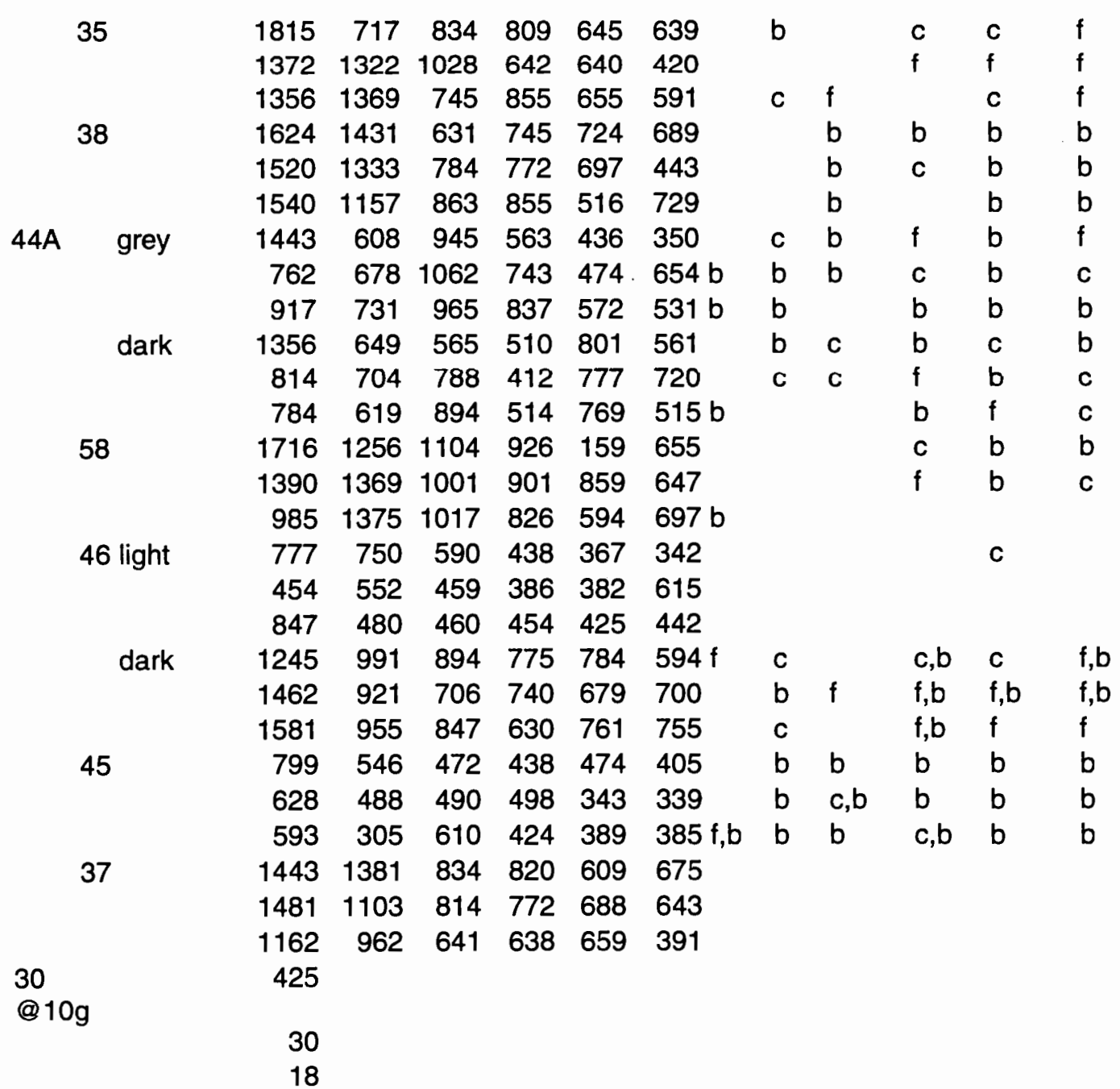

* The microhardness was measured on different grains. For Samples 49, 'Igt' indicates that the microhardness was measured for light colored grains, ' $m t x$ ' indicates that the microhardness was measured on the matrix material, 'drk' indicates a measurement on dark material. For sample 27, ' $m$ tx' indicates a measurment on the matrix material, or the cementing agent, 'part' indicates that the measurement was taken on a grain particle. For the remaining samples, the color of the material measured is indicated.

** The letters indicate the response of the rock as its loaded. 'c' indicates the the rock material surrounding the indentor point cracked upon loading, ' $f$ ' indicates fracturing, 'and ' $b$ ' indicates bursting. 


\section{Appendix IV; tabulated results from the Fourier analysis}

\begin{tabular}{|c|c|c|}
\hline ample slide & $\begin{array}{l}\text { wavelength, } \\
\text { mm }\end{array}$ & $\begin{array}{l}\text { relative } \\
\text { amplitude }\end{array}$ \\
\hline & $\begin{array}{r}1.9 \\
1.27\end{array}$ & $\begin{array}{r}0.01 \\
0.004\end{array}$ \\
\hline
\end{tabular}

$27 c 2 b$

$\begin{array}{rr}1.9 & 0.0078 \\ 1.084 & 0.0069 \\ 0.84 & 0.0025\end{array}$

37 gm 1-2a

$1.95 \quad 0.0038$

$37 \mathrm{gm} \mathrm{1-2b}$

$\begin{array}{ll}1.27 & 0.008 \\ 0.97 & 0.004 \\ 0.69 & 0.002 \\ 0.54 & 0.003\end{array}$

$37 \mathrm{gm} \mathrm{10a}$

$\begin{array}{rr}1.265 & 0.0016 \\ 0.69 & 0.0025 \\ 0.584 & 0.0017 \\ 0.506 & 0.001\end{array}$

$37 \mathrm{gm} \mathrm{10b}$

$\begin{array}{rr}1.265 & 0.003 \\ 0.949 & 0.0063 \\ 0.6325 & 0.0049 \\ 0.542 & 0.002 \\ 0.474 & 0.0032 \\ 0.373 & 0.002 \\ 0.33 & 0.0012\end{array}$


$0.3 \quad 0.0018$

$37 \mathrm{gm} \mathrm{3a}$

$\begin{array}{ll}1.518 & 0.0071 \\ 0.759 & 0.0038\end{array}$

$37 \mathrm{gm} \mathrm{3c}$
1.518
0.006

37 gm 9a

$\begin{array}{rr}1.518 & 0.0078 \\ 0.94875 & 0.0016 \\ 0.759 & 0.0018\end{array}$

$45+25 a$

$\begin{array}{rr}1.8975 & 0.013 \\ 1.265 & 0.0035\end{array}$

$45 t 25 b$

$\begin{array}{rr}1.8975 & 0.015 \\ 1.265 & 0.009 \\ 0.759 & 0.002\end{array}$

$45 t 25 c$

$\begin{array}{rr}2.53 & 0.002 \\ 1.518 & 0.0032 \\ 1.084 & 0.003 \\ 0.767 & 0.0028\end{array}$

$45 \mathrm{t} 26 \mathrm{a}$

$\begin{array}{lr}1.898 & 0.0035 \\ 1.265 & 0.001\end{array}$

$45 t 26 b$

$\begin{array}{rr}2.53 & 0.0035 \\ 1.265 & 0.002\end{array}$

$47 t 18$

$\begin{array}{rr}2.53 & 0.01 \\ 1.518 & 0.003 \\ 1.084 & 0.001\end{array}$


$49 \mathrm{t} 1 \mathrm{a}$

$\begin{array}{rr}2.53 & 0.049 \\ 1.518 & 0.012 \\ 0.949 & 0.002 \\ 0.759 & 0.001 \\ 0.506 & 0.001\end{array}$

$49 \mathrm{t} 1 \mathrm{~b}$

$\begin{array}{rr}1.8975 & 0.0058 \\ 1.265 & 0.0035 \\ 0.9488 & 0.0042\end{array}$

49 t $1 c$

$\begin{array}{rr}2.53 & 0.0059 \\ 1.265 & 0.0061 \\ 0.843 & 0.0025\end{array}$

49 t $4 a$

$\begin{array}{rr}2.53 & 0.0135 \\ 0.94875 & 0.002\end{array}$

$49+4 b$
1.0842
0.002
0.843
0.001 


\section{Appendix V; Quartz grain size data and statistical analysis}

\section{Raw grain size data}

Sample number indicated by top row of numbers. All data are in $\mathrm{mm}$.

\begin{tabular}{|c|c|c|c|c|c|c|c|c|c|c|c|}
\hline 58 & \#35 & \#38 & \#1 & $\# 44$ & 27 & $\# 49$ & $\# 37$ & 6 & 25 & $\# 30$ & $\# 45$ \\
\hline 4.06 & 0.6 & 0.15 & 4.35 & 3.48 & 0.87 & 1.45 & 0.87 &. & $\pi<$ & ו & 0 \\
\hline 8 & 1.05 & 0.075 & 7.83 & 2.9 & 45 & 48 & 29 & & 375 & 375 & \\
\hline 6 & 0.6 & 15 & 8.7 & 11.6 & 0.87 & 96 & 45 & & 3 & 0.3 & 045 \\
\hline 1.45 & 0.6 & 0.075 & 2.9 & 3.19 & 0.87 & 1.16 & 29 & 0.75 & 0.45 & 225 & 0.0525 \\
\hline 3.48 & 675 & 0.15 & 2.03 & 4.35 & 1.74 & 2.9 & 45 & 125 & 0.15 & 0.15 & .0375 \\
\hline 2.9 & 75 & 0.075 & .87 & 2.9 & 1.16 & 1.16 & 87 & .75 & 15 & 525 & 0.03 \\
\hline 1.74 & 975 & 0.15 & .25 & 2.61 & 0.87 & 0.58 & 29 & 225 & 0.45 & 0.6 & .06 \\
\hline .16 & 725 & 0.075 & 58 & 2.9 & 0.87 & 0.58 & 87 & 0.45 & 1125 & 0.6 & 0.075 \\
\hline 2.9 & 0.525 & 0.15 & 0.87 & 10.15 & 1. & 2.9 & 6 & 25 & 25 & 375 & 0.075 \\
\hline 48 & 825 & & 4 & 4 & 6 & & 9 & 5 & 15 & 375 & 675 \\
\hline 45 & 0.9 & 00 & .03 & .03 & 2.03 & 0.58 & 58 & 0. & 0.3 & 0.6 & .0225 \\
\hline 19 & 0.75 & 0.0 & 9 & 1.45 & 1.45 & 2.03 & 58 & 0.15 & .15 & .675 & 0.03 \\
\hline 45 & 3 & & 4 & 5.22 & 2.03 & 0.8 & 8 & 5 & 15 & 0.3 & 0.0375 \\
\hline 48 & 375 & 0 & 1 & 5 & 1.74 & 0 & 37 & & 375 & 675 & .0225 \\
\hline 45 & 9 & 5 & 8 & .87 & 1.45 & $0 . \varepsilon$ & 58 & .125 & 0.3 & .225 & 0.45 \\
\hline 58 & 45 & 5 & 67 & 32 & 2.03 & 0. & $\$ 5$ & 0.45 & .225 & 0.3 & 0.525 \\
\hline 19 & 75 & 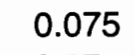 & 18 & 2.3 & 2.32 & 0. & 37 & & .4 & .375 & 0.0225 \\
\hline 16 & 525 & 5 & 9 & 3.48 & 1.16 & 0 & 37 & 375 & .225 & .225 & 0.015 \\
\hline 74 & 0.6 & & & 32 & 6 & 1.45 & 03 & 45 & 45 & 0.3 & 0.0375 \\
\hline 35 & 75 & 5 & & 7 & 1.45 & 0. & 87 & 1.275 & .3 & 525 & 0.0075 \\
\hline & 1.35 & 375 & 8.41 & & 2.03 & 0. & 87 & 0 & 225 & .975 & 0.0075 \\
\hline 74 & 0 & & & 2.0 & 2.61 & 0.2 & 29 & S & 0.225 & 225 & 0.015 \\
\hline 03 & 0.75 & 0.0375 & & & 4 & 0.87 & & 225 & .15 & .375 & 0.0225 \\
\hline 48 & 75 & 0.075 & 31 & 7. & 0.87 & 1. & 29 & 0.15 & .225 & 0.675 & 0.015 \\
\hline 3 & 375 & 0525 & 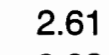 & & 1. & 0.5 & 0 & & 0 & .825 & 0.03 \\
\hline & & & & & 0.87 & 0.5 & 29 & & .3 & 0.3 & .0375 \\
\hline 2.32 & 675 & 0.0075 & 3.77 & & 1.74 & 2.9 & 29 & 225 & 175 & .225 & 0.0375 \\
\hline 2.32 & 1.275 & 0.075 & 3.77 & 12.18 & 2.03 & 1.45 & 1.45 & 0.0375 & 0.525 & 0.3 & 0.0375 \\
\hline 2.32 & 0.75 & 0.15 & 4.06 & 7.25 & 1.45 & 6.67 & 1.16 & 0.0375 & 0.6 & 0.15 & 0.0675 \\
\hline
\end{tabular}

Average grain size of samples, in $\mathrm{mm}$.

$\begin{array}{lllllllllll}\# 58 & \# 35 & \# 38 & \# 1 & \# 44 & \# 27 & \# 49 & \# 37 & \# 46 & \# 25 & \# 30 \quad \text { \#45 }\end{array}$

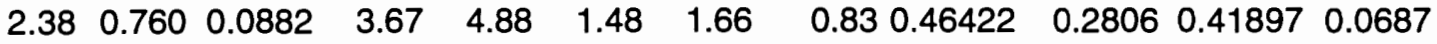




\section{F tests}

The following section contains the results of the F-tests. All the samples were tested against the other samples.

F-Test Two-Sample for Variances

\begin{tabular}{lrr}
\hline & Sample \#58 & Sample \#35 \\
\hline Mean & 2.38 & 0.760344828 \\
Variance & 1.011478571 & 0.092701663 \\
Observations & 29 & 29 \\
df & 28 & 28 \\
$F$ & 10.91111576 & \\
P(F<=f) one-tail & $6.01727 E-09$ & \\
F Critical one-tail & 1.882078493 & \\
\hline
\end{tabular}

F-Test Two-Sample for Variances

\begin{tabular}{lrr}
\hline & Sample\#58 & Sample \#38 \\
\hline Mean & 2.38 & 0.088189655 \\
Variance & 1.011478571 & 0.002067811 \\
Observations & 29 & 29 \\
df & 28 & 28 \\
F & 489.1542751 & \\
P(F<=f) one-tail & $4.23521 E-31$ & \\
F Critical one-tail & 1.882078493 & \\
\hline
\end{tabular}

F-Test Two-Sample for Variances

\begin{tabular}{lrr}
\hline & Sample \#58 & Sample \#27 \\
\hline Mean & 2.38 & 1.48 \\
Variance & 1.011478571 & 0.248364286 \\
Observations & 29 & 29 \\
df & 28 & 28 \\
F & 4.072560467 & \\
P(F<=f) one-tail & 0.000194771 & \\
F Critical one-tail & 1.882078493 & \\
\hline
\end{tabular}

F-Test Two-Sample for Variances

\begin{tabular}{lrr}
\hline & Sample \#58 & Sample \#1 \\
\hline Mean & 2.38 & 3.67 \\
Variance & 1.011478571 & 4.933521429 \\
Observations & 29 & 29 \\
df & 28 & 28 \\
$F$ & 4.877534303 & \\
$P(F<=f)$ one-tail & $3.65668 E-05$ & \\
F Critical one-tail & 0.531326982 & \\
\hline
\end{tabular}

F-Test Two-Sample for Variances

\begin{tabular}{lrr}
\hline & Sample \#58 & Sample \#44 \\
\hline Mean & 2.38 & 4.88 \\
Variance & 1.011478571 & 11.21575 \\
Observations & 29 & 29 \\
df & 28 & 28 \\
F & 11.0884702 & \\
P(F<=f) one-tail & $4.97206 \mathrm{E}-09$ & \\
F Critical one-tail & 0.531326982 & \\
\hline
\end{tabular}

F-Test Two-Sample for Variances

\begin{tabular}{lrr}
\hline & Sample \#58 & Sample \#49 \\
\hline Mean & 2.38 & 1.66 \\
Variance & 1.011478571 & 2.852771429 \\
Observations & 29 & 29 \\
df & 28 & 28 \\
$F$ & 2.820397297 & \\
$P(F<=f)$ one-tail & 0.003884014 & \\
F Critical one-tail & 0.531326982 & \\
\hline
\end{tabular}


F-Test Two-Sample for Variances

\begin{tabular}{lrr}
\hline & Sample \#58 & Sample \#30 \\
\hline Mean & 2.38 & 0.418965517 \\
Variance & 1.011478571 & 0.043600677 \\
Observations & 29 & 29 \\
df & 28 & 28 \\
$F$ & 23.1986894 & \\
P(F<=f) one-tail & $5.09786 \mathrm{E}-13$ & \\
F Critical one-tail & 1.882078493 & \\
\hline
\end{tabular}

F-Test Two-Sample for Variances

\begin{tabular}{lrr}
\hline & Sample \#58 & Sample \#37 \\
\hline Mean & 2.38 & 0.83 \\
Variance & 1.011478571 & 0.2146 \\
Observations & 29 & 29 \\
df & 28 & 28 \\
F & 4.713320463 & \\
P(F<=f) one-tail & $5.0709 E-05$ & \\
F Critical one-tail & 1.882078493 & \\
\hline
\end{tabular}

F-Test Two-Sample for Variances

\begin{tabular}{lrr}
\hline & Sample \#58 & Sample \#46 \\
\hline Mean & 2.38 & 0.464224138 \\
Variance & 1.011478571 & 0.123289332 \\
Observations & 29 & 29 \\
df & 28 & 28 \\
F & 8.204104571 & \\
P(F<=f) one-tail & $1.6029 E-07$ & \\
F Critical one-tail & 1.882078493 & \\
\hline
\end{tabular}

F-Test Two-Sample for Variances

\begin{tabular}{lrr}
\hline & Sample \#35 & Sample \#38 \\
\hline Mean & 0.760344828 & 0.088189655 \\
Variance & 0.092701663 & 0.002067811 \\
Observations & 29 & 29 \\
df & 28 & 28 \\
F & 44.83082077 & \\
P(F<=f) one-tail & $8.51119 \mathrm{E}-17$ & \\
F Critical one-tail & 1.882078493 & \\
\hline
\end{tabular}

F-Test Two-Sample for Variances

\begin{tabular}{lrr}
\hline & \multicolumn{1}{c}{ Sample \#58 } & \multicolumn{1}{c}{ Sample \#45 } \\
\hline Mean & 2.38 & 0.068793103 \\
Variance & 1.011478571 & 0.013950277 \\
Observations & 29 & 29 \\
df & 28 & 28 \\
F & 72.50598426 & \\
P(F<=f) one-tail & $1.26373 E-19$ & \\
F Critical one-tail & 1.882078493 & \\
\hline
\end{tabular}

F-Test Two-Sample for Variances

\begin{tabular}{lrr}
\hline & Sample \#58 & Sample \#25 \\
\hline Mean & 2.38 & 0.280603448 \\
Variance & 1.011478571 & 0.017540025 \\
Observations & 29 & 29 \\
df & 28 & 28 \\
F & 57.66688433 & \\
P(F<=f) one-tail & $2.84636 E-18$ & \\
F Critical one-tail & 1.882078493 & \\
\hline
\end{tabular}

F-Test Two-Sample for Variances

\begin{tabular}{lrr}
\hline & \multicolumn{1}{c}{ Sample \#38 } & Sample \#46 \\
\hline Mean & 0.088189655 & 0.464224138 \\
Variance & 0.002067811 & 0.123289332 \\
Observations & 29 & 29 \\
df & 28 & 28 \\
F & 59.62311558 & \\
P(F<=f) one-tail & $1.8105 E-18$ & \\
F Critical one-tail & 0.531326982 & \\
\hline
\end{tabular}

F-Test Two-Sample for Variances

\begin{tabular}{lrr}
\hline & \multicolumn{1}{c}{ Sample \#35 } & Sample \#1 \\
\hline Mean & 0.760344828 & 3.67 \\
Variance & 0.092701663 & 4.933521429 \\
Observations & 29 & 29 \\
df & 28 & 28 \\
F & 53.2193414 & \\
P(F<=f) one-tail & $8.43622 \mathrm{E}-18$ & \\
F Critical one-tail & 0.531326982 & \\
\hline
\end{tabular}


F-Test Two-Sample for Variances

\begin{tabular}{lrr}
\hline & Sample \#35 & Sample \#27 \\
\hline Mean & 0.760344828 & 1.48 \\
Variance & 0.092701663 & 0.248364286 \\
Observations & 29 & 29 \\
df & 28 & 28 \\
F & 2.679178332 & \\
P(F<=f) one-tail & 0.005621097 & \\
F Critical one-tail & 0.531326982 & \\
\hline
\end{tabular}

F-Test Two-Sample for Variances

\begin{tabular}{lrr}
\hline & Sample \#35 & Sample \#46 \\
\hline Mean & 0.760344828 & 0.464224138 \\
Variance & 0.092701663 & 0.123289332 \\
Observations & 29 & 29 \\
df & 28 & 28 \\
F & 1.329958153 & \\
P(F<=f) one-tail & 0.227690162 & \\
F Critical one-tail & 0.531326982 & \\
\hline
\end{tabular}

F-Test Two-Sample for Variances

\begin{tabular}{lrr}
\hline & Sample \#35 & Sample \#45 \\
\hline Mean & 0.760344828 & 0.068793103 \\
Variance & 0.092701663 & 0.013950277 \\
Observations & 29 & 29 \\
df & 28 & 28 \\
$F$ & 6.645148476 & \\
P(F<=f) one-tail & $1.59546 \mathrm{E}-06$ & \\
F Critical one-tail & 1.882078493 & \\
\hline
\end{tabular}

F-Test Two-Sample for Variances

\begin{tabular}{lrr}
\hline & Sample \#35 & Sample \#44 \\
\hline Mean & 0.760344828 & 4.88 \\
Variance & 0.092701663 & 11.21575 \\
Observations & 29 & 29 \\
df & 28 & 28 \\
F & 120.987582 & \\
P(F<=f) one-tail & $1.12337 \mathrm{E}-22$ & \\
F Critical one-tail & 0.531326982 & \\
\hline
\end{tabular}

F-Test Two-Sample for Variances

\begin{tabular}{lrr}
\hline & \multicolumn{1}{c}{ Sample \#35 } & Sample \#49 \\
\hline Mean & 0.760344828 & 1.66 \\
Variance & 0.092701663 & 2.852771429 \\
Observations & 29 & 29 \\
df & 28 & 28 \\
F & 30.7736814 & \\
P(F<=f) one-tail & $1.27398 E-14$ & \\
F Critical one-tail & 0.531326982 & \\
\hline
\end{tabular}

F-Test Two-Sample for Variances

\begin{tabular}{lrr}
\hline & \multicolumn{1}{c}{ Sample \#35 } & \multicolumn{1}{c}{ Sample \#25 } \\
\hline Mean & 0.760344828 & 0.280603448 \\
Variance & 0.092701663 & 0.017540025 \\
Observations & 29 & 29 \\
df & 28 & 28 \\
F & 5.285150079 & \\
P(F<=f) one-tail & $1.67194 \mathrm{E}-05$ & \\
F Critical one-tail & 1.882078493 & \\
\hline
\end{tabular}

F-Test Two-Sample for Variances

\begin{tabular}{lrr}
\hline & Sample \#35 & Sample \#37 \\
\hline Mean & 0.760344828 & 0.83 \\
Variance & 0.092701663 & 0.2146 \\
Observations & 29 & 29 \\
df & 28 & 28 \\
$F$ & 2.314953088 & \\
P(F<=f) one-tail & 0.01499309 & \\
F Critical one-tail & 0.531326982 & \\
\hline
\end{tabular}

F-Test Two-Sample for Variances

\begin{tabular}{lrr}
\hline & Sample \#35 & Sample \#30 \\
\hline Mean & 0.760344828 & 0.418965517 \\
Variance & 0.092701663 & 0.043600677 \\
Observations & 29 & 29 \\
df & 28 & 28 \\
F & 2.126151891 & \\
P(F<=f) one-tail & 0.025263728 & \\
F Critical one-tail & 1.882078493 & \\
\hline
\end{tabular}


F-Test Two-Sample for Variances

\begin{tabular}{lrr}
\hline & Sample \#38 & Sample \#1 \\
\hline Mean & 0.088189655 & 3.67 \\
Variance & 0.002067811 & 4.933521429 \\
Observations & 29 & 29 \\
df & 28 & 28 \\
$F$ & 2385.866756 & \\
$P(F<=f)$ one-tail & $1.02445 E-40$ & \\
$F$ Critical one-tail & 0.531326982 & \\
\hline
\end{tabular}

F-Test Two-Sample for Variances

\begin{tabular}{lrr}
\hline & Sample \#38 & Sample \#49 \\
\hline Mean & 0.088189655 & 1.66 \\
Variance & 0.002067811 & 2.852771429 \\
Observations & 29 & 29 \\
df & 28 & 28 \\
$F$ & 1379.609395 & \\
P(F<=f) one-tail & $2.17513 E-37$ & \\
F Critical one-tail & 0.531326982 & \\
\hline
\end{tabular}

F-Test Two-Sample for Variances

\begin{tabular}{lrr}
\hline & Sample \#38 & Sample \#25 \\
\hline Mean & 0.088189655 & 0.280603448 \\
Variance & 0.002067811 & 0.017540025 \\
Observations & 29 & 29 \\
df & 28 & 28 \\
$F$ & 8.48241206 & \\
$P(F<=f)$ one-tail & $1.10235 E-07$ & \\
F Critical one-tail & 0.531326982 & \\
\hline
\end{tabular}

F-Test Two-Sample for Variances

\begin{tabular}{lrr}
\hline & Sample \#38 & Sample \#27 \\
\hline Mean & 0.088189655 & 1.48 \\
Variance & 0.002067811 & 0.248364286 \\
Observations & 29 & 29 \\
df & 28 & 28 \\
F & 120.1097636 & \\
P(F<=f) one-tail & $1.24199 \mathrm{E}-22$ & \\
F Critical one-tail & 0.531326982 & \\
\hline
\end{tabular}

F-Test Two-Sample for Variances

\begin{tabular}{lrr}
\hline & Sampoe \#38 & Sample \#44 \\
\hline Mean & 0.088189655 & 4.88 \\
Variance & 0.002067811 & 11.21575 \\
Observations & 29 & 29 \\
df & 28 & 28 \\
$F$ & 5423.972604 & \\
P(F<=f) one-tail & $1.04654 \mathrm{E}-45$ & \\
F Critical one-tail & 0.531326982 & \\
\hline
\end{tabular}

F-Test Two-Sample for Variances

\begin{tabular}{lrr}
\hline & Sample \#38 & Sample \#37 \\
\hline Mean & 0.088189655 & 0.83 \\
Variance & 0.002067811 & 0.2146 \\
Observations & 29 & 29 \\
df & 28 & 28 \\
$F$ & 103.781247 & \\
$P(F<=f)$ one-tail & $9.28584 E-22$ & \\
$F$ Critical one-tail & 0.531326982 & \\
\hline
\end{tabular}

F-Test Two-Sample for Variances

\begin{tabular}{lrr}
\hline & \multicolumn{1}{c}{ Sample \#38 } & Sample \#30 \\
\hline Mean & 0.088189655 & 0.418965517 \\
Variance & 0.002067811 & 0.043600677 \\
Observations & 29 & 29 \\
df & 28 & 28 \\
$F$ & 21.08542714 & \\
$P(F<=f)$ one-tail & $1.74313 E-12$ & \\
F Critical one-tail & 0.531326982 & \\
\hline
\end{tabular}

F-Test Two-Sample for Variances

\begin{tabular}{lrr}
\hline & Sample \#38 & \multicolumn{1}{c}{ Sample \#45 } \\
\hline Mean & 0.088189655 & 0.068793103 \\
Variance & 0.002067811 & 0.013950277 \\
Observations & 29 & 29 \\
df & 28 & 28 \\
$F$ & 6.74639866 & \\
$P(F<=f)$ one-tail & $1.35847 E-06$ & \\
F Critical one-tail & 0.531326982 & \\
\hline
\end{tabular}


F-Test Two-Sample for Variances

\begin{tabular}{lrr}
\hline & \multicolumn{1}{c}{ Sample \#1 } & Sample \#44 \\
\hline Mean & 3.67 & 4.88 \\
Variance & 4.933521429 & 11.21575 \\
Observations & 29 & 29 \\
df & 28 & 28 \\
$F$ & 2.27337616 & \\
P(F<=f) one-tail & 0.016807687 & \\
F Critical one-tail & 0.531326982 & \\
\hline
\end{tabular}

F-Test Two-Sample for Variances

\begin{tabular}{lrr}
\hline & \multicolumn{1}{c}{ Sample \#1 } & Sample \#37 \\
\hline Mean & 3.67 & 0.83 \\
Variance & 4.933521429 & 0.2146 \\
Observations & 29 & 29 \\
df & 28 & 28 \\
F & 22.98938224 & \\
P(F<=f) one-tail & $5.73106 E-13$ & \\
F Critical one-tail & 1.882078493 & \\
\hline
\end{tabular}

F-Test Two-Sample for Variances

\begin{tabular}{lrr}
\hline & Sample \#1 & Sample \#30 \\
\hline Mean & 3.67 & 0.418965517 \\
Variance & 4.933521429 & 0.043600677 \\
Observations & 29 & 29 \\
df & 28 & 28 \\
F & 113.1524033 & \\
P(F<=f) one-tail & $2.82594 \mathrm{E}-22$ & \\
F Critical one-tail & 1.882078493 & \\
\hline
\end{tabular}

F-Test Two-Sample for Variances

\begin{tabular}{lrr}
\hline & \multicolumn{1}{c}{ Sample \#1 } & Sample 349 \\
\hline Mean & 3.67 & 1.66 \\
Variance & 4.933521429 & 2.852771429 \\
Observations & 29 & 29 \\
df & 28 & 28 \\
F & 1.729378449 & \\
P(F<=f) one-tail & 0.076701668 & \\
F Critical one-tail & 1.882078493 & \\
\hline
\end{tabular}

F-Test Two-Sample for Variances
F-Test Two-Sample for Variances

\begin{tabular}{|c|c|c|}
\hline & Sample \#1 & Sample \#27 \\
\hline Mean & 3.67 & 1.48 \\
\hline Variance & 4.933521429 & 0.248364286 \\
\hline Observations & 29 & 29 \\
\hline df & 28 & 28 \\
\hline$F$ & 19.86405338 & \\
\hline$P(F<=f)$ one-tail & $3.73823 E-12$ & \\
\hline F Critical one-tail & 1.882078493 & \\
\hline
\end{tabular}

F-Test Two-Sample for Variances

\begin{tabular}{lrr}
\hline & \multicolumn{1}{c}{ Sample \#1 } & Sample \#46 \\
\hline Mean & 3.67 & 0.464224138 \\
Variance & 4.933521429 & 0.123289332 \\
Observations & 29 & 29 \\
df & 28 & 28 \\
F & 40.01580147 & \\
P(F<=f) one-tail & $3.90034 \mathrm{E}-16$ & \\
F Critical one-tail & 1.882078493 & \\
\hline
\end{tabular}

F-Test Two-Sample for Variances

\begin{tabular}{lrr}
\hline & \multicolumn{1}{c}{ Sample \#1 } & Sample \#45 \\
\hline Mean & 3.67 & 0.068793103 \\
Variance & 4.933521429 & 0.013950277 \\
Observations & 29 & 29 \\
df & 28 & 28 \\
$F$ & 353.6504254 & \\
$P(F<=f)$ one-tail & $3.89234 E-29$ & \\
F Critical one-tail & 1.882078493 & \\
\hline
\end{tabular}

F-Test Two-Sample for Variances

\begin{tabular}{lrr}
\hline & \multicolumn{1}{c}{ Sample \#1 } & Sample \#25 \\
\hline Mean & 3.67 & 0.280603448 \\
Variance & 4.933521429 & 0.017540025 \\
Observations & 29 & 29 \\
df & 28 & 28 \\
$F$ & 281.2722064 & \\
$P(F<=f)$ one-tail & $9.42417 E-28$ & \\
F Critical one-tail & 1.882078493 & \\
\hline
\end{tabular}

F-Test Two-Sample for Variances 


\begin{tabular}{lrr}
\hline & Sample \#44 & Sample \#27 \\
\hline Mean & 4.88 & 1.48 \\
Variance & 11.21575 & 0.248364286 \\
Observations & 29 & 29 \\
df & 28 & 28 \\
$F$ & 45.15846539 & \\
P(F<=f) one-tail & $7.7181 E-17$ & \\
F Critical one-tail & 1.882078493 & \\
\hline
\end{tabular}

F-Test Two-Sample for Variances

\begin{tabular}{lrr}
\hline & Sample \#44 & \multicolumn{1}{c}{ Sample 46 } \\
\hline Mean & 4.88 & 0.464224138 \\
Variance & 11.21575 & 0.123289332 \\
Observations & 29 & 29 \\
df & 28 & 28 \\
$F$ & 90.97096908 & \\
P(F $<=f)$ one-tail & $5.67038 E-21$ & \\
F Critical one-tail & 1.882078493 & \\
\hline
\end{tabular}

F-Test Two-Sample for Variances

\begin{tabular}{lrr}
\hline & Sample \#44 & Sample \#45 \\
\hline Mean & 4.88 & 0.068793103 \\
Variance & 11.21575 & 0.013950277 \\
Observations & 29 & 29 \\
df & 28 & 28 \\
F & 803.980446 & \\
P(F<=f) one-tail & $4.1186 \mathrm{E}-34$ & \\
F Critical one-tail & 1.882078493 & \\
\hline
\end{tabular}

F-Test Two-Sample for Variances

\begin{tabular}{lrr}
\hline & Sample \#27 & Sample \#49 \\
\hline Mean & 1.48 & 1.66 \\
Variance & 0.248364286 & 2.852771429 \\
Observations & 29 & 29 \\
df & 28 & 28 \\
$F$ & 11.48623853 & \\
$P(F<=f)$ one-tail & $3.27074 E-09$ & \\
F Critical one-tail & 0.531326982 & \\
\hline
\end{tabular}

\begin{tabular}{lrr}
\hline & Sample \#44 & Sample \#49 \\
\hline Mean & 4.88 & 1.66 \\
Variance & 11.21575 & 2.852771429 \\
Observations & 29 & 29 \\
df & 28 & 28 \\
F & 3.931527737 & \\
P(F<=f) one-tail & 0.000266118 & \\
F Critical one-tail & 1.882078493 & \\
\hline
\end{tabular}

F-Test Two-Sample for Variances

\begin{tabular}{lrr}
\hline & Sample \#44 & Sample \#25 \\
\hline Mean & 4.88 & 0.280603448 \\
Variance & 11.21575 & 0.017540025 \\
Observations & 29 & 29 \\
df & 28 & 28 \\
F & 639.4375285 & \\
P(F<=f) one-tail & $1.00783 E-32$ & \\
F Critical one-tail & 1.882078493 & \\
\hline
\end{tabular}

F-Test Two-Sample for Variances

\begin{tabular}{lrr}
\hline & Sample \#44 & Sample \#37 \\
\hline Mean & 4.88 & 0.83 \\
Variance & 11.21575 & 0.2146 \\
Observations & 29 & 29 \\
df & 28 & 28 \\
F & 52.26351351 & \\
P(F<=f) one-tail & $1.07775 E-17$ & \\
F Critical one-tail & 1.882078493 & \\
\hline
\end{tabular}

F-Test Two-Sample for Variances

\begin{tabular}{lrr}
\hline & Sample \#27 & Sample \#37 \\
\hline Mean & 1.48 & 0.83 \\
Variance & 0.248364286 & 0.2146 \\
Observations & 29 & 29 \\
df & 28 & 28 \\
F & 1.157335907 & \\
P(F<=f) one-tail & 0.35086183 & \\
F Critical one-tail & 1.882078493 & \\
\hline
\end{tabular}


F-Test Two-Sample for Variances

\begin{tabular}{lrr}
\hline & Sample \#27 & Sample \#25 \\
\hline Mean & 1.48 & 0.280603448 \\
Variance & 0.248364286 & 0.017540025 \\
Observations & 29 & 29 \\
df & 28 & 28 \\
F & 14.15985958 & \\
P(F<=f) one-tail & $2.59704 \mathrm{E}-10$ & \\
F Critical one-tail & 1.882078493 & \\
\hline
\end{tabular}

F-Test Two-Sample for Variances

\begin{tabular}{lrr}
\hline & Sample \#27 & Sample \#46 \\
\hline Mean & 1.48 & 0.464224138 \\
Variance & 0.248364286 & 0.123289332 \\
Observations & 29 & 29 \\
df & 28 & 28 \\
F & 2.014483183 & \\
P(F<=f) one-tail & 0.034500202 & \\
F Critical one-tail & 1.882078493 & \\
\hline
\end{tabular}

F-Test Two-Sample for Variances

\begin{tabular}{lrr}
\hline & Sample \#49 & Sample \#37 \\
\hline Mean & 1.66 & 0.83 \\
Variance & 2.852771429 & 0.2146 \\
Observations & 29 & 29 \\
df & 28 & 28 \\
$F$ & 13.29343629 & \\
$P(F<=f)$ one-tail & $5.622 E-10$ & \\
F Critical one-tail & 1.882078493 & \\
\hline
\end{tabular}

F-Test Two-Sample for Variances

\begin{tabular}{lrr}
\hline & Sample \#49 & Sample \#30 \\
\hline Mean & 1.66 & 0.418965517 \\
Variance & 2.852771429 & 0.043600677 \\
Observations & 29 & 29 \\
df & 28 & 28 \\
F & 65.42952088 & \\
P(F<=f) one-tail & $5.12133 \mathrm{E}-19$ & \\
F Critical one-tail & 1.882078493 & \\
\hline
\end{tabular}

\section{F-Test Two-Sample for Variances}

\begin{tabular}{lrr}
\hline & Sample \#27 & Sample \#30 \\
\hline Mean & 1.48 & 0.418965517 \\
Variance & 0.248364286 & 0.043600677 \\
Observations & 29 & 29 \\
df & 28 & 28 \\
F & 5.696340077 & \\
P(F<=f) one-tail & $7.89502 E-06$ & \\
F Critical one-tail & 1.882078493 & \\
\hline
\end{tabular}

F-Test Two-Sample for Variances

\begin{tabular}{lrr}
\hline & Sample \#27 & Sample \#45 \\
\hline Mean & 1.48 & 0.068793103 \\
Variance & 0.248364286 & 0.013950277 \\
Observations & 29 & 29 \\
df & 28 & 28 \\
F & 17.80353781 & \\
P(F<=f) one-tail & $1.49945 E-11$ & \\
F Critical one-tail & 1.882078493 & \\
\hline
\end{tabular}

F-Test Two-Sample for Variances

\begin{tabular}{lrr}
\hline & Sample \#49 & Sample \#46 \\
\hline Mean & 1.66 & 0.464224138 \\
Variance & 2.852771429 & 0.123289332 \\
Observations & 29 & 29 \\
df & 28 & 28 \\
$F$ & 23.13883436 & \\
P(F<=f) one-tail & $5.2709 E-13$ & \\
F Critical one-tail & 1.882078493 & \\
\hline
\end{tabular}

F-Test Two-Sample for Variances

\begin{tabular}{lrr}
\hline & Sampel \#49 & Sample \#45 \\
\hline Mean & 1.66 & 0.068793103 \\
Variance & 2.852771429 & 0.013950277 \\
Observations & 29 & 29 \\
df & 28 & 28 \\
$F$ & 204.495682 & \\
P(F<=f) one-tail & $7.89512 E-26$ & \\
F Critical one-tail & 1.882078493 & \\
\hline
\end{tabular}


F-Test Two-Sample for Variances

\begin{tabular}{lrr}
\hline & Sample \#49 & Sample \#25 \\
\hline Mean & 1.66 & 0.280603448 \\
Variance & 2.852771429 & 0.017540025 \\
Observations & 29 & 29 \\
df & 28 & 28 \\
F & 162.6435247 & \\
P(F<=f) one-tail & $1.88548 E-24$ & \\
F Critical one-tail & 1.882078493 & \\
\hline
\end{tabular}

F-Test Two-Sample for Variances

\begin{tabular}{lrr}
\hline & Sample \#37 & Sample \#46 \\
\hline Mean & 0.83 & 0.464224138 \\
Variance & 0.2146 & 0.123289332 \\
Observations & 29 & 29 \\
df & 28 & 28 \\
$F$ & 1.740620999 & \\
P(F<=f) one-tail & 0.074328157 & \\
F Critical one-tail & 1.882078493 & \\
\hline
\end{tabular}

F-Test Two-Sample for Variances

\begin{tabular}{lrr}
\hline & Sample \#37 & Sample \#45 \\
\hline Mean & 0.83 & 0.068793103 \\
Variance & 0.2146 & 0.013950277 \\
Observations & 29 & 29 \\
df & 28 & 28 \\
F & 15.38320698 & \\
P(F<=f) one-tail & $9.33497 E-11$ & \\
F Critical one-tail & 1.882078493 & \\
\hline
\end{tabular}

F-Test Two-Sample for Variances

\begin{tabular}{lrr}
\hline & Sample \#46 & Sample \#25 \\
\hline Mean & 0.464224138 & 0.280603448 \\
Variance & 0.123289332 & 0.017540025 \\
Observations & 29 & 29 \\
df & 28 & 28 \\
F & 7.029028436 & \\
P(F<=f) one-tail & $8.75157 E-07$ & \\
F Critical one-tail & 1.882078493 & \\
\hline
\end{tabular}

F-Test Two-Sample for Variances

\begin{tabular}{lrr}
\hline & \multicolumn{1}{c}{ Sample \#25 } & Sample \#45 \\
\hline Mean & 0.280603448 & 0.068793103 \\
Variance & 0.017540025 & 0.013950277 \\
Observations & 29 & 29 \\
df & 28 & 28 \\
F & 1.257324461 & \\
P(F<=f) one-tail & 0.274317125 & \\
F Critical one-tail & 1.882078493 & \\
\hline
\end{tabular}

F-Test Two-Sample for Variances

\begin{tabular}{lrr}
\hline & Sample \#37 & Sample \#25 \\
\hline Mean & 0.83 & 0.280603448 \\
Variance & 0.2146 & 0.017540025 \\
Observations & 29 & 29 \\
df & 28 & 28 \\
$F$ & 12.2348745 & \\
P(F<=f) one-tail & $1.53543 E-09$ & \\
F Critical one-tail & 1.882078493 & \\
\hline
\end{tabular}

F-Test Two-Sample for Variances

\begin{tabular}{lrr}
\hline & Sample \#37 & Sample \#30 \\
\hline Mean & 0.83 & 0.418965517 \\
Variance & 0.2146 & 0.043600677 \\
Observations & 29 & 29 \\
df & 28 & 28 \\
F & 4.921941885 & \\
P(F<=f) one-tail & $3.3512 \mathrm{E}-05$ & \\
F Critical one-tail & 1.882078493 & \\
\hline
\end{tabular}

F-Test Two-Sample for Variances

\begin{tabular}{lrr}
\hline & Sample \#46 & Sample \#30 \\
\hline Mean & 0.464224138 & 0.418965517 \\
Variance & 0.123289332 & 0.043600677 \\
Observations & 29 & 29 \\
df & 28 & 28 \\
F & 2.827693041 & \\
P(F<=f) one-tail & 0.003811205 & \\
F Critical one-tail & 1.882078493 & \\
\hline
\end{tabular}


F-Test Two-Sample for Variances

\begin{tabular}{lrr}
\hline & Sample \#46 & Sample \#45 \\
\hline Mean & 0.464224138 & 0.068793103 \\
Variance & 0.123289332 & 0.013950277 \\
Observations & 29 & 29 \\
df & 28 & 28 \\
F & 8.837769391 & \\
P(F<=f) one-tail & $6.92949 E-08$ & \\
F Critical one-tail & 1.882078493 & \\
\hline
\end{tabular}

F-Test Two-Sample for Variances

\begin{tabular}{lrr}
\hline & Sample \#25 & Sample \#30 \\
\hline Mean & 0.280603448 & 0.418965517 \\
Variance & 0.017540025 & 0.043600677 \\
Observations & 29 & 29 \\
df & 28 & 28 \\
$F$ & 2.485781991 & \\
P(F<=f) one-tail & 0.009419385 & \\
F Critical one-tail & 0.531326982 & \\
\hline
\end{tabular}

F-Test Two-Sample for Variances

\begin{tabular}{lrr}
\hline & \multicolumn{1}{c}{ Sample \#30 } & \multicolumn{1}{c}{ Sample \#45 } \\
\hline Mean & 0.418965517 & 0.068793103 \\
Variance & 0.043600677 & 0.013950277 \\
Observations & 29 & 29 \\
df & 28 & 28 \\
$F$ & 3.125434502 & \\
P(F<=f) one-tail & 0.001787069 & \\
F Critical one-tail & 1.882078493 & \\
\hline
\end{tabular}




\section{t tests}

The following section contains the results of the $t$ tests. The tests were performed after variances were determined to be similar from the $F$ test.

t-Test: Two-Sample

Assuming Equal Variances

\begin{tabular}{lrr}
\hline & Sample \#1 & Sample \#49 \\
\hline Mean & 2.38 & 1.66 \\
Variance & 1.01147857 & 2.852771429 \\
Observations & 29 & 29 \\
Pooled Variance & 1.932125 & \\
Hypothesized Mean & 0 & \\
Difference & & \\
$d f$ & 1.97241768 & \\
$t$ Stat & 0.02675371 & \\
$P(T<=t)$ one-tail & 1.67252210 & \\
$t$ Critical one-tail & 0.05350742 & \\
$P(T<=t)$ two-tail & 2.00323938 & \\
$t$ Critical two-tail & & \\
\hline
\end{tabular}

t-Test: Two-Sample

Assuming Equal Variances

\begin{tabular}{lrr}
\hline & Sample \#37 & Sample \#46 \\
\hline Mean & 0.83 & 0.464224138 \\
Variance & 0.2146 & 0.123289332 \\
Observations & 29 & \\
Pooled Variance & 0.16894466 & \\
Hypothesized Mean & 0 & \\
Difference & 56 & \\
df & 3.38865067 & \\
$t$ Stat & 0.00064600 & \\
$P(T<=t)$ one-tail & 1.67252210 & \\
$t$ Critical one-tail & 0.00129200 & \\
$P(T<=t)$ two-tail & 2.00323938 & \\
$t$ Critical two-tail & & \\
\hline
\end{tabular}


t-Test: Two-Sample

Assuming Equal Variances

\begin{tabular}{lrrr}
\hline & Sample \#27 & Sample \#37 & \\
\hline Mean & 1.48 & & 0.83 \\
Variance & 0.248364286 & 0.2146 \\
Observations & 29 & \\
Pooled Variance & 0.231482143 & \\
Hypothesized Mean & 0 & \\
Difference & 56 & \\
df & 5.144445975 & \\
t Stat & $1.78113 \mathrm{E}-05$ & \\
$P(T<=t)$ one-tail & 1.672522103 & \\
t Critical one-tail & $3.56225 \mathrm{E}-05$ & \\
$P(T<=t)$ two-tail & 2.003239388 & \\
t Critical two-tail & & \\
\hline
\end{tabular}

t-Test: Two-Sample

Assuming Equal Variances

\begin{tabular}{lrr}
\hline & Sample \#25 & Sample \#45 \\
\hline Mean & 0.280603448 & 0.068793103 \\
Variance & 0.017540025 & 0.013950277 \\
Observations & 29 & \\
Pooled Variance & 0.015745151 & \\
Hypothesized Mean & 0 & \\
Difference & 56 & \\
df & 6.427731918 & \\
$t$ Stat & $1.51851 \mathrm{E}-07$ & \\
$P(T<=t)$ one-tail & 1.672522103 & \\
$t$ Critical one-tail & $3.03701 \mathrm{E}-07$ & \\
$P(T<=t)$ two-tail & 2.003239388 & \\
$t$ Critical two-tail & & \\
\hline
\end{tabular}




\section{Appendix VII; Program to perform Fourier analysis}

Writen by Kenneth M. Cruikshank.

// esco.cpp

// Ugly hack of a program to perform fourier analysis of $(x, z)$ data

// Original data files is in DXF, or $(x, y)$ format

// Assumes file contains a single, continuous interface

$/ /$ although Adobe Streamline may split line into more than one POLYLINES

// this program will assemble a single, continuous line.

// Step 1. Read in DXF file, and convert to $(x, z)$ coordinates

// Step 2. Sort $(\mathrm{x}, \mathrm{z})$ coordinates wrt $\mathrm{x}$

// Step 3. Program first performs a linear fit to the data. This linear

/I trend is then be subtracted from the original data set

// Step 4. Spline modified data, and interpolate $\mathrm{z}$ on equal $\mathrm{x}$-spacing

// Step 5. Perform Fourier analysis

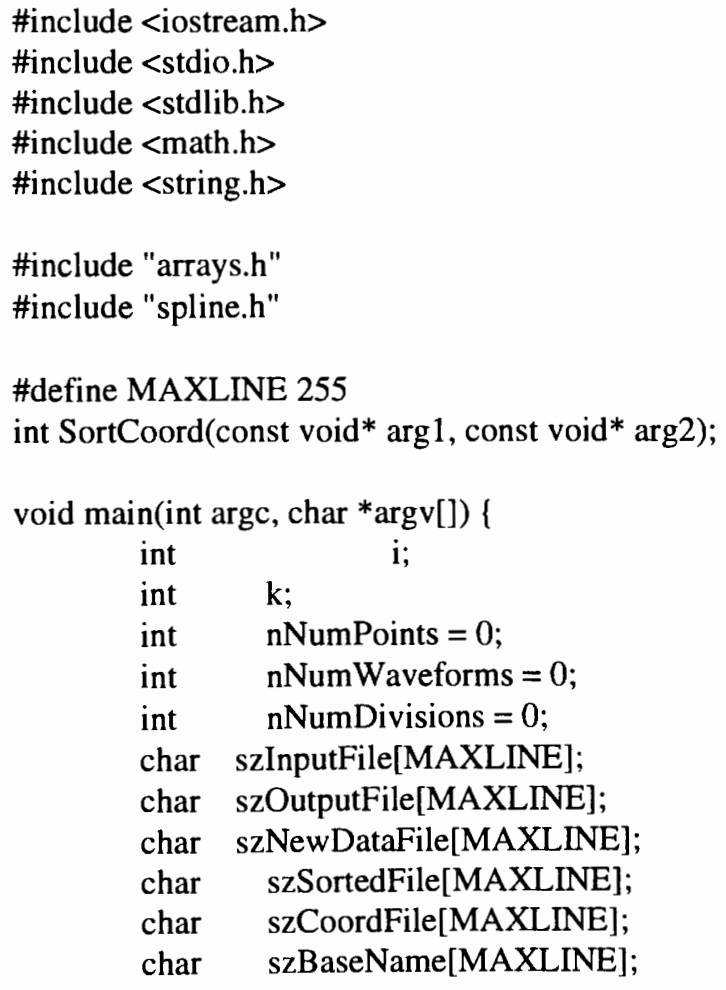




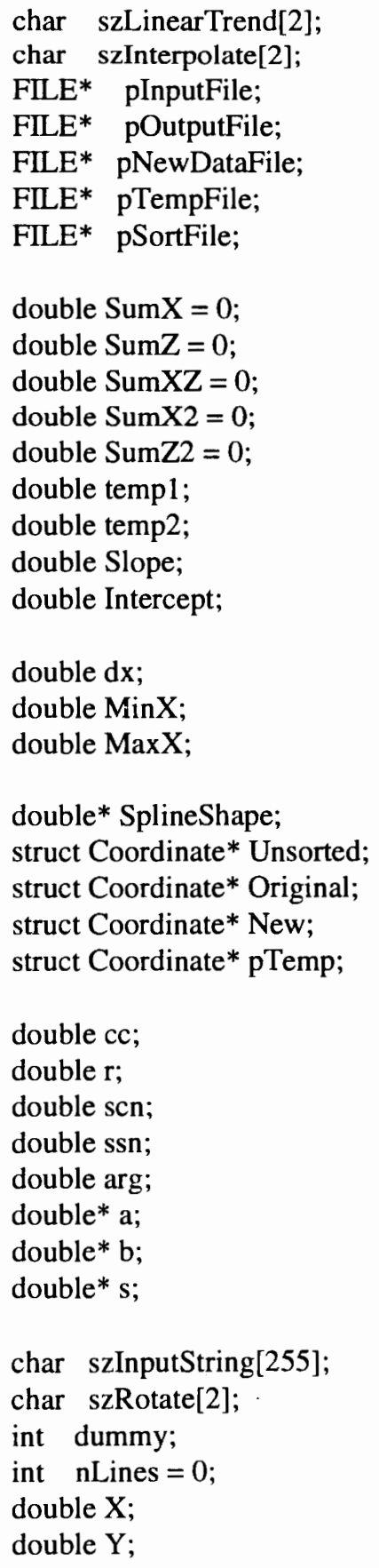


cout $<<$ "Rotate lines by $90^{\circ}(\mathrm{y} / \mathrm{n}) \quad \rightarrow>$ "; cin $\gg$ szRotate; $\quad$ szRotate[1] = 'l0'; cout $\ll<$ "Remove linear trend from data $(y / n)->$ "; cin $\gg$ szLinearTrend;

szLinearTrend[1] = ' 10 ';

10 ; cout $\ll$ "Interpolate data $(y / n) \quad->$ "; cin $\gg>$ szInterpolate; szInterpolate[1] =

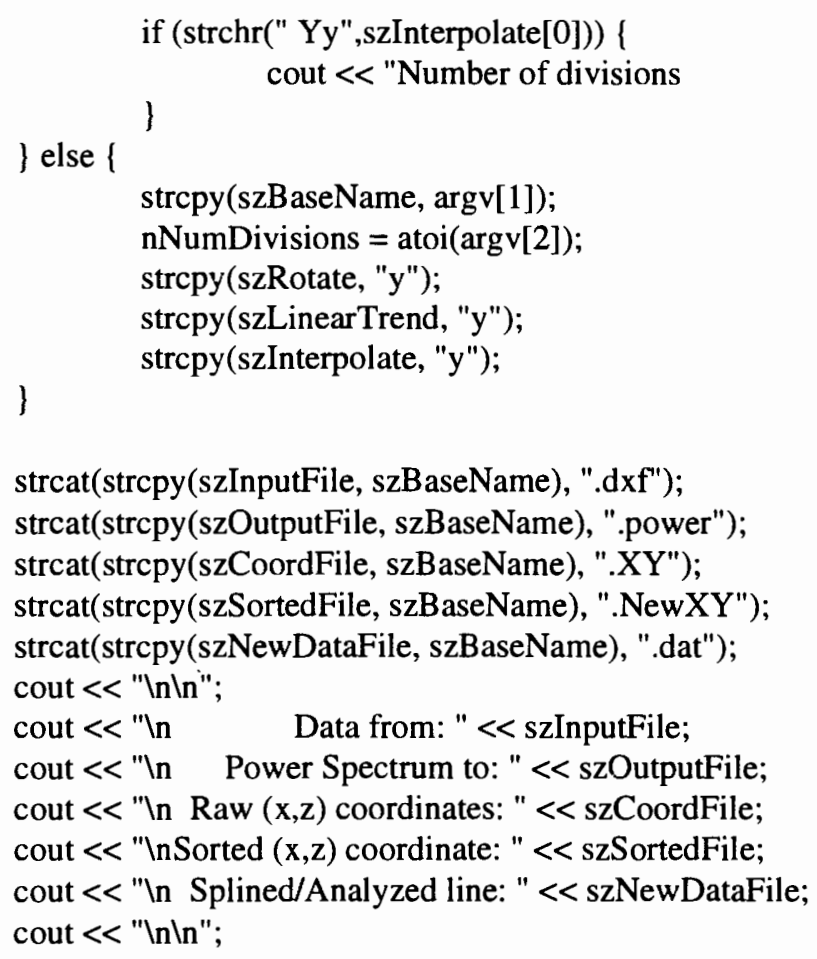




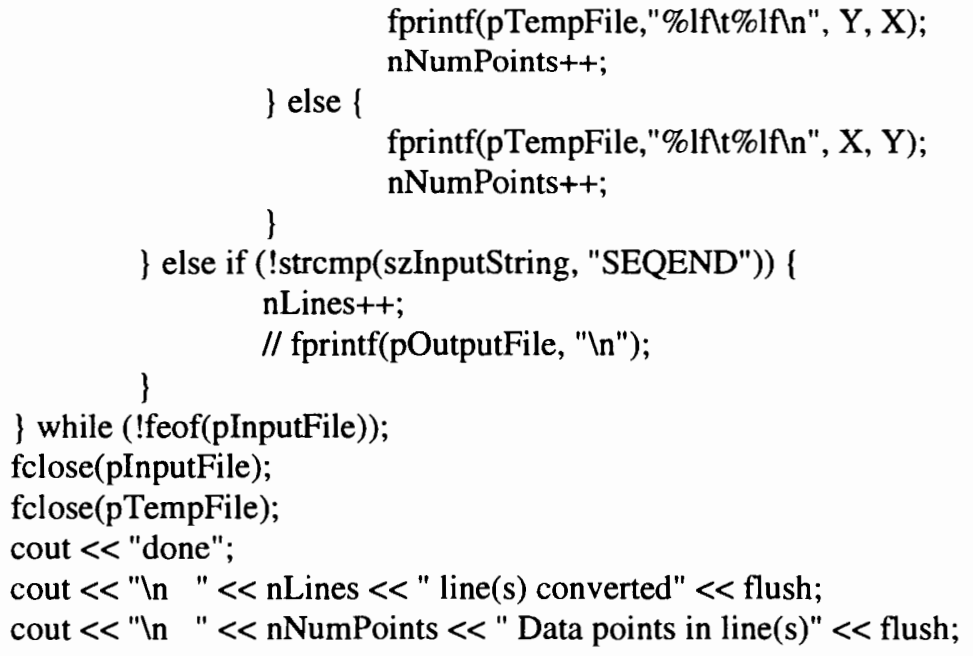

// Allocate space for data set

pTemp $=($ struct Coordinate $*)$ malloc $(($ unsigned $)($ nNumPoints +1$) *$ sizeof(struct Coordinate $)$; if (!pTemp) 1

printf("In $\backslash n$ Out of memory: Original $\ln \backslash n ") ;$

exit $(-2)$;

\}

Unsorted = pTemp;

// Read (x,z) data pairs

if $(($ pTempFile $=$ fopen $($ szCoordFile, $" r "))==$ NULL $)\{$ cout $<<$ "InError opening " $<<$ szCoordFile $<<$ " for temporary storage (read)"; exit(-1);

\}

$\operatorname{Max} X=-10000$;

$\operatorname{MinX}=10000$;

for $(\mathrm{i}=0$; $\mathrm{i}<\mathrm{nNumPoints} ; \mathrm{i}++)$ (

fscanf(pInputFile, "\%lf", \&(Unsorted[i].x));

fscanf(pInputFile, "\%lf", \&(Unsorted[i].z));

$\operatorname{MaxX}=\operatorname{Max} X>$ Unsorted[i].x ? MaxX : Unsorted[i].x;

$\operatorname{Min} X=\operatorname{Min} X<$ Unsorted[i].x ? MinX : Unsorted[i].x;

\}

fclose(pTempFile);

// We now have to sort the data file

cout $\ll$ "InSorting the data points ... " $<$ flush;

qsort(Unsorted, (size_t)nNumPoints, sizeof(struct Coordinate), SortCoord);

cout $<<$ "done" $<$ flush;

int iOffset;

cout $\ll$ "InChecking for duplicate points ... " $<$ flush;

do \{

iOffset $=0$;

for $(\mathrm{i}=1 ; \mathrm{i}<\mathrm{nNumPoints} ; \mathrm{i}++)\{$ 


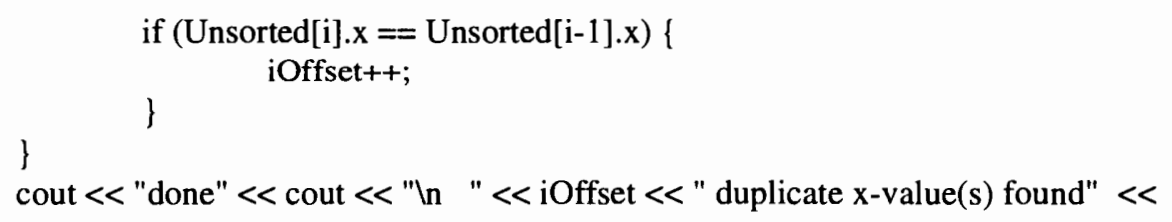

flush;

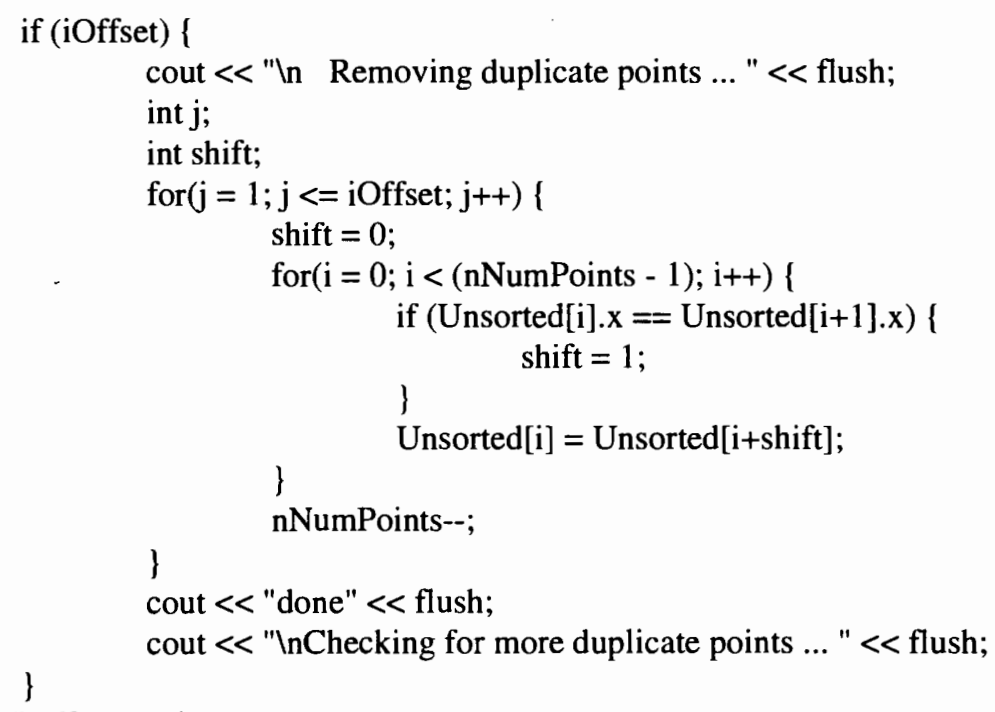




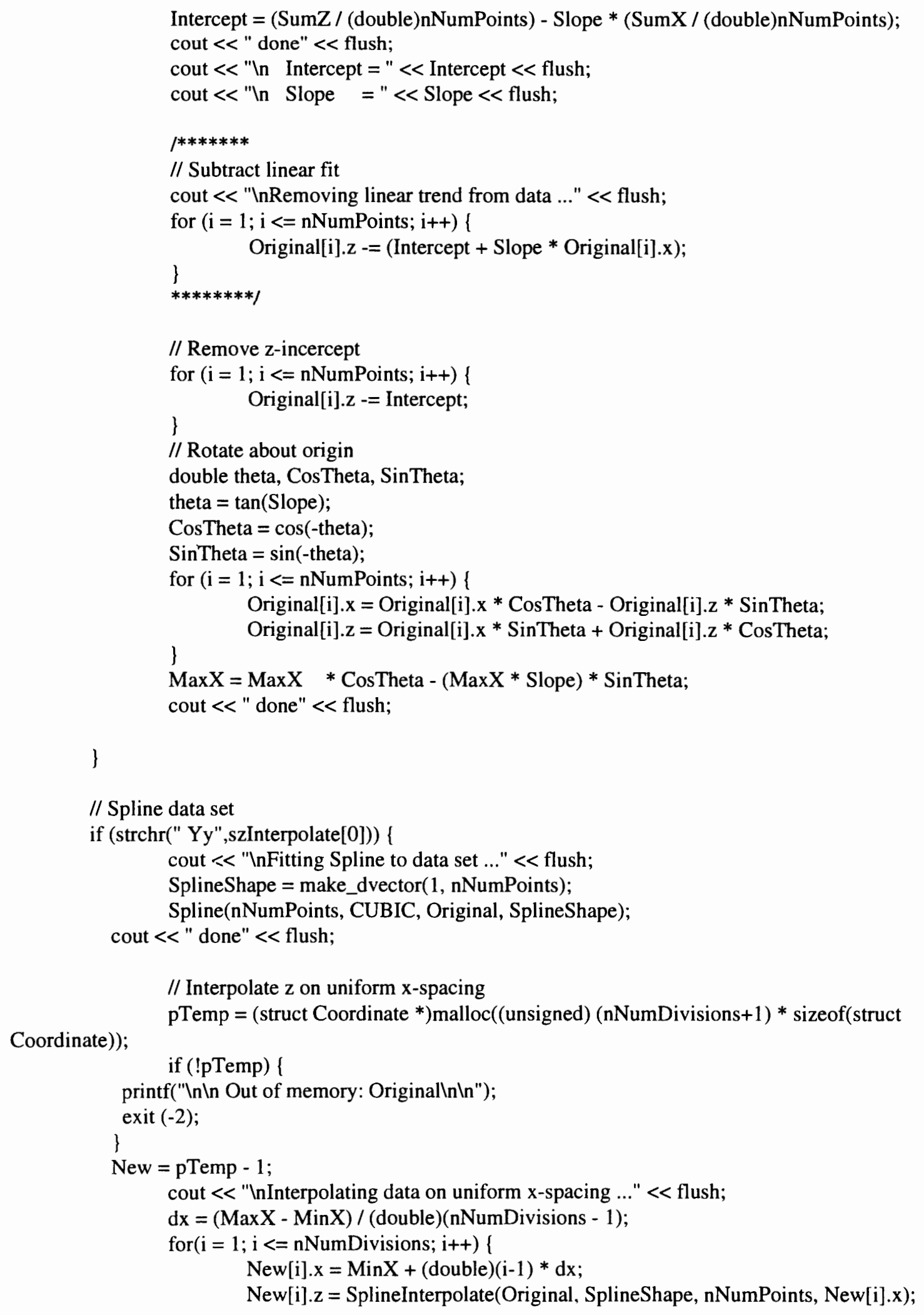




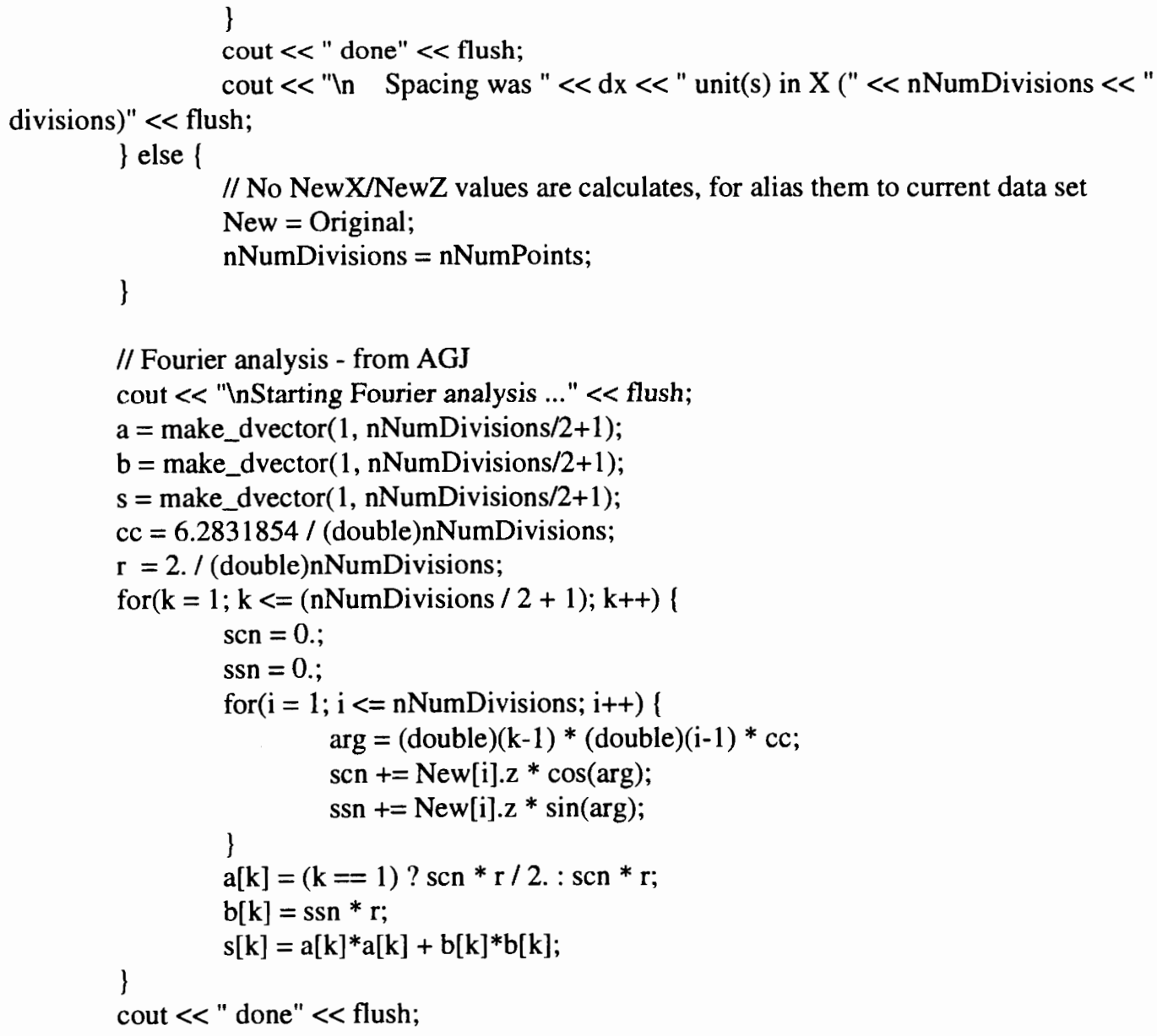


